\title{
ADSORÇÃO COMPETITIVA DE CÁDMIO, COBRE, NÍQUEL E ZINCO EM SOLOS
}

\author{
Cindy Silva MoREIRA
}

Dissertação apresentada à Escola Superior de Agricultura "Luiz de Queiroz", Universidade de São Paulo, para obtenção do título de Mestre em Agronomia, Área de Concentração: Solos e Nutrição de Plantas.

P I R A C I C A B A

Estado de São Paulo - Brasil

Agosto - 2004 


\title{
ADSORÇÃO COMPETITIVA DE CÁDMIO, COBRE, NÍQUEL E ZINCO EM SOLOS
}

\author{
Cindy Silva MoREIRA
}

Engenheira Agrônoma

Orientador: Prof. Dr. LUIS REYNALDO FERRACCIÚ ALLEONI

Dissertação apresentada à Escola Superior de Agricultura "Luiz de Queiroz", Universidade de São Paulo, para obtenção do título de Mestre em Agronomia, Área de Concentração: Solos e Nutrição de Plantas.

P I R A C I C A B A

Estado de São Paulo - Brasil

Agosto - 2004 


\section{Dados Internacionais de Catalogação na Publicação (CIP) DIVISÃO DE BIBLIOTECA E DOCUMENTAÇÃO - ESALQ/USP}

Moreira, Cindy Silva

Adsorção competitiva de cádmio, cobre, níquel e zinco em solos / Cindy Silva

Moreira - - Piracicaba, 2004

$108 \mathrm{p}$.

Dissertação (mestrado) - - Escola Superior de Agricultura Luiz de Queiroz, 2004.

Bibliografia.

1. Adsorção - Competição 2. Metal pesado do solo 3. Propriedade físico-quimica do solo 4. Química do solo I. Título

CDD 631.41

"Permitida a cópia total ou parcial deste documento, desde que citada a fonte - O autor" 
Aos meus pais, João e Carmen, pelo exemplo de amor e força em todos os momentos. Vocês são os verdadeiros mestres.

\section{OFEREÇO}

Aos meus irmãos, Ivy, Carol e Raphael, pelo companheirismo e união. Ao Ricardo, pelo apoio desde o início.

\section{DEDICO}




\section{AGRADECIMENTOS}

A Deus, pela oportunidade de trabalhar e crescer frente às dificuldades e desafios da vida.

Ao Dr. Luís Reynaldo Ferracciú Alleoni, pela orientação, confiança e profissionalismo;

À Escola Superior de Agricultura "Luiz de Queiroz", nas pessoas dos Profs. Drs. Álvaro Pires da Silva, Luís Reynaldo Ferracciú Alleoni e Pablo Vidal-Torrado, membros da Comissão Coordenadora do Programa de Pós-Graduação em Solos e Nutrição de Plantas pela oportunidade oferecida;

Ao Conselho Nacional de Desenvolvimento Científico e Tecnológico (CNPq), pela bolsa concedida;

Ao Prof. Dr. José Carlos Casagrande pelo incentivo desde o início

Aos Profs. Arnaldo Antônio Rodella, Ronaldo Berton e Álvaro Pires da Silva pelas contribuições dadas à dissertação no Exame de qualificação.

Aos Profs. Celso Augusto Clemente, Célia Regina Montes, Rafael Aloisi, Pablo Vidal Torrado, Jairo Antonio Mazza, Luís Reynaldo Ferracciú Alleoni e Jorge de Castro Kiehl, pelo aprendizado em dois semestres no Programa de Aperfeiçoamento ao Ensino, frente às disciplinas Ciência do Solo I e II. Ao pesquisador Igo Fernando Lepsch, pelas contribuições dadas à dissertação.

Em especial às amigas Camila, Susian, Francirose (as “Soletes”) e Miriam, e aos amigos Gilmar, Caio, Simão, Michel, Jonas, Marcos, Alex, Eros, Márcio, Fernando, Aline, Sandra, Valdomiro, Tiago, Jack, e tantos outros, pela amizade conquistada. 
Ao químico Luiz Silva e aos técnicos Beth, João, Leandro, Anderson (Departamento de Solos e Nutrição de Plantas- ESALQ/USP) e Sérgio (NUPEGEL/USP) pela paciência e ajuda no preparo das amostras.

Aos funcionários Nancy, Jackeline, Cida, Martinha, Karina, Udso e Dorival, pela ajuda e convivência. 


\section{SUMÁRIO}

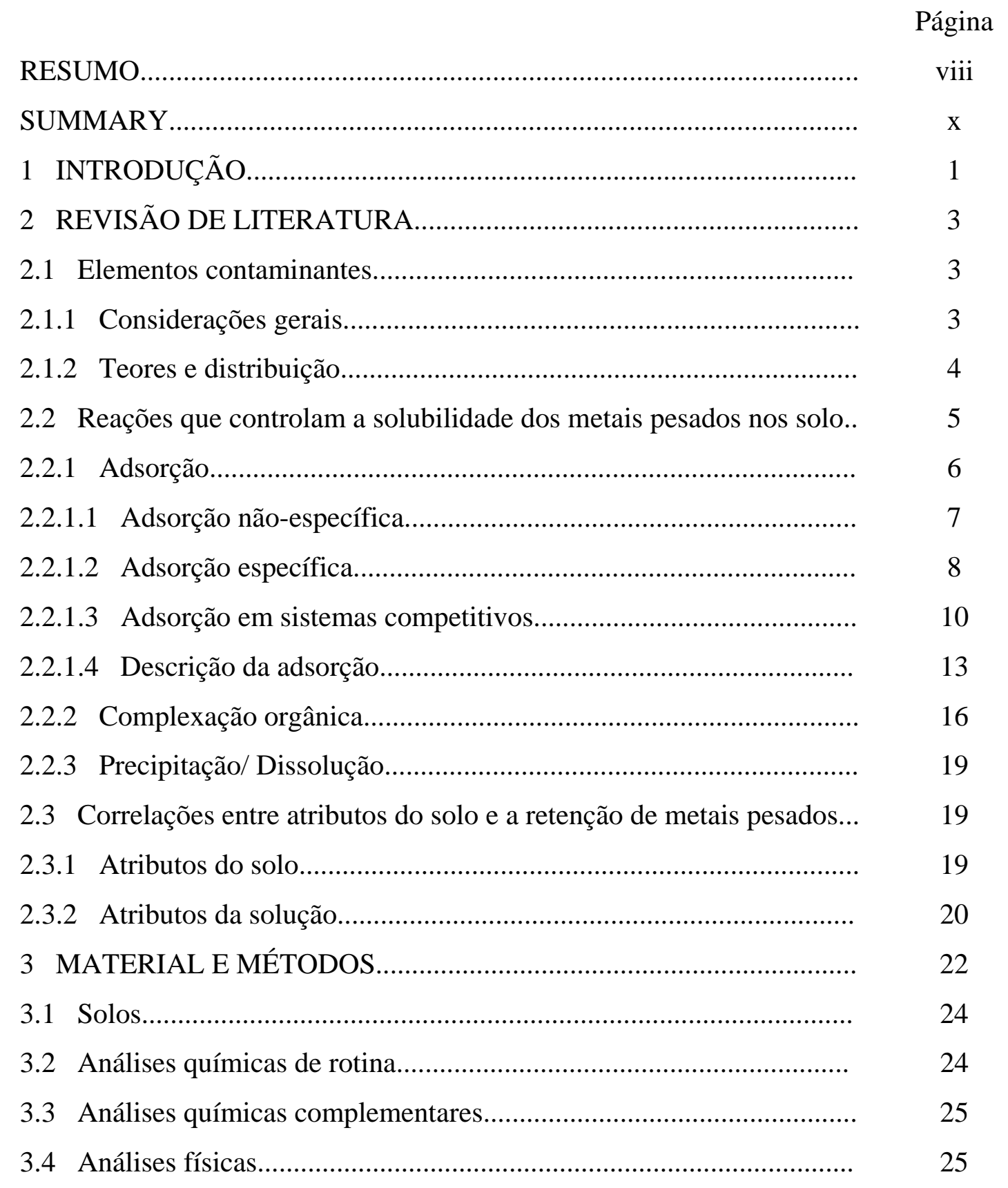


3.5 Isotermas de adsorção..................................................................... 26

3.5.1 Delineamento experimental e forma de análise dos resultados....... 29

4 RESULTADOS E DISCUSSÃO........................................................

4.1 Análises químicas e físicas.................................................................. 30

4.1.1 Análises químicas de rotina............................................................ 30

4.1.2 Análises químicas complementares................................................. 32

4.1.3 Análises físicas..................................................................................

4.2 Modelo de Langmuir......................................................................

4.3 Isotermas de adsorção de $\mathrm{Cd}, \mathrm{Cu}, \mathrm{Ni}$ e Zn.......................................... 36

4.3.1 Sistema não-competitivo................................................................

4.3.2 Sistema competitivo.......................................................................

4.4 Seqüências de afinidade metálica....................................................... 54

4.5 Correlação entre adsorção máxima de Cd, Cu, Ni e Zn e atributos

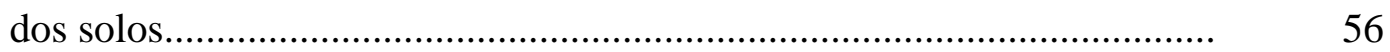

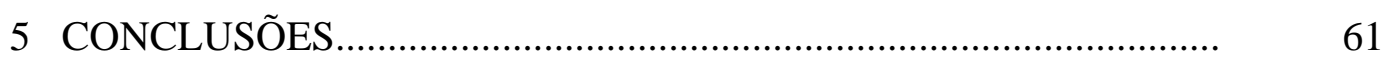

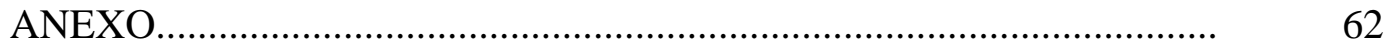

REFERÊNCIAS BIBLIOGRÁFICAS...................................................... 65

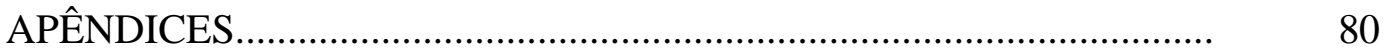




\title{
ADSORÇÃO COMPETITIVA DE CÁDMIO, COBRE, NÍQUEL E ZINCO EM SOLOS
}

\author{
Autora: CINDY SILVA MOREIRA \\ Orientador: Prof. Dr. LUIS REYNALDO FERRACCIÚ ALLEONI
}

\section{RESUMO}

Dentre os processos envolvidos no comportamento e biodisponiblidade dos metais pesados nos solos, aqueles relacionados com a adsorção são de grande importância. Tendo em vista a natureza multielementar do sistema solo-solução e a complexidade das reações envolvidas, o conhecimento dos mecanismos de adsorção em sistemas competitivos permite uma avaliação mais realista do comportamento dos metais no solo. Os objetivos desse trabalho foram (i) avaliar a adsorção competitiva de cádmio, cobre, níquel e zinco, tomadas da camada mais superficial (horizonte A) de 14 solos representativos dos do Estado de São Paulo; (ii) obter isotermas de adsorção em sistemas competitivo e não-competitivo, utilizando a equação matemática de Langmuir para simular a adsorção; (iii) estabelecer seqüências de afinidade metálica para cada solo e (iv) estabelecer a relação entre o comportamento adsortivo dos metais e alguns atributos dos solos, mediante estudos de correlações simples e regressões múltiplas. Ao correspondente a 2,0 g de terra foram adicionados $20 \mathrm{~mL}$ de solução $0,01 \mathrm{~mol} \mathrm{~L}^{-1}$ de $\mathrm{NaNO}_{3}$ (relação $\left.1: 10\right)$ contendo concentrações equimolares $(0,017 ; 0,034 ; 0,085 ; 0,17$; 0,255; 0,51; 0,85 e 1,275 mmol L-1) de $\mathrm{Cu}, \mathrm{Ni}$, Cd e Zn, na forma isolada (sistema não- 
competitivo) e em conjunto (sistema competitivo). O conjunto foi agitado por $1 \mathrm{~h} \mathrm{e}$, em seguida, as amostras foram centrifugadas a $1.100 \mathrm{rpm}$ durante 10 minutos e filtradas. As concentrações dos metais em solução foram determinadas por espectrofotometria de absorção atômica. A quantidade de metal adsorvida foi estimada pela diferença entre a concentração inicial e a concentração de equilíbrio. O Latossolo Vermelho eutroférrico, o Nitossolo Vermelho eutroférrico, o Argissolo Vermelho-Amarelo (textura argilosa e muito argilosa) e o Chernossolo Argilúvico foram os solos que apresentaram maior capacidade de adsorção dos metais, enquanto que os menores valores de metais adsorvidos foram do Neossolo Quartzarênico e do Argissolo Vermelho-Amarelo (textura arenosa). A competição entre os metais diminuiu, de maneira, a adsorção máxima dos mesmos. A seqüência de afinidade mais comum encontrada no sistema não-competitivo foi $\mathrm{Cu}>\mathrm{Zn}>\mathrm{Ni}>\mathrm{Cd}$. No sistema competitivo, a seqüência mais comum foi $\mathrm{Cu}>\mathrm{Cd}>$ Zn > Ni. Em geral, o modelo de Langmuir simulou de maneira satisfatória a adsorção dos metais. Os atributos que apresentaram correlação positiva com a adsorção máxima dos metais foram $\mathrm{pH}, \mathrm{MnO}$, CTC efetiva e silte. A correlação foi negativa com os teores de areia dos solos. Na regressão múltipla, as adsorções máximas de Zn, Cd e Ni estiveram relacionadas a CTC efetiva e com $\mathrm{MnO}$. Para o $\mathrm{Cu}$, somente o conteúdo de MnO relacionou-se com a adsorção máxima. Tais resultados reforçam a importância desse óxido no comportamento de metais pesados em solos de regiões tropicais úmidas. 


\title{
COMPETITIVE ADSORPTION OF CADMIUM, COPPER, NICKEL AND ZINC IN SOILS
}

\author{
Author: CINDY SILVA MOREIRA \\ Adviser: Prof. Dr. LUIS REYNALDO FERRACCIÚ ALLEONI
}

\section{SUMMARY}

Among the processes involved in the behavior and the bioavailabilty of heavy metals in soil, those related with the adsorption are of great importance. Despite of the multielementary nature of the soil-solution system and the complexity of the involved reactions, the knowledge of the adsorption mechanisms in competitive systems allows a more realistic evaluation of the metals behavior in the soil. The objectives of this work was (i) to evaluate the competitive adsorption of cadmium, copper, nickel and zinc in surface samples (A horizons) of 14 representative soils of the State of São Paulo, Brazil; (ii) to obtain adsorption isotherms in competitive and non-competitive systems, using the Langmuir model in order to simulate the adsorption; (iii) to establish metal affinity sequences for each soil and (iv) to establish relationships between the adsorptive behavior of metals and some soils attributes using simple correlations and multiple regressions analysis. Two grams soil subsamples were set into $50 \mathrm{~mL}$ centrifuge tubes, adding $20 \mathrm{~mL}$ of $0.01 \mathrm{~mol} \mathrm{~L}^{-1} \mathrm{NaNO}_{3}$ solution (relation 1:10) at equimolar concentrations (0.017; 0.034; 0.085; 0.17; 0.255; 0.51; 0.85 and $1.275 \mathrm{mmol} \mathrm{L}^{-1}$ ) of $\mathrm{Cu}$, $\mathrm{Ni}, \mathrm{Cd}$ and $\mathrm{Zn}$, in the isolated form (non-competitive system) and in set (competitive system). The obtained suspensions were shaked during one hour, centrifuged afterwards 
(1,100 rpm) through $10 \mathrm{~min}$ and filtered. The metals concentrations in solution were determined by atomic absorption spectrophotometry. The adsorbed metal amounts were assumed to be equal to the difference between the initial amount and the metal remaining content at the ending of the reaction period. The Rhodic Eutrudox, Kandiudalf Eutrudalf, Typic Hapludult-2 (clayey-textured), Typic Hapludult (clayeytextured) and Typic Haplaquoll presented the highest metals adsorption capacity, whereas the lowest was observed for Typic Quartzipsamment and for Arenic Hapludult. In general, the competition between metals diminished their maximum adsorption. In the non-competitive system, the most common affinity sequence was $\mathrm{Cu}>\mathrm{Zn}>\mathrm{Ni}>\mathrm{Cd}$, whereas in the competitive system, the most common sequence was $\mathrm{Cu}>\mathrm{Cd}>\mathrm{Zn}>\mathrm{Ni}$. In general, the Langmuir model simulate satisfactorily the adsorption of metals of the studied soils. The soils attributes presenting positive correlation with the maximum adsorption of metals were $\mathrm{pH}, \mathrm{MnO}, \mathrm{CTC}$ and silt. The correlation was negative with the soil sand content. Employing the multiple regression, the maximum adsorption of $\mathrm{Zn}$, $\mathrm{Cd}$ and $\mathrm{Ni}$ was found to be related with CTC and $\mathrm{MnO}$, while for $\mathrm{Cu}$ only the $\mathrm{MnO}$ content was related with it maximum adsorption. Such results pointed out the importance of the manganese interactions as a controlling factor related to the behavior of heavy metals in soils from tropical humid areas. 


\section{INTRODUÇÃO}

O crescente consumo, produção e exploração de matérias primas, como fósseis e minerais, associado ao crescimento exponencial da população nas últimas décadas e ao desenvolvimento agrícola e industrial, têm originado uma série de problemas ambientais em função da geração de resíduos contendo elementos tóxicos, como os metais pesados.

Tendo em vista que a disposição de resíduos, principalmente os de origem urbana e industrial, nos solos, tem se tornado prática comum nos últimos anos, é evidente que a freqüência e a extensão de contaminações poderão aumentar significativamente.

Os elementos podem se acumular na fase sólida por diversas formas, com níveis energéticos distintos, que estabelecem maior ou menor reversibilidade de suas reações. Reações de troca iônica, de adsorção específica, de complexação com a matéria orgânica, precipitação/dissolução e de óxido-redução determinam a quantidade do elemento que estará disponível aos sistemas biológicos na solução do solo.

Dentre os processos químicos que mais afetam o comportamento e a biodisponibilidade de metais pesados no solo, a adsorção, ou o acúmulo de elementos químicos na interface solo-solução, destaca-se pela sua grande importância. O conhecimento desse mecanismo de retenção pode gerar subsídios para a previsão de fitotoxidez e da possível contaminação do lençol freático por tais elementos. A complexidade das reações envolvidas nesse processo deve-se aos diversos componentes do solo, que se comportam de diferentes formas e interagem entre si, bem como à natureza multielementar da solução do solo. Essa é a razão pela qual muitas vezes tornase difícil prevermos a biodisponibilidade, a mobilidade e a retenção dos metais pesados no solo. 
Estudos de adsorção envolvendo apenas um metal podem ser adequados para predizer somente o comportamento de íons fortemente adsorvidos ao solo, nas situações em que a competição com outros cátions presentes na solução do solo não afetaria sua retenção. Dentre os que investigam a adsorção competitiva entre metais, poucos são os que avaliam os efeitos de alguns elementos na retenção de outros ou que utilizam modelos de adsorção, buscando o ajuste de equações matemáticas (e.g. equação de Langmuir e Freundlich) nos dados obtidos. O solo é um sistema complexo, onde está presente uma série de íons que competem, com diferentes intensidades, por superfícies adsorventes do solo. Isso justifica o estudo detalhado desses mecanismos principalmente em solos tropicais, cujas características químicas, físicas e mineralógicas diferem daquelas encontradas em solos de clima temperado.

Nesse contexto, os principais objetivos desse trabalho são:

a) Avaliar a adsorção competitiva de cádmio, cobre, níquel e zinco em amostras superficiais de solos representativos do Estado de São Paulo;

b) Obter isotermas de adsorção em sistemas competitivos e não-competitivos, utilizando a equação matemática de Langmuir para simular a adsorção;

c) Estabelecer seqüências de seletividade metálica para cada solo, baseadas na adsorção máxima dos metais;

d) Estabelecer a relação entre o comportamento adsortivo dos metais e as propriedades físico-químicas e mineralógicas dos solos, mediante estudos de correlações simples e regressões múltiplas.

As hipóteses a serem testadas são: a adsorção dos metais será distinta para os diferentes solos; o efeito da competição entre o metais irá diminuir a magnitude da adsorção dos elementos nos solos; a equação de Langmuir irá simular a adsorção competitiva de maneira satisfatória; a seqüência de seletividade mais comum será $\mathrm{Cu}>$ $\mathrm{Cd} \cong \mathrm{Zn}>\mathrm{Ni}$; a adsorção dos metais estará mais bem correlacionada positivamente com os teores de matéria orgânica, argila e óxidos. 


\section{REVISÃO DE LITERATURA}

\subsection{Elementos contaminantes}

\subsubsection{Considerações gerais}

O termo “metais pesados” está associado ao conjunto de elementos químicos pertencentes aos grupos de transição da tabela periódica, cujas formas iônicas possuem densidade atômica elevada (maior que $6,0 \mathrm{~g} \mathrm{~cm}^{-3}$ ) ou massa atômica maior que 20. Além dos metais, fazem parte desse conjunto o grupo dos semi-metais e não-metais (Matos et al., 1996). Alguns elementos deste grupo, os chamados micronutrientes ou elementos traços essenciais, são requeridos pela maioria dos organismos vivos em pequenas concentrações, podendo causar toxicidade quando em excesso ( $\mathrm{Cu}, \mathrm{Mn}$, Fe e $\mathrm{Zn}$, essenciais às plantas e animais; Co, Cr, Se e I essenciais aos animais; B, Mo e possivelmente o $\mathrm{Ni}$, essenciais às plantas). Os elementos que não apresentam funções biogeoquímicas essenciais são chamados de “elementos não-essenciais” ou "elementos tóxicos” (As, Cd, Hg, Pb, Pu, Sb, Tl, e U). Tais elementos causam toxicidade em concentrações que excedem a tolerância dos organismos, mas não causam deficiência em baixas concentrações, como os micronutrientes (Alloway \& Ayers, 1996).

Em termos geológicos, os elementos traços, entre eles os metais pesados, constituem menos de 1\% das rochas da crosta terrestre. Esses elementos, considerados impurezas, são isomorficamente substituídos por macroelementos na estrutura cristalina de muitos minerais primários. Tendo em vista a variação do conteúdo de elementos traços presentes nos minerais primários e secundários, as rochas ígneas e sedimentares 
formadas a partir desses minerais apresentam composição variável de metais pesados (Alloway \& Ayers, 1996).

\subsubsection{Teores e Distribuição}

O teor natural dos elementos potencialmente tóxicos no solo varia muito com o tempo de intemperismo e a composição química do material de origem. A composição elementar total no solo tem utilidade limitada, mas é importante conhecê-la para se ter uma idéia do seu teor no ambiente tanto em estudos de contaminação e poluição, como para estudos pedológicos. Se um elemento pode representar um perigo eminente à cadeia alimentar, é importante avaliar seus teores disponíveis ou solúvel uma vez que eles vão estar relacionados com a mobilidade e com a absorção pelas plantas (Camargo et al., 2001). No Quadro 1 estão os teores totais e solúveis de alguns elementos potencialmente tóxicos.

\begin{tabular}{|c|c|c|c|c|c|}
\hline \multirow{2}{*}{ Elemento } & \multirow{2}{*}{ Litosfera } & \multicolumn{2}{|c|}{ Global } & \multicolumn{2}{|c|}{ São Paulo } \\
\hline & & total & solúvel & total & solúvel \\
\hline & $\ldots \ldots \ldots \ldots \ldots$ & 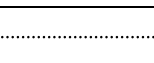 & $\mathrm{mg} \mathrm{kg}$ & & $\ldots$ \\
\hline $\mathrm{Cu}$ & 70 & $2-100$ & $1-8$ & $2-340$ & $0,08-0,80$ \\
\hline $\mathrm{Zn}$ & 80 & $10-300$ & $1-20$ & $1-315$ & $0,09-0,32$ \\
\hline $\mathrm{Ni}$ & 100 & $5-500$ & $1-10$ & $<10-126$ & $0,10-1,40$ \\
\hline $\mathrm{Pb}$ & 16 & $20-500$ & $0-20$ & - & - \\
\hline As & - & $1-50$ & - & - & - \\
\hline Co & 40 & $0,05-40$ & $0,02-5$ & 0,14 & 86 \\
\hline Mo & 2,3 & $0,2-5$ & $0-0,2$ & $0,11-2,9$ & $0,01-0,13$ \\
\hline
\end{tabular}

Quadro 1- Valores mínimos e máximos dos teores totais e solúveis de alguns elementos em solos na camada superficial

Fonte: Camargo et al. (2001) 
A distribuição de metais pesados, entre eles, $\mathrm{Mn}, \mathrm{Zn}, \mathrm{Cu}, \mathrm{Co}, \mathrm{Cr} \mathrm{Pb}$ e $\mathrm{Cd}$ ao longo de perfis de solo e na camada superficial demonstram que os processos formados de solos trazem como conseqüência uma separação desses elementos entre vários componentes, o que causa diferença no padrão de distribuição e que os raios iônicos dos elementos teriam um papel de destaque nesta separação (Anderson, 1977). Os mesmos estudos apontaram para correlação positiva entre a quantidade de metal extraída e o teor de argila das amostras, em função da diminuição dos raios iônicos dos elementos. A relação foi linear para os elementos com número de coordenação seis em função de seu aprisionamento nas posições octaedrais dos minerais secundários, sendo mais efetivamente retidos quanto menor seu tamanho. Elementos com número de coordenação maior que seis, correlacionaram-se melhor com a quantidade de matéria orgânica, uma vez que seu tamanho não permite ocupar as posições octaedrais dos minerais citados anteriormente. Estes elementos mostraram um padrão de distribuição semelhante ao dos teores de matéria orgânica, evidenciando sua ligação com material humificado.

\subsection{Reações que controlam a solubilidade dos metais pesados no solo}

A disponibilidade dos elementos às plantas e aos microrganismos depende essencialmente de sua presença na solução do solo (Figura 1). Esta presença é governada pela composição do solo, pela reação do solo, pelas condições de óxido-redução e pela cinética das reações, que dependem de atributos do solo e de suas tendências para formar precipitados insolúveis e coprecipitados com outros mineras, formar complexos com a matéria orgânica e absorver minerais (Camargo et al., 2001).

Os diversos constituintes do solo tais como os minerais de argila, materiais amorfos, compostos orgânicos e carbonatos, interagem entre si na presença de água e dos solutos nela dissolvidos. Os processos interativos envolvem reações químicas, físicas, ou mesmo a combinação de ambas. As reações físicas são geralmente eletrostáticas. 


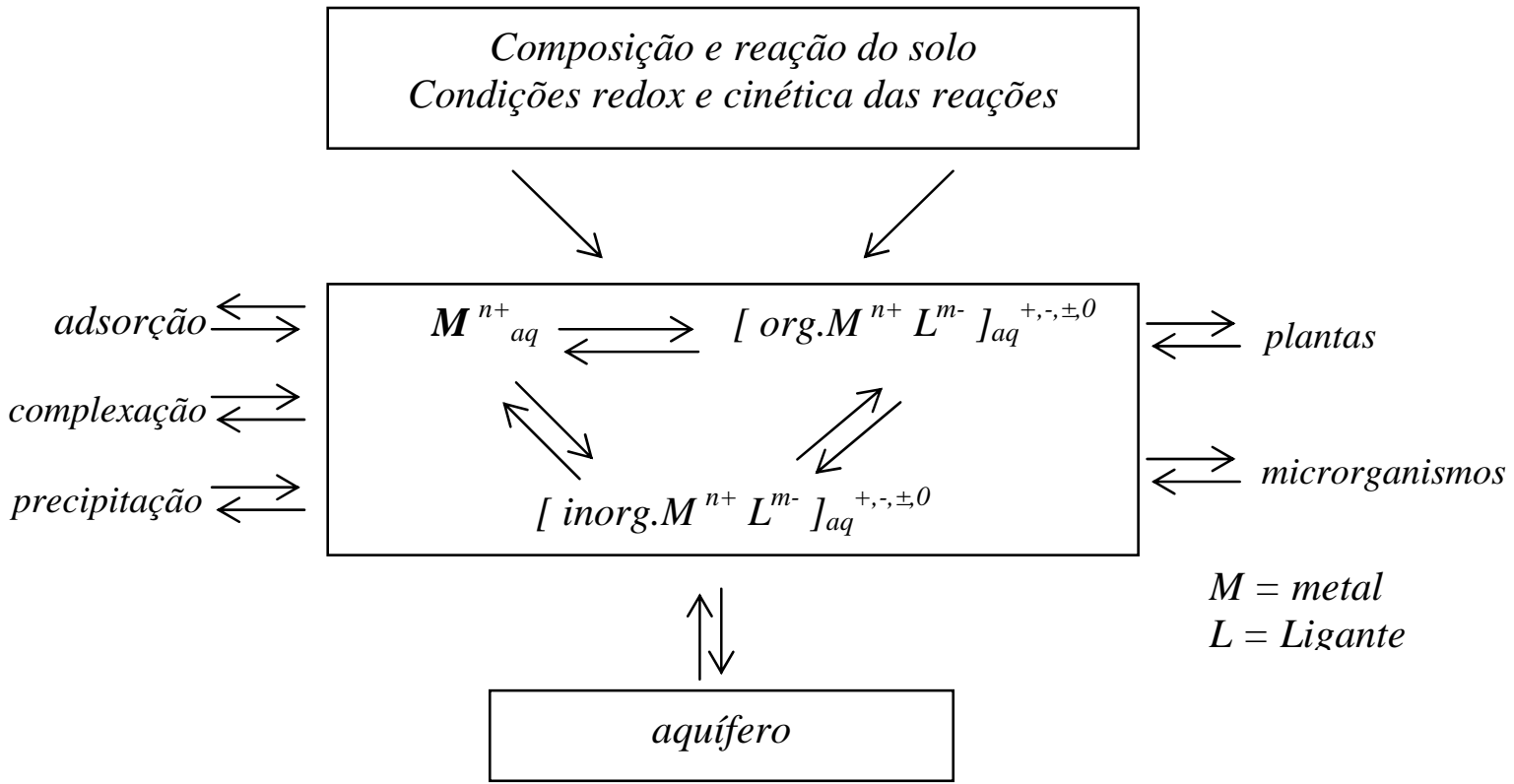

Figura 1 - Esquema representativo das reações e fluxo de elementos no solo. Adaptado de Camargo et al. (2001)

Tendo em vista que a maioria dos estudos sobre a retenção de metais pesados no solo aponta para processos mais específicos de ligação (Ross, 1994), os mecanismos de adsorção são reconhecidamente os determinantes no controle da disponibilidade e solubilidade dos metais no solo (Ford et al., 2001; Chang et al., 2002). Nesse contexto, destacam-se a adsorção não-específica, adsorção específica e complexação com o material orgânico do solo (Camargo et al., 2001).

\subsubsection{Adsorção}

A adsorção pode ser definida como o acúmulo de um determinado elemento ou substância na interface entre a superfície sólida e a solução adjacente. Define-se adsorbato o material que se acumula numa interface; adsorvente é a superfície sólida na qual o adsorbato se acumula; adsorvito é o íon ou molécula em solução que tem o potencial de ser adsorvido (Sposito, 1989). 
A força de retenção dos íons na interface solo-solução é determinada pelo tipo de interação entre os íons e a superfície das partículas. Em geral, íons adsorvidos por meio de ligações covalentes ou iônicas são mais fortemente retidos, e o fenômeno é chamado de adsorção específica. Quando a interação entre os íons e as superfícies das partículas do solo é de natureza eletrostática, os íons são retidos por forças físicas (van der Waals) sendo, portanto, caracterizada como adsorção não-específica (Ji \& Li et al., 1997; Meurer et al., 2000).

\subsubsection{Adsorção não-específica}

Todos os solos apresentam, invariavelmente, cargas nas superfícies de seus constituintes. De acordo com o princípio de eletroneutralidade, deve haver sempre uma quantidade equivalente de íons com carga contrária (contra-íons) adsorvidos na superfície dos colóides do solo. Sendo assim, a adsorção não-específica de íons é geralmente decorrente da troca iônica com demais espécies iônicas (Ji \& Li, 1997).

Na adsorção não-específica de cátions metálicos pelo solo, existe a formação de complexos de esfera externa. Nesse tipo de mecanismo, o íon é atraído eletrostaticamente pelas superfícies carregadas do solo sem que haja grande dependência da configuração eletrônica do grupo funcional da superfície do solo. Além disso, a interação envolve a adsorção do íon na sua forma hidratada, o que diminui a energia de ligação entre a superfície do solo e o elemento (Sposito, 1989).

A quantidade que pode ser reversivelmente adsorvida de forma trocável no solo é chamada capacidade de troca catiônica. Esse fenômeno tem certas características que merecem ser destacadas: 1) é reversível; 2) é controlado por difusão iônica; 3) é estequiométrico e 4) na maioria dos casos existe seletividade ou preferência de um íon pelo outro, que está relacionada com o raio iônico hidratado e com a energia de hidratação dos cátions de mesma valência. Um íon com raio iônico hidratado grande é retido com menor intensidade, enquanto um com raio pequeno chega mais perto da 
superfície e, assim, a atração coulômbica é maior. Íons com maior valência têm maior força de deslocamento, exceção feita ao $\mathrm{H}^{+}$(Camargo et al., 2001).

A troca iônica é considerada um mecanismo de pequena influência na disponibilidade dos metais pesados, embora em algumas situações ela tenha sido apontada como um mecanismo importante (Cunha et al., 1994; Camargo et al., 1998).

\subsubsection{Adsorção específica}

A adsorção específica é um fenômeno de elevada afinidade, envolvendo mecanismos de troca entre metais e ligantes da superfície dos colóides por meio de ligações covalentes ou iônicas, e tem sido utilizada para explicar a razão pela qual o solo adsorve determinados íons em concentrações superiores à sua capacidade de troca de cátions (Yong et al., 1992; Phillips, 1999).

Na adsorção específica de cátions, os íons penetram na estrutura do átomo e ligam-se por meio de ligações covalentes com os grupos $\mathrm{O}$ e $\mathrm{OH}$ da superfície do solo. Os principais tipos de ligações químicas envolvidos entre os átomos na adsorção específica são (Yong et al., 1992):

- covalente: neste tipo de ligação, ocorre compartilhamento de elétrons de ambas as espécies iônicas envolvidas;

- covalente-coordenada: nesta ligação, o compartilhamento ocorre somente por uma das espécies iônicas envolvidas.

De maneira geral, os principais constituintes do solo responsáveis pela adsorção específica de metais são os óxidos. Dentre os diversos óxidos que ocorrem no solo $\left(\mathrm{SiO}_{2}, \mathrm{TiO}_{2}, \mathrm{Al}_{2} \mathrm{O}_{3}\right.$ e hidróxidos), os que estão mais relacionados com o comportamento dos metais pesados são os óxidos de Fe e Mn. Hidróxidos de Al podem adsorver uma variedade de metais e, em alguns solos, sua importância pode ser até maior que a dos óxidos de Fe na retenção de metais (Kabata-Pendias \& Pendias, 1984).

Óxidos e hidróxidos de Fe e Mn são constituintes relativamente comuns em solos, podendo ocorrer ou como recobrimento de partículas do solo, ou preenchendo 
rachaduras no perfil, ou como concreções ou nódulos. O mecanismo de adsorção envolve substituição isomórfica de cátions divalentes ou trivalentes por íons de Fe e Mn, reações de troca catiônica ou ainda em função da oxidação da superfície dos precipitados de óxidos (Kabata-Pendias \& Pendias, 1984). A importância do óxido de Mn na retenção de metais já foi reportada, sendo que em alguns estudos, a adsorção de metais pesados foi mais intensa do que nos óxidos de ferro (McLaren \& Crawford, 1973; McKenzie, 1980; Fu et al., 1991).

Os óxidos apresentam diferentes capacidades de adsorver cátions metálicos especificamente. Para a adsorção de Zn, por exemplo, Yu et al. (1997) relataram que a retenção é maior em óxidos de $\mathrm{Al}$ amorfo do que em óxidos de Fe amorfos. Os mesmo autores afirmam que para um mesmo tipo de óxido, a capacidade de adsorver cátions varia com o grau de cristalização do óxido. Isso ocorre em função de o processo de intemperismo promover mudanças na forma do cristal, na área superficial e nas propriedades químicas da superfície dos óxidos. De maneira geral, substâncias amorfas possuem grande superfície específica e elevada capacidade de adsorção de metais. Em contrapartida, a atividade de substâncias bem cristalizadas é comparativamente menor (Yu et al., 1997).

Dentre as evidências que indicam a formação de ligações fortes entre as superfícies dos óxidos cristalinos ou microcristalinos com metais pesados, tem-se a liberação de até dois íons $\mathrm{H}^{+}$para cada cátion metálico divalente adsorvido (Forbes et al., 1976; McKenzie, 1980), o alto grau de especificidade mostrado por certos óxidos com relação a determinados metais (Kinniburgh et al., 1976) e alterações das propriedades de carga superficial do óxido como resultado da adsorção (Stumm \& Morgan, 1981). Os sítios de adsorção de metais pesados, na superfície dos óxidos, são específicos a baixa concentrações, e a energia de ligação é maior se comparada com os íons adsorvidos aos sítios de troca de argilominerais (Clark \& McBride, 1984).

Os solos ácricos, comuns no Estado de São Paulo, são caracterizados pelo intenso processo de intemperismo e dessilicatização, resultando no acúmulo de óxidos de Fe (hematita e goetita) e Al (gibbsita), além de caulinita (mineral de argila do tipo 1:1) (Alleoni \& Camargo, 1995). Nesses solos, geralmente com predomínio de cargas 
variáveis, os sítios de carga superficial negativa dos óxidos de Fe e Al, que podem atrair eletrostaticamente cátions metálicos, existem em menores proporções. Pode-se esperar, assim, que a adsorção específica de cátions metálicos por solos ricos em óxidos e oxidróxidos de Fe e Al tenha maior significância (Yu et al., 1997).

Os silicatos também podem apresentar a habilidade de adsorver especificamente íons metálicos (Yu et al., 1997). Alguns estudos revelam que os grupos Al-OH e Si-OH expostos nas extremidades das lâminas dos silicatos apresentam propriedades similares aos grupos $\mathrm{OH}$ da superfície dos óxidos, sendo capazes de adsorver, em um determinado grau, íons de forma específica. Esse tipo de adsorção específica está relacionado à retenção de cátions metálicos na forma $\mathrm{MOH}^{+}$(Yu et al., 1997).

\subsubsection{Adsorção em sistemas competitivos}

A retenção de metais é um processo competitivo entre os íons em solução e aqueles adsorvidos na superfície do solo. Conseqüentemente, a composição iônica da solução exerce grande efeito na adsorção desses íons nas partículas do solo (Muraly \& Aylmore, 1983; Echeverría et al., 1998).

Devido a diversos fatores, incluindo tipo de adsorbato e condições experimentais (ex.: concentração do metal, pH da solução, eletrólito suporte, força iônica etc.) diferentes seqüências de afinidade podem surgir, sendo praticamente impossível estabelecer uma seqüência universal. No Quadro 2, tem-se uma série de seqüências de afinidade baseadas em algumas propriedades metálicas para $\mathrm{Cd}, \mathrm{Cu}$, $\mathrm{Ni}$ e Zn.

Se a habilidade do metal em ser retido fosse baseada somente em ligações eletrostáticas, as ligações mais fortes seriam aquelas formadas entre os metais com a maior relação carga:raio iônico. Para ligações eletrostáticas de metais com cargas iguais, a afinidade seria inversamente proporcional ao raio iônico não hidratado. Assim, a afinidade seria proporcional ao potencial iônico $\left(Z^{2} / r\right)$, em que $Z$ é a carga e $r$ é o raio 
iônico do metal (McBride, 1989; Basta \& Tabatabai, 1992). No entanto, as ligações metálicas não são inteiramente eletrostáticas.

\begin{tabular}{|cc|}
\hline Propriedade metálica & Seqüência de afinidade metálica \\
\hline${\text { Constante de hidrólise }{ }^{\mathrm{a}}}^{\text {Grau de “dureza” ("Softness”) }}$ & $\mathrm{Cu}(8,0)>\mathrm{Zn}(9,0)>\mathrm{Ni}(9,9)>\mathrm{Cd}(10,1)$ \\
Eletronegatividade (Pauling) & $\mathrm{Cu}(2,89)>\mathrm{Ni}(2,82)>\mathrm{Zn}(2,34)$ \\
Potencial iônico & $\mathrm{Cu}>\mathrm{Ni}>\mathrm{Cd}>\mathrm{Zn}$ \\
\end{tabular}

Quadro 2 - Seqüências de afinidade de metais baseadas em algumas propriedades metálicas

Fontes: Basta \& Tabatabai (1992b); McBride (1989)

a logaritmo negativo da primeira constante de hidrólise

Na seqüência de afinidade metálica baseada na constante de hidrólise, considera-se que a ligação covalente seria o principal mecanismo de retenção metálica. A adsorção de metais, neste caso, seria dependente na retenção de seus produtos de hidrólise $\left(\mathrm{MOH}^{+}\right)$. Esses complexos são mais fortemente adsorvidos do que os cátions metálicos divalentes livres. Esse fenômeno ocorre por meio da formação de um complexo considerado termodinamicamente mais estável e mais fácil de ser adsorvido do que o metal na forma livre (James \& Healy, 1972).

A eletronegatividade é um importante fator na determinação de qual metal é retido pelos constituintes do solo de forma preferencial (McBride, 1989). De uma maneira resumida, a eletronegatividade é uma grandeza que mede a atração exercida sobre os elétrons de uma ligação, tendo relação com o raio atômico. Quanto menor o tamanho do átomo, maior será a força de atração, uma vez que a distância entre o núcleo e a eletrosfera é menor. Existem algumas escalas que relacionam a eletronegatividade dos elementos, sendo que a escala de Pauling é a mais utilizada (Quadro 2).

O conceito grau de “dureza”, também um parâmetro relacionado às ligações do tipo covalente, deriva da teoria de ácidos e bases fortes e fracos de Pearson (1963). De acordo com essa teoria, ácidos fortes tendem a se associarem com bases fortes e ácidos 
fracos com bases fracas. Segundo Pearson, metais com elétrons fracamente presos nos orbitais externos (especialmente orbitais- $d$ ) apresentam alta polarizabilidade e se comportam como ácidos fracos. A estabilidade de complexos ácido-base fracos depende de ligações covalente dativas entre os orbitais- $d$ do metal e os orbitais já preenchidos do ligante. Dessa forma, o conceito de “dureza” de um metal pode ser usado como uma medida do grau de ligações covalente na adsorção de um metal pelo solo. Alguns estudos obtiveram estreita relação entre a capacidade de troca de cátions e o grau de “dureza” dos metais (Sullivan, 1977). Sugere-se ainda que essa teoria poderia descrever a seletividade de cátions no sistema solo.

A adsorção competitiva de metais vem sendo relatada por muitos pesquisadores há algumas décadas. Kuo \& Baker (1980) estudaram a adsorção de Cu, Zn e Cd por alguns solos ácidos e observaram que o Cu era adsorvido preferencialmente em relação aos demais e que a presença desse metal interferia na retenção de Cd e Zn. O mesmo foi obtido por McBride \& Blasiak (1979) no sistema binário Cu-Zn.

Basta \& Tabatabai (1992b) obtiveram isotermas de adsorção competitiva de $\mathrm{Cd}, \mathrm{Cu}, \mathrm{Zn}, \mathrm{Ni}$ e $\mathrm{Pb}$ em função do $\mathrm{pH}$ de dois solos (Haplaquolls e Hapludols) e observaram aumento da competição conforme se aumentavam as concentrações iniciais dos metais. Em geral, a afinidade dos metais para ambos os solos foi: $\mathrm{Pb}>\mathrm{Cu}>\mathrm{Ni} \geq$ Cd Zn. Echeverría et al. (1998) também utilizaram isotermas para explicar o comportamento competitivo desses metais em três solos (Calcixerollic Xerochrept, Paralithic Xerorthent e Lithic Haplumbrept) e concluíram que $\mathrm{Cu}$ e $\mathrm{Pb}$ foram adsorvidos em grandes quantidades e principalmente com uma força de ligação mais elevada, se comparados com Cd, Ni e Zn. A competição entre os elementos variou, em magnitude, com o tipo de solo. A retenção, nesse caso, estaria relacionada ao teor de matéria orgânica de alguns solos, o que possibilitou a formação de complexos mais estáveis. Phillips (1999), em estudos sobre adsorção de Cd, Zn, e Pb em solos, relatou a existência de competição entre os elementos, principalmente onde o número de sítios de adsorção era limitado e/ou onde os colóides do solo apresentavam afinidade mais elevada por determinados cátions (e.g. $\mathrm{Al}^{3+}>\mathrm{Cd}^{2+}$ ). 
Fontes et al. (2000) estudaram a adsorção competitiva de $\mathrm{Cd}, \mathrm{Cu}$, $\mathrm{Zn}$ e $\mathrm{Pb}$ em solos tropicais e relataram a influência dos metais na mobilidade e na retenção de Zn e Cd. Nas soluções mais concentradas, houve decréscimo na adsorção desses dois cátions metálicos. Em contrapartida, a competição praticamente não afetou a adsorção de $\mathrm{Cu}$ e $\mathrm{Pb}$, o que indica um mecanismo de retenção mais específico, envolvendo ligações covalentes entre esses elementos e as estruturas dos minerais do solo. Ainda em solos altamente intemperizados, Gomes et al. (2001) avaliaram a seqüência de seletividade e a adsorção competitiva de $\mathrm{Cd}, \mathrm{Cu}, \mathrm{Zn}, \mathrm{Ni}, \mathrm{Cr}$ e $\mathrm{Pb}$ em diversos solos brasileiros. Foram discriminadas duas seqüências mais comuns de seletividade: $\mathrm{Cr}>\mathrm{Pb}>\mathrm{Cu}>\mathrm{Cd}>\mathrm{Zn}>$ $\mathrm{Ni}$ e $\mathrm{Pb}>\mathrm{Cr}>\mathrm{Cu}>\mathrm{Cd}>\mathrm{Ni}>\mathrm{Zn}$. No geral, $\mathrm{Cr}$, Pb e Cu foram os cátions metálicos retidos com maior força, ao passo que $\mathrm{Cd}$, Ni e $\mathrm{Zn}$ foram os menos influenciados pela competição.

Fontes \& Gomes (2003) avaliaram a adsorção competitiva de Cr, Ni, Cu, Zn, $\mathrm{Cd}$ e $\mathrm{Pb}$ em solos representativos do Brasil (Latossolos, Argissolos e Nitossolo) após a remoção da matéria orgânica, e observaram que os metais com maior efeito competitivo foram $\mathrm{Cr}$, $\mathrm{Cu}$ e $\mathrm{Pb}$. A seqüência de seletividade mais comum foi $\mathrm{Cr} \sim \mathrm{Pb}>>\mathrm{Cu}>>>\mathrm{Ni}$ $>$ Cd $\sim$ Zn. Sem a remoção da matéria orgânica, no entanto, o Ni foi sempre o metal menos retido pelos solos, evidenciando sua baixa afinidade por esse atributo do solo.

\subsubsection{Descrição da adsorção}

Existem diversas maneiras de se descrever o fenômeno da adsorção de elementos no solo. A escolha de um método irá depender dos objetivos traçados pela pesquisa e, principalmente, do nível de aprofundamento que se deseja atingir a respeito do fenômeno adsortivo.

Isotermas de adsorção são amplamente utilizadas para caracterizar a retenção de elementos químicos no solo (Sposito, 1989; Harter, 1991; Hinz, 2001). Inicialmente, os estudos eram voltados para explicar a adsorção de ânions, principalmente fosfato (Olsen \&Watanabe, 1957), por meio de modelos que procuravam descrever sua adsorção 
no solo. Dentre as vantagens em se utilizar tal técnica está a conveniência de representar a relação entre a concentração de metais pesados dissolvidos e adsorvidos no solo (Mesquita \& Vieira, 2002), especialmente se outras variáveis como pH, força iônica, temperatura e pressão são controladas (Sposito, 1989). Além disso, com as isotermas é possível obterem-se maiores informações a respeito da natureza dos processos de adsorção (Cunha et al., 1994) e determinar a capacidade máxima de adsorção de um solvente (Harter, 1991).

Giles et al. (1974) classificaram as isotermas de adsorção com base nas suas inclinações iniciais e curvaturas, distinguindo-as em quatro classes, de acordo com determinadas características: $H$ para alta afinidade; $L$ para Langmuir; $C$ para fracionamento constante e $S$ para aquelas com formato sigmoidal. Sposito (1989) discutiu a interpretação dessa classificação e sua significância para a adsorção de elementos químicos nos solos, apresentando exemplos para cada grupo. A isoterma do tipo $L$ é a mais comum em estudos de química de solo (Sposito, 1989; Hinz, 2001).

O emprego de isotermas de adsorção para explicar o comportamento de metais pesados em solos e sedimentos já foi descrito para muitas situações (Msaky \& Calvet, 1990; Echeverría et al., 1998; Mesquita \& Silva, 2002). Para as condições tropicais, temse observado um crescente empenho no sentido de formar uma base de dados sobre o comportamento de metais pesados em solos altamente intemperizados. Cunha et al. (1994) estudaram a aplicabilidade de diferentes isotermas na adsorção de Zn em solos intemperizados, permitindo boa comparação entre a adsorção do metal entre os solos de composição mineralógica semelhante. Da mesma forma, Dias et al. (2001), empregando isotermas de adsorção para confrontar o comportamento de Cd em dois Latossolos e um Nitossolo, observaram maior adsorção do metal pelo Nitossolo do que pelos demais, além de terem obtido parâmetros para estudos de correlação entre a adsorção de Cd e a composição dos solos. Jordão et al. (2000), utilizando isotermas de adsorção para descrever a adsorção de $\mathrm{Cu}$ em um Latossolo com elevado teor de matéria orgânica, relataram duas porções lineares nas isotermas do metal, sugerindo que o metal estaria ligado aos sítios de adsorção das partículas do solo de duas formas: através da formação 
de complexo, nas concentrações mais baixas do metal, e por meio de interações eletrostáticas ou força de van der Waals, nas doses mais elevadas de Cu.

As reações de adsorção podem ser descritas por diversos modelos empíricos e químicos (Goldberg, 1992; 1995). Os modelos empíricos, apesar de serem simplesmente relações numéricas usadas para o ajuste de curvas de dados, são os mais utilizados em Ciência do Solo (Sposito, 1989; Camargo et al., 2001). Os modelos empíricos mais conhecidos são as equações de Langmuir e Freundlich. Os parâmetros obtidos por tais modelos são válidos apenas para as condições nas quais o experimento foi desenvolvido, não havendo relação entre a adsorção e variáveis como força iônica e pH. Os modelos eletrostáticos ou químicos ou de complexação de superfície dão uma descrição molecular da adsorção levando-se em conta o equilíbrio químico, além de calcularem valores de propriedades termodinâmicas. O maior avanço desses modelos foi considerar a espécie iônica e a superfície adsorvente como espécies carregadas, além da possibilidade de ser aplicado a solos e minerais sob diferentes condições de $\mathrm{pH}$, força iônica e concentração de soluto (Goldberg, 1983, 1992), como verificado por Casagrande (1993), Casagrande (1997) e Casagrande et al. (1998) para solos ácricos do Estado de São Paulo.

A equação de Langmuir baseia-se em superfícies energeticamente homogêneas (Sposito, 1982) e foi inicialmente empregada para descrever a adsorção de gases por sólidos. O modelo baseia-se em três pressupostos:

- a superfície de adsorção é homogênea, isto é, a adsorção é constante e independente da extensão da cobertura da superfície;

- a adsorção ocorre em sítios específicos, sem interação com as moléculas do soluto;

- a adsorção torna-se máxima quando uma camada monomolecular cobre totalmente a superfície do adsorvente.

A forma mais comum da equação de Langmuir é:

$$
\mathrm{C}_{\mathrm{ads}}=\mathrm{KC} \mathrm{b} / 1+\mathrm{KC}
$$


em que C é a concentração de equilíbrio do soluto, $\mathrm{C}_{\text {ads }}$ é a massa de soluto por unidade de massa do adsorvente, $\mathrm{K}$ é a constante relacionada à energia de ligação solutoadsorvente, e b é a quantidade máxima de soluto que pode ser adsorvida, isto é, após a formação de uma camada monomolecular completa. Esta equação é freqüentemente rearranjada para a forma linear, a fim de verificar se os dados se ajustam ao modelo:

$$
\mathrm{C} / \mathrm{C}_{\mathrm{ads}}=1 / \mathrm{Kb}+\mathrm{C} / \mathrm{b}
$$

São exemplos de bons ajustes desta equação para solos do Brasil os trabalhos desenvolvidos por Camargo et al. (1989) e Pombo et al. (1989) para níquel, os de Cunha et al. (1994) e os de Pombo (1995) e Dias et al. (2001) para cádmio e os de Jordão et al. (2000) para cobre.

Devido à competição por sítios de adsorção diminuir a retenção de metais pesados nos solos, Murali e Aylmore (1983) aplicaram a modelos de adsorção de multicomponentes, uma equação de Langmuir modificada para estudo de sistemas competitivos. No entanto, Mesquita \& Vieira (2002) estudaram a adsorção competitiva de Cu e Zn por meio da aplicação das isotermas de Langmuir nas duas formas citadas e não encontraram diferença significativa entre as equações.

\subsubsection{Complexação orgânica}

A complexação de metais pela matéria orgânica em solos e ambientes aquáticos é considerada um dos principais mecanismos que governam a solubilidade e biodisponibilidade de metais no sistema solo-planta (Ross, 1994).

A matéria orgânica do solo consiste de uma mistura de produtos de origem animal e vegetal, em diferentes estágios de decomposição, além de substâncias sintetizadas química e biologicamente. De uma forma bastante simplificada, esse material complexo pode ser subdividido em substâncias húmicas e não-húmicas. Os compostos mais estáveis no solo são as substâncias húmicas, que por sua vez podem ser 
fracionadas em ácido húmico, ácido fúlvico e humina. As substâncias húmicas apresentam um número relativamente grande de grupos funcionais $\left(\mathrm{CO}_{2}, \mathrm{OH}, \mathrm{C}=\mathrm{C}\right.$, $\mathrm{COOH}, \mathrm{SH}, \mathrm{CO}_{2} \mathrm{H}$ ) que apresentam elevada afinidade por íons metálicos, podendo formar complexos organo-metálicos (Kabata-Pendias \& Pendias, 1984).

Em termos de capacidade de ligação e transporte de metais potencialmente tóxicos, sabe-se que os ácidos fúlvicos fazem parte da fração mais importante da matéria orgânica. Os ácidos húmicos retém metais, mas seu tamanho molecular e configuração conferem a essas substâncias menor mobilidade através dos poros do solo, diminuindo sua mobilidade no perfil. A importância dos ácidos húmicos reside, portanto, no potencial de imobilização de metais (Ross, 1994).

Parece não haver consenso nas referências bibliográficas a respeito da seqüência de estabilidade das ligações entre metais e as substâncias húmicas da matéria orgânica. Atributos como concentração do metal, pH da solução de equilíbrio e quantidade de substâncias húmicas podem afetar as reações de adsorção (Kerndorff \& Schnitzer, 1980). Tais autores sugeriram a seguinte seqüência de adsorção de metais nos ácidos húmicos:

$$
\begin{aligned}
& \mathrm{pH}=3,7: \mathrm{Hg}=\mathrm{Fe}>\mathrm{Al}>\mathrm{Pb}>\mathbf{C u}>\mathrm{Cr}>\mathbf{C d}=\mathbf{N i}=\mathbf{Z n}>\mathrm{Co}>\mathrm{Mn} \\
& \mathrm{pH}=4,7: \mathrm{Hg}=\mathrm{Fe}=\mathrm{Pb}=\mathbf{C u}=\mathrm{Al}=\mathrm{Cr}>\mathbf{C d}=\mathbf{N i}=\mathbf{Z n}>\mathrm{Co}>\mathrm{Mn} \\
& \mathrm{pH}=5,8: \mathrm{Hg}=\mathrm{Fe}=\mathrm{Pb}=\mathrm{Al}=\mathrm{Cr}=\mathbf{C u}>\mathbf{C d}>\mathbf{Z n}>\mathbf{N i}>\mathrm{Co}>\mathrm{Mn}
\end{aligned}
$$

Essas seqüências de adsorção não se correlacionaram com os respectivos números e pesos atômicos, valência e raio iônico hidratado dos metais. Discordando dessa informação, Ferreira \& Cruz (1991) propuseram que a seqüência de estabilidade dos complexos formados entre o ácido húmico e cátions divalentes seria: $\mathbf{C u}>\mathbf{N i}>$ Co $>$ Zn $>$ Fe $>$ Mn. Kerndoff \& Schnittzer (1980) estabeleceram a seguinte ordem de afinidade de íons metálicos para formar complexos insolúveis em água com ácidos fúlvicos: $\mathrm{Fe}=\mathrm{Cr}=\mathrm{Al}>\mathrm{Pb}=\mathbf{C u}>\mathrm{Hg}>\mathbf{Z n}=\mathbf{N i}=\mathrm{Co}=\mathbf{C d}=\mathrm{Mn}$. Os metais complexados por ácido fúlvico são mais disponíveis às raízes das plantas e à biota do solo do que os metais retidos pelo ácido húmico (Kabata Pendias \& Pendias, 1984). 
Embora a ligação entre a matéria orgânica e metais possa ser vista como um processo de troca iônica entre os íons $\mathrm{H}^{+}$e os íons metálicos nos grupos funcionais ácidos, o alto grau de seletividade apresentado pela matéria orgânica por determinados metais sugere que alguns deles são coordenados diretamente com os grupos funcionais, via formação de complexos de esfera interna (McBride, 1989). McBride (1989) apresentou uma seqüência típica de afinidade entre metais e a matéria orgânica (a pH =5), baseada em algumas propriedades de metais divalentes (Quadro 3). No geral, íons metálicos com maior eletronegatividade ligam-se a matéria orgânica com maior intensidade, evidenciando ligação do tipo covalente.

\begin{tabular}{|lcccccccccc|}
\hline Seqüência de afinidade & $\mathbf{C u}$ & $\mathbf{N i}$ & $\mathbf{P b}$ & $>$ & $\mathrm{Co}$ & $>$ & $\mathrm{Ca}$ & $\mathbf{Z n}$ & $\mathrm{Mn}$ & $\mathrm{Mg}$ \\
\hline Eletronegatividade & 2,0 & 1,91 & 1,87 & 1,88 & 1,00 & 1,65 & 1,55 & 1,31 \\
$\mathrm{pK}_{1}{ }^{\mathrm{a}}$ & 7,5 & 9,4 & 7,8 & 9,6 & 12,7 & 9,6 & 10,7 & 11,4 \\
\hline
\end{tabular}

Quadro 3 - Sequência de afinidade de metais divalentes pela matéria orgânica

Fonte: McBride (1989)

alogaritmo negativo da primeira constante de hidrólise

A adsorção de metais pela matéria orgânica é particularmente importante para Cu e Pb (Singh, 1971; Ross, 1994). O alto grau de seletividade da matéria orgânica com o Cu é causado pela formação de complexos de esfera interna, também referidos como adsorção específica (Guilherme \& Anderson, 1998). Em concentrações baixas de Cu na solução, este será imobilizado pelos ácidos húmicos, mas, à medida que os sítios de ligação forte vão sendo saturados, uma quantidade maior de Cu será solubilizada pelos ácidos fúlvicos ou por compostos orgânicos mais simples (McBride, 1989). A formação de complexos de esfera interna com o Cu dá lugar ao mecanismo de complexação de esfera externa quando o Cu está em elevada concentração na solução do solo (McBride, 1989). Para o autor, o mecanismo de equilíbrio entre a formação desses dois tipos de complexos é sensível a fatores como pH, extensão de ocupação do metal nos sítios de adsorção e ao estado de hidratação do metal. 


\subsubsection{Precipitação/ Dissolução}

Os mecanismos de precipitação/ dissolução, juntamente com os de adsorção/ dessorção, são considerados os principais processos que controlam a concentração de espécies metálicas na solução do solo (Ross, 1994). As reações de precipitação e dissolução são geralmente descritas pelo produto de solubilidade, quando um sólido dissolve-se para formar o soluto nesta solução (Camargo et al., 2001). Esse fenômeno está normalmente associado a solos alcalinos e calcários, com concentrações relativamente altas de metais pesados, além de condições que favoreçam a baixa solubilidade desses metais ou sítios reduzidos de adsorção específica (Brümmer et al., 1983; Ross, 1994).

Uma das dificuldades em experimentos de adsorção consiste em se distinguir o

que é adsorção química daquilo que é conhecido como precipitação. Algumas vezes existem formas de fazer tal distinção, no entanto, a formação de uma nova fase sólida durante o processo de adsorção não é reconhecida (McBride, 1989). Normalmente, isotermas de adsorção que apresentam a mesma concentração de equilíbrio para diferentes concentrações iniciais de um metal refletem um mecanismo de precipitação (Brümmer et al., 1983).

Tanto a precipitação/ dissolução como a adsorção/dessorção são mecanismos influenciados pela acidez e pelo potencial redox do solo. Teoricamente, o processo de precipitação/dissolução ocorre em um determinado $\mathrm{pH}$ e, de maneira contrária a adsorção, é menos dependente da quantidade de reagente ou diferentes superfícies minerais presentes no solo (Ross, 1994).

\subsection{Correlações entre atributos do solo e da solução e retenção de metais pesados}

\subsubsection{Atributos do solo}

A maioria dos estudos de adsorção de metais pesados no solo tem como finalidade correlacionar o comportamento e a dinâmica desses elementos em função de 
atributos do solo. Em função das características químicas, físicas e mineralógicas que os solos podem apresentar e da seletividade de cada elemento por sítios de adsorção, é comum encontrarmos resultados divergentes quanto aos atributos do solo que melhor se correlacionam com a adsorção desses elementos (Matos et al., 2001). No entanto, a quantidade retida da maioria dos metais pesados correlaciona-se positivamente com matéria orgânica, capacidade de troca de cátions, superfície específica, conteúdo de argila e teor de óxidos (Schulthess \& Huang, 1990; Singh \& Gilkes, 1992; Zhu \& Alva, 1993; Pombo, 1995; Matos et al., 1996; Dias et al., 2001; Matos et al., 2001).

Araújo et al. (2002) utilizaram análise de trilha para demonstrar a relação entre os parâmetros de adsorção obtidos para alguns metais, entre eles Cd, Cu e Zn, e os atributos de uma série de solos tropicais. Para os autores, os principais atributos do solo responsáveis pela retenção de Cd e Zn foram o teor de argila, carbono orgânico (Corg.) e CTC efetiva, destacando-se o Corg em função dos maiores valores do efeito direto. Para esses dois elementos, a adsorção não-específica, de menor estabilidade, exerceu papel importante na retenção dos mesmos em solos intemperizados. No caso do $\mathrm{Cu}$, as variáveis do solo que apresentaram coeficientes de correlação simples significativos com a adsorção do elemento foram Corg, CTC efetiva, teores de argila e de óxido de alumínio. Os resultados para $\mathrm{Cu}$ confirmaram a existência de um forte mecanismo de retenção do metal com argila e carbono orgânico, descrito por diversos autores (Matos et al., 1996; Matos et al., 2001; Araújo et al., 2002; Silveira et al., 2002). No caso de Cd e Zn, a elevada solubilidade desses elementos no solo é indício de ligação não-específica ou da formação de esfera externa (Matos et al., 2001).

\subsubsection{Atributos da solução do solo}

Os atributos da solução do solo que afetam a disponibilidade de metais são pH, composição e força iônica da solução, espécies e concentração dos elementos e presença de ligantes e íons competidores (Harter \& Naidu, 2001). De todos os parâmetros da solução do solo, o pH é um dos mais importantes, haja vista que está positivamente 
correlacionado com a adsorção dos metais no solo (McBride \& Blasiak, 1979; Harter, 1983; Basta \& Tabatabai, 1992a; Ross, 1994). Em solos altamente intemperizados, o pH modifica a superfície de carga dos colóides, regulando, juntamente com outros atributos, a magnitude da adsorção nesses solos (Naidu et al., 1994). No entanto, tal magnitude varia conforme o metal e o tipo de solo. Msaky \& Calvet (1990) estudaram a influência do $\mathrm{pH}$ no comportamento de $\mathrm{Cu}$ e $\mathrm{Zn}$ em diversos solos e observaram que para um Podzol a quantidade de Zn adsorvida foi praticamente constante em toda faixa de $\mathrm{pH}$ estudada, em função do conteúdo de matéria orgânica. Basta \& Tabatabai (1992a) observaram que em concentrações baixas, as adsorções de $\mathrm{Cd}, \mathrm{Cu}, \mathrm{Zn}, \mathrm{Pb}$ e $\mathrm{Ni}$ para um Typic Hapludoll e um Typic Haplaquoll ocorreram independentemente do pH. Em concentrações elevadas, a retenção dos metais mostrou-se altamente relacionada com o aumento do $\mathrm{pH}$.

Naidu et al. (1994) avaliaram o efeito da força iônica e do pH na adsorção de Cd em diferentes solos (Oxisols, Inceptisols e Alfisols) e observaram que a retenção do metal aumentou com o aumento do $\mathrm{pH}$ e que o efeito da força iônica variou com o tipo de solo e com o pH. Para os solos com cargas variáveis houve um $\mathrm{pH}$ característico, abaixo do qual aumentos na força iônica levavam a um aumento da adsorção, ocorrendo o inverso acima desse $\mathrm{pH}$. 


\section{MATERIAL E MÉTODOS}

\subsection{Solos}

Os solos foram selecionados, a princípio, pela representatividade e distribuição dentro do Estado de São Paulo, com vista a compor um conjunto heterogêneo quanto a características físicas e químicas (Tabela 1). O segundo critério de seleção baseou-se na localização em relação aos maiores centros urbanos do Estado, considerando a grande probabilidade de esses solos estarem sujeitos à contaminação por metais pesados, principalmente em virtude do estabelecimento de aterros sanitários, disposição de resíduos sólidos e águas residuárias urbanas e/ou industriais. Como os estudos de adsorção normalmente presumem que o elemento de interesse não esteja inicialmente presente no solo, em quantidades elevadas, as amostras foram coletadas em áreas adjacentes a matas nativas ou reflorestamento antigo, o que minimiza a possibilidade de escolha de áreas que tenham sofrido efeito antrópico num passado recente (Singh \& Steinnes, 1994). 
Tabela 1. Solos selecionados para o estudo

\begin{tabular}{|c|c|c|c|}
\hline Solo & Horizonte A & Símbolo & Cidade \\
\hline \multicolumn{4}{|c|}{ ARGISSOLOS } \\
\hline Argissolo Vermelho-Amarelo & fraco & PVA-1 & Piracicaba \\
\hline Argissolo Vermelho-Amarelo & moderado & PVA-2 & Americana \\
\hline Argissolo Vermelho-Amarelo & chernozêmico & PVA-3 & Piracicaba \\
\hline \multicolumn{4}{|c|}{ LATOSSOLOS } \\
\hline Latossolo Vermelho & moderado & $\mathrm{LV}$ & Piracicaba \\
\hline Latossolo Vermelho acriférrico & moderado & LVwf & Ribeirão Preto \\
\hline Latossolo Vermelho eutroférrico & moderado & LVef & Ribeirão Preto \\
\hline Latossolo Amarelo ácrico & moderado & LAw & Guaíra \\
\hline \multicolumn{4}{|c|}{ NITOSSOLO } \\
\hline Nitossolo Vermelho eutroférrico & chernozêmico & NVef & Ribeirão Preto \\
\hline \multicolumn{4}{|c|}{ CAMBISSOLO } \\
\hline Cambissolo Háplico & moderado & CX & Araras \\
\hline \multicolumn{4}{|c|}{ NEOSSOLO } \\
\hline Neossolo Quartzarênico & fraco & RQ & Piracicaba \\
\hline \multicolumn{4}{|c|}{ GLEISSOLO } \\
\hline Gleissolo Melânico & moderado & GM & Pariquera-Açu \\
\hline \multicolumn{4}{|c|}{ ORGANOSSOLO } \\
\hline Organossolo Háplico & húmico & $\mathrm{OX}$ & Pariquera-Açu \\
\hline \multicolumn{4}{|c|}{ CHERNOSSOLO } \\
\hline Chernossolo Argilúvico & chernozêmico & MT & Analândia \\
\hline \multicolumn{4}{|c|}{ LUVISSOLO } \\
\hline Luvissolo Crômico & moderado & TC & Marília \\
\hline
\end{tabular}


Foram coletadas amostras superficiais $(0-0,2 \mathrm{~m})$ de acordo com procedimentos padrões estabelecidos pela CETESB (2001), de forma a evitar contaminação das amostras. O armazenamento e preparo das amostras seguiram os critérios da EMBRAPA (1997).

\subsection{Análises químicas de rotina}

Seguindo métodos descritos em Raij et al. (2001), foram realizadas as seguintes análises químicas:

- $\quad$ pH em água, $\mathrm{CaCl}_{2}$ 0,01 $\mathrm{mol} \mathrm{L}^{-1}$ e $\mathrm{KCl} 1 \mathrm{~mol} \mathrm{~L}^{-1}$, com relação solo solução 1:2,5. A partir dos valores obtidos, calculou-se o $\Delta \mathrm{pH}$, definido como $\mathrm{pH} \mathrm{KCl}-\mathrm{pH}$ $\mathrm{H}_{2} \mathrm{O}$.

- Acidez potencial $(\mathrm{H}+\mathrm{Al})$ : extração do $\mathrm{H}+\mathrm{Al}$ pelo acetato de cálcio (CaOAc $0,5 \mathrm{~mol} \mathrm{~L}^{-1}$ ) a $\mathrm{pH} 7$;

- Al trocável: extração com solução de $\mathrm{KCl} 1 \mathrm{~N}$ e titulação com $\mathrm{NaOH}$ 0,05 mol L ${ }^{-1}$, em presença de azul de bromotimol.

- Cátions trocáveis (K, Ca, Mg): extração dos elementos com resina trocadora de íons e leitura no espectrofotômetro de absorção atômica (Ca e Mg) e fotômetro de chama (K). A partir dos resultados obtidos, calcularam-se:

a) Soma de bases $(\mathrm{SB})=\mathrm{Ca}+\mathrm{Mg}+\mathrm{K}$

b) $\mathrm{CTC}$ efetiva $\left(\mathrm{CTC}_{\mathrm{e}}\right)=\mathrm{SB}+\mathrm{Al}$;

c) $\mathrm{CTC}$ total $\left(\mathrm{CTC}_{\mathrm{t}}\right)=\mathrm{SB}+\mathrm{H}+\mathrm{Al}$;

d) Saturação por bases $(\mathrm{V} \%)=(\mathrm{SB} / \mathrm{CTC}$ total $) * 100$;

e) Saturação por alumínio $(\mathrm{m} \%)=(\mathrm{Al} * 100) / C T C$ efetiva.

- Carbono orgânico: oxidação da matéria orgânica com solução de dicromato de potássio em presença ácido sulfúrico e titulação do excesso dicromato com sulfato ferroso amoniacal;

- Fósforo (P): extração dos teores disponíveis de P pela resina trocadora de íons e quantificação por colorimetria. 


\subsection{Análises químicas complementares}

- Teores de óxidos ( $\mathrm{Si}, \mathrm{Fe}, \mathrm{Al}$ e $\mathrm{Mn}$ ): solubilização de amostras de terra com $\mathrm{H}_{2} \mathrm{SO}_{4}$ 1:1. Com os resultados foram calculados os índices:

a) $\mathrm{Ki}=\left(\% \mathrm{SiO}_{2} / 60\right) /\left(\% \mathrm{Al}_{2} \mathrm{O}_{3} / 102\right)$, e

b) $\mathrm{Kr}=\left(\% \mathrm{SiO}_{2} / 60\right) /\left[\left(\% \mathrm{Al}_{2} \mathrm{O}_{3} / 102\right)+\left(\% \mathrm{Fe}_{2} \mathrm{O}_{3} / 160\right)\right]$.

- Fe livre ou cristalino $\left(\mathrm{Fe}_{\mathrm{DCB}}\right)$ : determinação pelo método do ditionito-citratobicarbonato (DCB), descrito em Loeppert \& Inskeep (1996).

- Fe mal cristalizado ou pouco cristalino $\left(\mathrm{Fe}_{\mathrm{o}}\right)$ e $\mathrm{Al}$ mal cristalizado ou pouco cristalino $\left(\mathrm{Al}_{\mathrm{o}}\right)$ : extração com solução ácida de oxalato de amônio, na ausência de luz (Loeppert \& Inskeep, 1996; Bertsch \& Bloom, 1996).

- Óxidos de Mn: foram realizadas duas metodologias para sua determinação. A primeira, obtida pelo ataque sulfúrico e alcalino das amostras, forneceu o teor "total” de MnO. Tendo em vista que a maioria do manganês potencialmente disponível em solos agrícolas aeróbicos estão em minerais contendo óxidos de $\mathrm{Mn}$, ou adsorvidos ou coprecipitados com óxidos de Fe, utilizou-se a metodologia referida como dissolução seletiva de $\mathrm{MnO}$, usando hidrocloreto de hidroxilamina e ácido nítrico como extratores (Gambrell, 1996). Esta, especialmente utilizada quando se deseja determinar íons metálicos que possam estar coprecipitados com $\mathrm{MnO}$, promove a extração de $\mathrm{MnO}$ com o mínimo de ataque aos óxidos de ferro, coexistentes no solos. Para fins de discussão, serão utilizadas as nomenclaturas $\mathrm{Mn}_{\mathrm{as}}$, para o $\mathrm{Mn}$ extraído pelo ataque sulfúrico e $\mathrm{Mn}_{\mathrm{ds}}$ para o Mn extraído pela metodologia da dissolução seletiva.

\subsection{Análises físicas}

A granulometria foi avaliada, após dispersão química, empregando-se o método do densímetro (EMBRAPA, 1997). Foram tomados $20 \mathrm{~g}$ de terra e adicionados $100 \mathrm{~mL}$ da solução dispersante, preparada a partir da dissolução de 20 g de hidróxido e sódio em 5 L de água destilada e posterior adição de 50 g de hexametafosfato de sódio. 
Em seguida, a suspensão (solo + dispersante) foi agitada por 16 h em agitador rotatório a 30 rpm. Transferiu-se a suspensão para uma proveta, completando o volume com água destilada até atingir $1 \mathrm{~L}$. Com um agitador manual, a amostra foi agitada por 40 segundos. Ao término dessa agitação, introduziu-se o densímetro na suspensão, realizando a primeira leitura, correspondente às frações argila + silte. Após 2 h, realizouse a segunda leitura, correspondente à fração argila. As frações silte e areia foram calculadas por diferença.

\subsection{Isotermas de adsorção}

Ao correspondente a 2,0 g de terra fina seca ao ar, passada em peneira de 2 $\mathrm{mm}$, foram adicionados $20 \mathrm{~mL}$ de solução de $\mathrm{NaNO}_{3}$ 0,01 mol L${ }^{-1}$ (relação 1:10) contendo diferentes concentrações iniciais de $\mathrm{Cu}\left(\mathrm{Cu}\left(\mathrm{NO}_{3}\right)_{2} 2,5 \mathrm{H}_{2} \mathrm{O}\right), \mathrm{Ni}\left(\mathrm{Ni}\left(\mathrm{NO}_{3}\right)_{2}\right.$ $\left.6 \mathrm{H}_{2} \mathrm{O}\right)$ e $\mathrm{Zn}\left(\mathrm{Zn}\left(\mathrm{NO}_{3}\right)_{2}\right)$, na forma isolada (sistema não-competitivo) e em conjunto (sistema competitivo) (Tabela 2). O nitrato foi escolhido como eletrólito suporte devido à sua menor habilidade em complexar cátions metálicos (Msaky \& Calvet, 1990; Silveira, 1999). As amostras foram tomadas em duplicata, e por se tratar de um experimento de competição, as doses foram padronizadas em termos de concentração molar, eliminando assim o efeito de massa entre os metais e possibilitando um estudo mais detalhado do fenômeno da adsorção.

Tendo em vista que $\mathrm{Cu}$, Ni e $\mathrm{Zn}$ pertencem ao mesmo período da tabela periódica, seus números atômicos são próximos, o que possibilitou a utilização de doses

semelhantes em mg $\mathrm{L}^{-1}$, para os três metais. Para o Cd, que ocupa um período inferior na tabela periódica e, portanto, possui número atômico maior que os demais elementos em questão, foram utilizadas doses mais elevadas em $\mathrm{mg} \mathrm{L}^{-1}$. 
Tabela 2. Doses de $\mathrm{Cd}, \mathrm{Cu}, \mathrm{Zn}$ e $\mathrm{Ni}$ utilizadas nas isotermas de adsorção e sua equivalência em mmol $\mathrm{L}^{-1}$

\begin{tabular}{ccccc}
\hline Cd & $\mathrm{Cu}$ & $\mathrm{Zn}$ & $\mathrm{Ni}$ & $\mathrm{mmol} \mathrm{L}^{-1}$ \\
\hline 1,91 & 1,08 & $\mathrm{mg} \mathrm{L}^{-1}$ & & \\
3,82 & 2,17 & 2,22 & 1,00 & 0,017 \\
9,55 & 5,41 & 5,56 & 2,00 & 0,034 \\
19,10 & 10,83 & 11,11 & 5,00 & 0,085 \\
28,65 & 16,24 & 16,67 & 10,00 & 0,170 \\
57,30 & 32,48 & 33,33 & 15,00 & 0,255 \\
95,51 & 54,14 & 55,56 & 30,00 & 0,510 \\
143,26 & 81,21 & 83,33 & 50,00 & 0,850 \\
\hline
\end{tabular}

O conjunto foi agitado por $1 \mathrm{~h}$ em agitador horizontal a 100 osc $\min ^{-1}$ (Fontes \& Gomes, 2003). Após a agitação, as amostras foram centrifugadas a 1.100 rpm durante 10 minutos e em seguida foram filtradas em papel de filtro qualitativo, para a remoção de raízes ou qualquer tipo de impureza que pudesse impedir a leitura dos metais. As determinações das concentrações de $\mathrm{Cd}, \mathrm{Cu}$, Ni e $\mathrm{Zn}$ em equilíbrio foram feitas por espectrofotometria de absorção atômica.

As concentrações dos metais pesados adsorvidos ao solo foram estimadas utilizando-se a expressão: $\mathrm{C}_{\mathrm{ads}}=\left(\mathrm{C}_{0}-\mathrm{C}_{\mathrm{eq}}\right) \mathrm{FD}$, em que $\mathrm{C}_{\mathrm{ads}}$ é a quantidade de metal pesado retida pela fase sólida, $\mathrm{C}_{0}$ é a concentração de metal pesado da solução colocada em contato com o solo, $C_{\text {eq }}$ é a concentração de metal pesado na solução após a agitação e D é fator de diluição, que considera a relação solução/solo (FD = $20 \mathrm{~mL}$ de solução / 2 g de terra $=10)$.

Foram elaborados gráficos das quantidades adsorvidas $\mathrm{C}_{\mathrm{ads}}$ em função das concentrações em equilíbrio $C_{e q}$, para os metais no sistema não-competitivo e no sistema competitivo. As isotermas de adsorção de Langmuir foram ajustadas com o auxílio do programa Fitfunc.bas (Barrow, 1987), que ajusta equações não lineares aos resultados de adsorção, seguindo a metodologia dos “desvios mínimos” (Mead, 1981; 
Shani et al., 1992), para a obtenção da adsorção máxima para cada metal. Nos gráficos das isotermas de adsorção em que modelo não se ajustou de maneira satisfatória, optouse por apresentar somente os pontos obtidos experimentalmente. Para os demais solos, os gráficos apresentam os pontos que compõe as isotermas de adsorção obtidas experimentalmente e a curva referente ao modelo de Langmuir.

A equação de Langmuir, expressa na forma linear (eq. 2), permite verificar, com maior facilidade, se os resultados experimentais obtidos ajustam-se ao modelo de Langmuir (Meurer et al., 2000).

$$
\mathrm{C}_{\mathrm{eq}} \cdot / \mathrm{C}_{\mathrm{ads}}=(1 / \mathrm{Kb})-\mathrm{c} / \mathrm{b}
$$

Sendo: $\mathrm{C}_{\mathrm{ads}}$ - quantidade do íon adsorvido na fase sólida; $\mathrm{C}_{\mathrm{eq}}$ - - concentração do íon em solução de equilíbrio com a fase sólida; $\mathrm{K}$ - constante de afinidade; $b$ adsorção máxima.

Como o modelo de Langmuir não simulou de maneira satisfatória os valores de $b$ para os solos com elevada capacidade de adsorção de metais, preferiu-se linearizar os resultados experimentais, calculando assim, novos valores de $b$, da seguinte forma:

- Etapa 1: para a isoterma de cada metal, construiu-se um gráfico plotando a concentração de equilíbrio - Ceq. (eixo x) em função da [ $\left.\mathrm{C}_{\mathrm{eq}} \cdot /\left(\mathrm{C}_{\mathrm{ads}}\right)\right]$ (eixo y), obtendose assim uma reta, com declividade igual a 1/b, da qual pode-se estimar a $b$ e 0 parâmetro $1 / \mathrm{K} b$;

- Etapa 2: A partir da equação da reta $(y=a x+b)$, calculou-se a adsorção máxima (b) e a constante de afinidade $(\mathrm{K})$, da seguinte forma:

$$
\begin{gathered}
b=1 / \mathrm{a} \\
\mathrm{K}=1 /\left(b^{*} \mathrm{~b}\right)
\end{gathered}
$$

- Etapa 3: obtidos os valores de $b$ e K, construiu-se a equação de Langmuir na forma linear: 


$$
\mathrm{y}=\left(b^{*} \mathrm{~K}\right) \mathrm{x} /(1+\mathrm{K}) \mathrm{x}
$$

sendo, $\mathrm{y}=\mathrm{C}_{\mathrm{ads}}$ ou a quantidade do íon adsorvido na fase sólida.

\subsubsection{Delineamento experimental e forma de análise dos resultados}

O experimento de adsorção foi conduzido em um delineamento inteiramente casualizado. As comparações entre os solos e a obtenção das seqüências de afinidade dos metais em cada solo, nos sistemas não-competitivo e competitivo, foram feitas com base nos valores de adsorção máxima $(b)$, obtidos após linearização das isotermas de adsorção (eq. 3), convertidos em mmol kg-1.

O efeito da competição na adsorção dos metais, em cada solo, foi avaliado a partir da proporção de variação na adsorção máxima dos metais nos sistemas estudados, da seguinte forma:

$$
\text { \% variação na } b=\left(b_{\mathrm{SNC}}-b_{\mathrm{SC}}\right) * 100 / b_{\mathrm{SNC}}
$$

Sendo: $b_{\mathrm{SNC}}=$ adsorção máxima $\left(\mathrm{mmol} \mathrm{kg}^{-1}\right)$ obtida no sistema nãocompetitivo; $b_{\mathrm{SC}}=$ adsorção máxima $\left(\mathrm{mmol} \mathrm{kg}{ }^{-1}\right)$ obtida no sistema competitivo.

A contribuição das propriedades dos solos aos valores de adsorção máxima para cada metal, nos sistemas não-competitivo e competitivo, foi avaliada mediante estudos de correlação simples e equacionamento de modelos de regressão múltipla do tipo “passo a passo”. Os resultados foram analisados com o auxílio do pacote estatístico Statistical Analysis System for Windows - V8 (SAS Institute, 1988) através das entradas proc CORR e proc REG, respectivamente. 


\section{RESULTADOS E DISCUSSÃO}

\subsection{Análises químicas e físicas}

\subsubsection{Análise química de rotina}

Os resultados das análises químicas dos solos estudados estão expressos no anexo (Tabela 3). Segundo critérios propostos por Raij et al. (2001), serão feitas algumas considerações a respeito dos atributos dos solos.

Houve predomínio de solos com acidez muito alta $(\mathrm{pH} \leq 4,3)$. Esses solos foram o LV, RQ, OX, CX e GM. Em seguida, vieram os solos com acidez alta: LVwf, LAw, PVA-1 e TC (pH 4,4 - 5,0); os solos com acidez média: PVA-2, NVef e MT (pH 5,1 - 5,5); e, finalmente, os solos PVA-3 e Lvef, cuja acidez foi baixa ( $\mathrm{pH} \mathrm{5,6} \mathrm{-} \mathrm{6,0)} \mathrm{e}$ muito baixa $(\mathrm{pH} \geq 6,0)$, respectivamente. Com relação aos valores de $\Delta \mathrm{pH}$, todos os solos apresentaram balanço negativo de cargas, provavelmente pelo efeito da matéria orgânica.

Os solos LAw, OX, CX e GM são pobres em cátions básicos, apresentando valores considerados muito baixos de saturações por bases (V\% 0-25\%), seguidos pelos solos LV, LVwf, RQ (V\% 26-50\%), PVA-1, NVef e TC (V\% 51-70\%), PVA-2, PVA-3 e MT (V\% 71-90\%) e LVef, cuja saturação por bases foi muito alta (V\%>90\%). Os valores de $\mathrm{pH}$ e V\% apresentaram correlação positiva, o que já era esperado para amostras retiradas da camada superficial.

A maioria dos solos apresentou valores altos de cálcio $\left(>7 \mathrm{mmol}_{\mathrm{c}} \mathrm{kg}^{-1}\right)$, exceção feita aos solos LAw, PVA-1, RQ, TC, GM e CX, para os quais os teores encontrados foram baixos. Os solos LVA, PVA-1, RQ, GM, OX, CX e TC apresentaram 
baixos teores de magnésio (0-4 mmol $\left._{\mathrm{c}} \mathrm{kg}^{-1}\right)$. Em contrapartida, os solos LV, LVef, PVA3, NVef e MT apresentaram alto teor do elemento $\left(>8 \mathrm{mmol}_{\mathrm{c}} \mathrm{kg}^{-1}\right)$. Em relação ao teor de potássio, somente os solos PVA-1 e RQ apresentaram valores muito baixos do elemento. Os solos GM, OX, CX e TC apresentaram teores baixos e os solos LV e LAw, teores considerados médios. Os demais solos apresentaram alto teor de potássio. Analisando os cátions básicos, é importante destacar os resultados expressivos de soma de bases (SB) obtidos para os solos LVef, MT, PVA-3, PVA-2 e NVef, que, juntamente com os valores de V\%, evidenciam a elevada fertilidade desses solos. Com relação aos teores de fósforo, o maior valor foi encontrado para o solo OX e os menores teores para os solos PVA-1, RQ e TC.

Os teores de carbono (C) foram altos para a maioria dos solos, com exceção do LVA e GM, que apresentaram teor médio de C e os solos PVA-1, RQ e TC, que apresentaram teor baixo desse atributo. O predomínio de solos com elevado teor de $\mathrm{C}$ refletiu a condição natural dos solos, coletados em áreas adjacentes a matas nativas ou reflorestamento antigo, além de pertencerem ao horizonte A dos perfis amostrados. Os solos GM e OX foram os que apresentaram os teores mais elevados de C (130,7 e $119,17 \mathrm{~g} \mathrm{~kg}^{-1}$, respectivamente).

Os valores de $\mathrm{CTC}_{\mathrm{pH} 7,0}$ dos solos NVef, MT, GM e OX foram os mais elevados. No entanto, analisando os valores de V\% e $\mathrm{H}+\mathrm{Al}$ dos solos GM e OX, torna-se evidente a deficiência de cátions básicos compondo a CTC de ambos os solos. Os menores valores de $\mathrm{CTC}_{\mathrm{pH} 7,0}$ foram obtidos para os solos RQ, PVA-1 e TC. Com relação a CTC efetiva, os maiores valores encontrados foram para os solos MT e PVA-3, corroborando os valores de $\mathrm{pH}$ e $\mathrm{V} \%$ destes solos.

Os teores de Al trocável foram muito altos para os solos OX, CX e GM, assim como seus valores de saturação por alumínio $(\mathrm{m} \%)$, indicando níveis tóxicos deste elemento. Para os demais solos, os teores de Al trocável variaram de baixo (LVef, PVA1, 2 e 3, NVef, TC e MT) a médio (LV, LVwf e LAw). No RQ, apesar de o teor de Al trocável ter sido baixo $\left(3,9 \mathrm{mmol}_{\mathrm{c}} \mathrm{kg}^{-1}\right)$, a $\mathrm{m} \%$ foi alta. A $\mathrm{m} \%$ foi alta para os solos RQ, LAw e LV, média para os solos LVwf e baixa para LVef, PVA-1, 2 e 3, NVef, e MT. 


\subsubsection{Análises químicas complementares}

$\mathrm{O} \mathrm{Ki}$, demonstrativo da composição quantitativa média dos principais elementos constituintes dos minerais secundários da fração argila, é geralmente utilizado para caracterizar o horizonte diagnóstico de solos, mas seu conhecimento para amostras da camada superficial pode fornecer indícios sobre a proporção global de tais elementos, para inferência do grau de intemperismo do solo. Os menores valores de $\mathrm{Ki}$ foram

obtidos para os Latossolos, principalmente para os ácricos (LVwf e LAw), que representam o extremo em termos de intemperização (Tabela 4). $\mathrm{O}$ valor mais alto foi encontrado para o TC. O mesmo pode ser dito a respeito do índice $\mathrm{Kr}$, que permite classificar um solo, a partir dos teores totais dos óxidos de $\mathrm{Si}$, Al e Fe do horizonte diagnóstico, como sesquioxídico ou não.

Os teores mais elevados de ferro extraído com ácido sulfúrico $\left(\mathrm{Fe}_{\mathrm{as}}\right)$ foram encontrados para os solos LVwf, NVef, LVef, MT, LAw e LV. A proporção de ferro na forma livre $\left(\mathrm{Fe}_{\mathrm{d}}\right)$ para esses solos variou de 27,5\% (LV) a 51,1\% (NVef) do $\mathrm{Fe}_{\text {as. }}$ Os solos que apresentaram maior proporção de ferro livre foram $\mathrm{CX}$ e $\mathrm{OX}\left(>60 \%\right.$ do $\left.\mathrm{Fe}_{\mathrm{as}}\right)$. Com relação à proporção de formas de ferro mal cristalizadas $\left(\mathrm{Fe}_{\mathrm{o}}\right)$, os valores foram menores, variando de 0,3\% (PVA-1) a 22,6\% (OX) do $\mathrm{Fe}_{\mathrm{as}}$. As maiores relações $\mathrm{Fe}_{\mathrm{o}} / \mathrm{Fe}_{\mathrm{d}}$ foram encontradas nos solos MT, OX e GM (0,24; 0,37 e 0,46, respectivamente). Os solos PVA-1 e 2, NVef, CX e LAw apresentaram os menores valores para essa relação $(0,02-0,05)$. Em relação aos Latossolos, os resultados são superiores aos encontrados por Guilherme \& Anderson (1998) que obtiveram, para dois Latossolos (Latossolo Vermelho-Amarelo e Latossolo Vermelho-Escuro), relações entre 0,02 e 0,05 e dos encontrados por Silveira (1999), que obteve, para Latossolo Roxo e Latossolo variação Una, as relações 0,08 e 0,05, respectivamente. A autora obteve, no entanto, a relação 0,08 para amostras superficiais de um Nitossolo Vermelho Eutróférrico, enquanto que a relação encontrada para o NVef, em estudo, foi de apenas 0,03.Os Latossolos (LVwf, LVef, LV e LAw) foram os solos que apresentaram os teores mais elevados de óxido de alumínio extraído com ácido sulfúrico. Além desses, o NVef, GM, MT, CX e OX 
também apresentaram valores consideráveis desse atributo. Os menores valores foram encontrados nos solos PVA-1, TC e RQ.

Os solos com maior teor de MnO foram LVef, LVwf, PVA-2, PVA-3, NVef e MT. Embora os resultados obtidos nas duas metodologias tenham sido qualitativamente iguais, numericamente eles foram diferentes. Esse fato evidencia a relevância da utilização da dissolução seletiva para uma determinação mais criteriosa dos óxidos de manganês presentes em solos e sedimentos, principalmente em estudos ambientais, tendo em vista que a associação entre muitos elementos-traços, entre eles os metais pesados, é reportada em muitos trabalhos.

\subsubsection{Análises físicas}

Os solos LVef, LVwf e NVef foram classificados como muito argilosos, os solos LV, LAw, PVA-3, GM e MT como argilosos e os solos PVA-1 e RQ como arenosos (tabela 5). Os demais solos se enquadraram na classe textural média (Tabela 5). 
Tabela 5. Resultados das análises físicas dos solos estudados

\begin{tabular}{ccccc}
\hline Solo & Argila & Silte & Areia & Textura $^{1}$ \\
\hline & & & & \\
LV & 502,2 & 118,5 & 379,3 & argilosa \\
LVef & 676,9 & 218,4 & 104,7 & muito argilosa \\
LVwf & 726,5 & 138,2 & 135,3 & muito argilosa \\
LAw & 450,0 & 135,4 & 414,6 & argilosa \\
PVA - 1 & 55,9 & 99,8 & 844,3 & arenosa \\
PVA - 2 & 251,2 & 187,5 & 561,3 & média \\
PVA - 3 & 382,2 & 428,7 & 189,1 & argilosa \\
RQ & 82,1 & 55,6 & 862,3 & arenosa \\
NVef & 605,9 & 297,6 & 96,5 & muito argilosa \\
GM & 496,3 & 363,6 & 140,1 & argilosa \\
OX & 296,7 & 381,2 & 322,1 & média \\
CX & 267,8 & 132,3 & 599,9 & média \\
TC & 35,6 & 251,4 & 713,0 & média \\
MT & 550,0 & 295,0 & 155,0 & argilosa \\
\hline
\end{tabular}

1 Grupamentos texturais segundo Embrapa (1999). Textura referente ao horizonte superficial

\subsection{Modelo de Langmuir}

Em alguns casos, as isotermas de adsorção obtidas a partir dos valores de Concentração em equilíbrio (Ceq.) e Quantidade adsorvida, estimados pela equação de Langmuir, não se adequaram à distribuição dos pontos obtidos, experimentalmente, principalmente nos solos cuja adsorção de $\mathrm{Cu}$ foi elevada, mesmo a baixas concentrações metálicas adicionadas (LVef, NVef, MT e PVA-3). Para esses solos, o programa somente foi capaz de predizer os valores de Ceq e Quantidade adsorvida para 
as concentrações iniciais, não sendo possível estimá-los nas concentrações finais. Nestes casos, optou-se por não utilizar, nos gráficos, as isotermas obtidas pelo modelo.

Quando a forma da isoterma obtida por esse modelo não coincide com a experimental, e somente baixas concentrações são empregadas na sua obtenção, os erros advindo da estimativa da adsorção máxima podem atingir 50\% ou mais (Harter, 1983). O autor alerta, ainda, que a predição da adsorção máxima seria melhor se concentrações mais elevadas forem utilizadas, o que tornaria inútil a adoção do modelo para estimativa Ooxissolos, Alfissolos e Ultissolos, Cunha et al. (1994) afirmam que o uso de maiores concentrações de $\mathrm{Zn}$ na solução inicial talvez pudesse diminuir tal distorção. No entanto, é difícil prever essa possibilidade no início de um ensaio, quando são estabelecidas as concentrações a serem empregadas. Para os autores, embora a equação de Langmuir tenha subestimado a adsorção de $\mathrm{Zn}$, o aspecto qualitativo dessa estimativa permite a comparação entre solos de uma mesma região que não se diferenciem quanto à sua mineralogia.

Tendo em vista que a obtenção dos valores de $b$ a partir do modelo e da equação linearizada de Langmuir não foi satisfatória para alguns solos, optou-se por utilizar os valores de $b$ obtidos por meio da linearização dos dados experimentais (isotermas de adsorção) de cada metal. Um dos aspectos negativos desse procedimento consiste no fato de se plotar (Ceq./Quantidade adsorvida) contra Ceq., o que reduz a variabilidade dos dados, uma vez que a Ceq. é plotada contra si mesma (Harter, 1984). Além disso, nem sempre a adoção de formas lineares de Langmuir proporciona curvas mais bem ajustadas às isotermas obtidas experimentalmente (Cunha et al., 1994). Em alguns casos, com a utilização de formas lineares da equação de Langmuir, não somente o ajuste das curvas para algumas dessas equações foi pior como, também, a predição da adsorção máxima não era adequada (Harter, 1984). Alguns estudos, tendo apresentado esse mesmo problema, efetuaram a construção das isotermas de adsorção e a observação das curvas com base na forma não linear das equações (Cunha et al., 1994). 


\subsection{Isotermas de adsorção de $\mathrm{Cd}, \mathrm{Cu}$, Ni e $\mathrm{Zn}$}

Os resultados referentes à adsorção dos metais nos sistemas não-competitivo (SNC) e competitivo (SC) estão expressos nas Figuras 2 a 11. Os valores que originaram as isotermas de adsorção, encontram-se nas Tabelas A1 a A13 (SS) e Tabelas A14 a A27 (SC), nos apêndices.

\subsubsection{Sistema não-competitivo}

Para todos os solos, as quantidades de $\mathrm{Cd}, \mathrm{Cu}$, Ni e $\mathrm{Zn}$ adsorvidas aumentaram com o aumento das doses adicionadas. Nas menores quantidades de metais adicionadas aos solos, foram encontradas as menores concentrações dos metais em solução. À medida que as doses adicionadas aumentaram, o incremento da adsorção foi menos acentuado. Isso pode ter ocorrido, principalmente, pela saturação dos sítios de adsorção (Ross, 1994).

Para os solos MT, PVA-2, PVA-3, NVef e LVef, praticamente toda quantidade de metais adicionada foi adsorvida, o que pode ser comprovado pela inclinação das curvas (Figuras 2 e 3). Esse comportamento evidencia a elevada afinidade dos metais pelos sítios de adsorção desses solos. Não podemos descartar, no entanto, a possibilidade de ter ocorrido o fenômeno de precipitação. Normalmente, isotermas que apresentam concentrações de equilíbrio similares para diferentes doses metálicas adicionadas, evidenciam o mecanismo de precipitação, principalmente em solos alcalinos ou com $\mathrm{pH}$ próximo da neutralidade (Brümmer et al., 1983). Apesar de não haver solos calcários ou com sítios de adsorção específica reduzidos, ou ainda com concentrações naturalmente elevadas de metais, o que favoreceria o fenômeno da precipitação (Brümmer et al., 1983), os valores de pH dos solos em questão variaram de 5,7 (MT) a 7,8 (LVef).

Para os demais solos, observou-se comportamento mais distinto entre os metais, o que pode ser comprovado pelas isotermas de adsorção (Figuras 4 a 7). Pelas inclinações menos acentuadas das curvas desses solos, nota-se que o incremento na 
adsorção dos metais foi maior nas doses mais baixas, tendo diminuído com incremento da dose de metal adicionada. Com o aumento na concentração dos metais, mais sítios de superfícies de adsorção do solo são preenchidos e se torna mais difícil encontrar sítios disponíveis (Petruzzelli et al., 1985).

Considerando a dose máxima de $\mathrm{Zn}$ adicionada, ou seja, 105,0 $\mathrm{mg} \mathrm{dm}^{-3}(1,60$ mmol $\mathrm{kg}^{-1}$ ) o solo que adsorveu a maior quantidade do metal, em termos de porcentagem, foi o LVef (99,5\%), seguido dos solos MT (95,2\%), PVA-2 (85,0\%), NVef (72,2\%) e PVA-3 (72,1\%). O menor percentual de adsorção de Zn, em relação à máxima dose adicionada foi encontrado para o RQ $(7,4 \%)$. Para o Ni, considerando a dose máxima adicionada de $71,76 \mathrm{mg} \mathrm{dm}^{-3}\left(1,529 \mathrm{mmol} \mathrm{kg}^{-1}\right)$ o LVef adsorveu a maior quantidade relativa (97,5\%), seguidos pelos solos PVA-3 (95,4\%), NVef e MT (95,1\% para ambos os solos) e PVA-2 (88,0\%). Os menores percentuais de adsorção de Ni foram encontrados para os solos RQ (10,3\%) e PVA-1 (14,3\%). Em relação à dose máxima adicionada de $\mathrm{Cu}$, ou seja $108,40 \mathrm{mg} \mathrm{dm}^{-3}\left(1,28 \mathrm{mmol} \mathrm{kg}^{-1}\right)$, os maiores percentuais de adsorção foram encontrados para os solos NVef, LVef e MT $(98,2 \%)$, seguidos pelos solos PVA-3 (97,4\%), PVA-2 (95,8\%) e LV $(84,0 \%)$. Os menores percentuais de adsorção foram encontrados para os solos RQ (14,0\%) e PVA-1 (20,6\%). Para o Cd, na dose máxima adicionada de $143,0 \mathrm{mg} \mathrm{dm}^{-3}\left(1,272 \mathrm{mmol} \mathrm{kg}^{-1}\right)$, o solo que adsorveu maior quantidade percentual do metal foi o LVef (99,4\%), seguido do MT (95,0\% da dose máxima de $\left.80,0 \mathrm{mg} \mathrm{kg}^{-1}\right)$. Os solos OX e RQ apresentaram os menores percentuais de adsorção em relação à máxima dose adicionada (20,0 e 23,4\%, respectivamente).

Pela inclinação das isotermas de $\mathrm{Cu}$ dos solos NVef, LVef, MT, PVA-2 e PVA-3 (Figuras 2 e 3), e pela porcentagem de adsorção em relação à dose máxima adicionada, nota-se que, de uma maneira geral, a adsorção de $\mathrm{Cu}$ foi maior em relação aos outros metais. Resultados semelhantes foram obtidos por Matos et al. (1996); Fontes et al. (2000); Gomes et al. (2001) e Alumaa et al. (2001).

Os valores referentes à adsorção máxima $(b)$ dos metais, obtidos a partir da linearização dos dados experimentais, estão na Tabela 6 , sendo evidenciada a elevada capacidade de adsorção dos solos MT, PVA-2, PVA-3 e NVef. Os resultados para o 
NVef estão em conformidade com Fontes \& Gomes (2003). Para o Lvef, não foi possível obter esses dados, uma vez que os valores de adsorção máxima, obtidos a partir da linearização dos pontos das isotermas desse solo não foram satisfatórios. Isso talvez tenha ocorrido em função da elevada capacidade de adsorção apresentada por esse solo, que de alguma forma impediu uma linearização coerente dos dados e, consequentemente, a obtenção da adsorção máxima. Apesar de não ter sido possível calcular os valores de $b$ para o LVef, as isotermas de adsorção dos metais, obtidas para esse solo, confirmam seu elevado potencial adsortivo. Os solos RQ e PVA-1 também se destacaram por terem apresentado a menor capacidade de adsorção dos metais em estudo. Os demais solos apresentaram valores intermediários de b, variando de 5,88 $10,19 \mathrm{mmol} \mathrm{kg}^{-1}$ para o $\mathrm{Zn}, 3,55-7,09 \mathrm{mmol} \mathrm{kg}^{-1}$ para Ni, 5,42 - 9,25 para $\mathrm{Cu}$ e de 3,55 $-4,44 \mathrm{mmol} \mathrm{kg}{ }^{-1}$ para Cd.

Tabela 6. Valores de adsorção máxima de $\mathrm{Zn}, \mathrm{Ni}, \mathrm{Cu}$ e Cd, obtidos a partir das isotermas de adsorção dos metais em sistema não-competitivo, para os solos estudados

\begin{tabular}{|c|c|c|c|c|}
\hline Solo & $\mathrm{Zn}$ & $\mathrm{Ni}$ & $\mathrm{Cu}$ & $\mathrm{Cd}$ \\
\hline & \multicolumn{4}{|c|}{$\mathrm{mm} \circ \mathrm{kg}^{-1}$} \\
\hline LV & 5,88 & 4,87 & 9,26 & 3,87 \\
\hline LVwf & 8,50 & 7,10 & 9,84 & 4,45 \\
\hline LAw & 6,37 & 5,88 & 9,26 & 4,04 \\
\hline PVA - 1 & 5,46 & 1,77 & 2,62 & 3,29 \\
\hline PVA - 2 & 15,29 & 14,20 & 31,47 & 5,93 \\
\hline PVA - 3 & 13,90 & 15,49 & 26,23 & 6,84 \\
\hline RQ & 1,27 & 1,31 & 1,67 & 3,42 \\
\hline NVef & 12,74 & 14,20 & 19,67 & 6,84 \\
\hline GM & 6,65 & 7,10 & 9,84 & 4,24 \\
\hline $\mathrm{OX}$ & 7,28 & 6,55 & 9,26 & 4,04 \\
\hline CX & 9,00 & 3,55 & 6,29 & 3,56 \\
\hline $\mathrm{TC}$ & 10,20 & 4,37 & 5,43 & 3,71 \\
\hline MT & 15,29 & 12,17 & 17,49 & 6,84 \\
\hline
\end{tabular}

* a obtenção da adsorção máxima dos metais no LVef não foi possível 

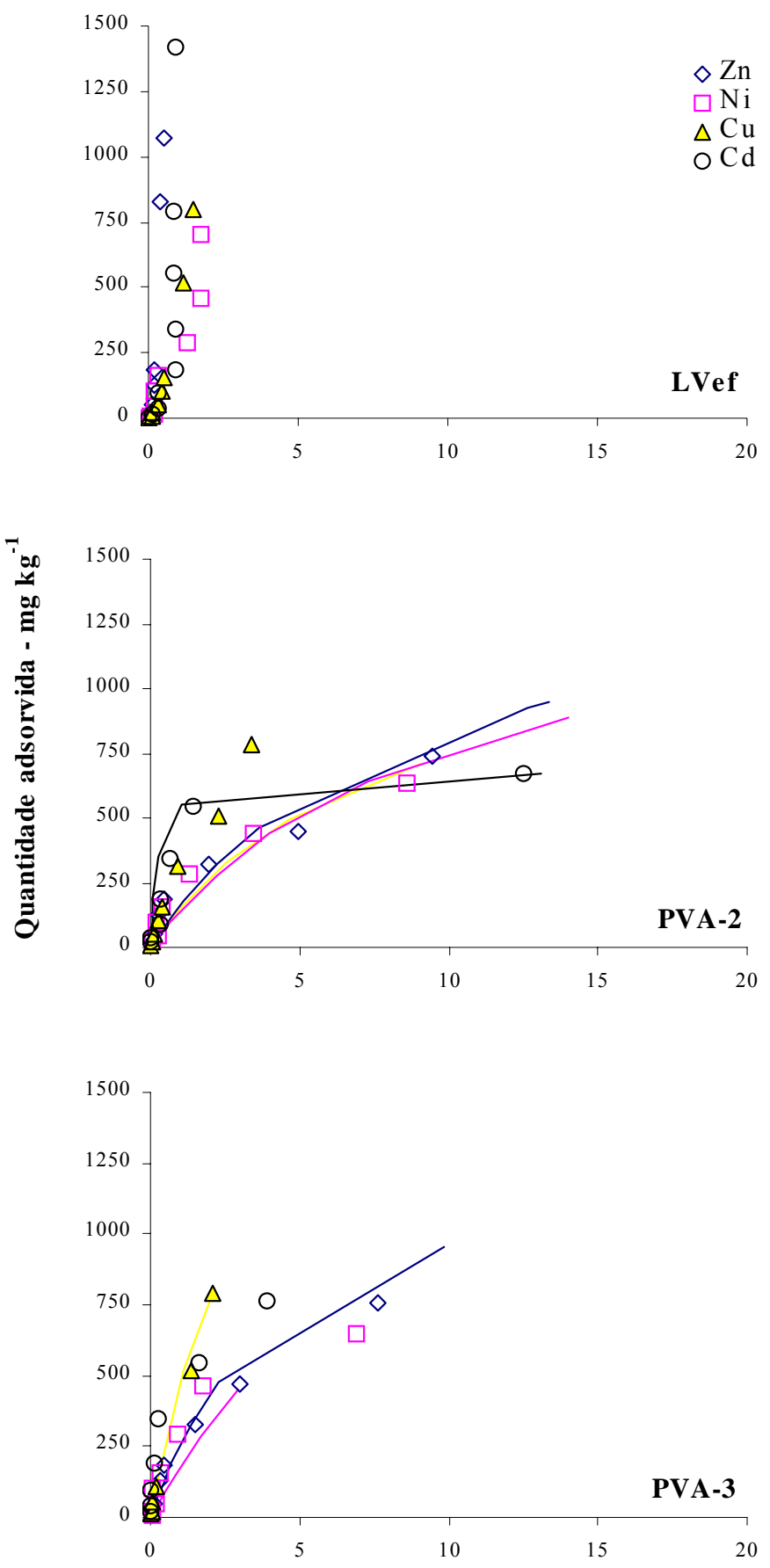

Concentração em equilíbrio - mg L

Figura 2 - Isotermas de adsorção de $\mathrm{Cd}, \mathrm{Cu}, \mathrm{Ni}$ e $\mathrm{Zn}$, no sistema não- competitivo, para Latossolo Vermelho eutroférrico (LVef), Argissolo Vermelho-Amarelo (PVA-2) e Argissolo Vermelho-Amarelo (PVA-3) 


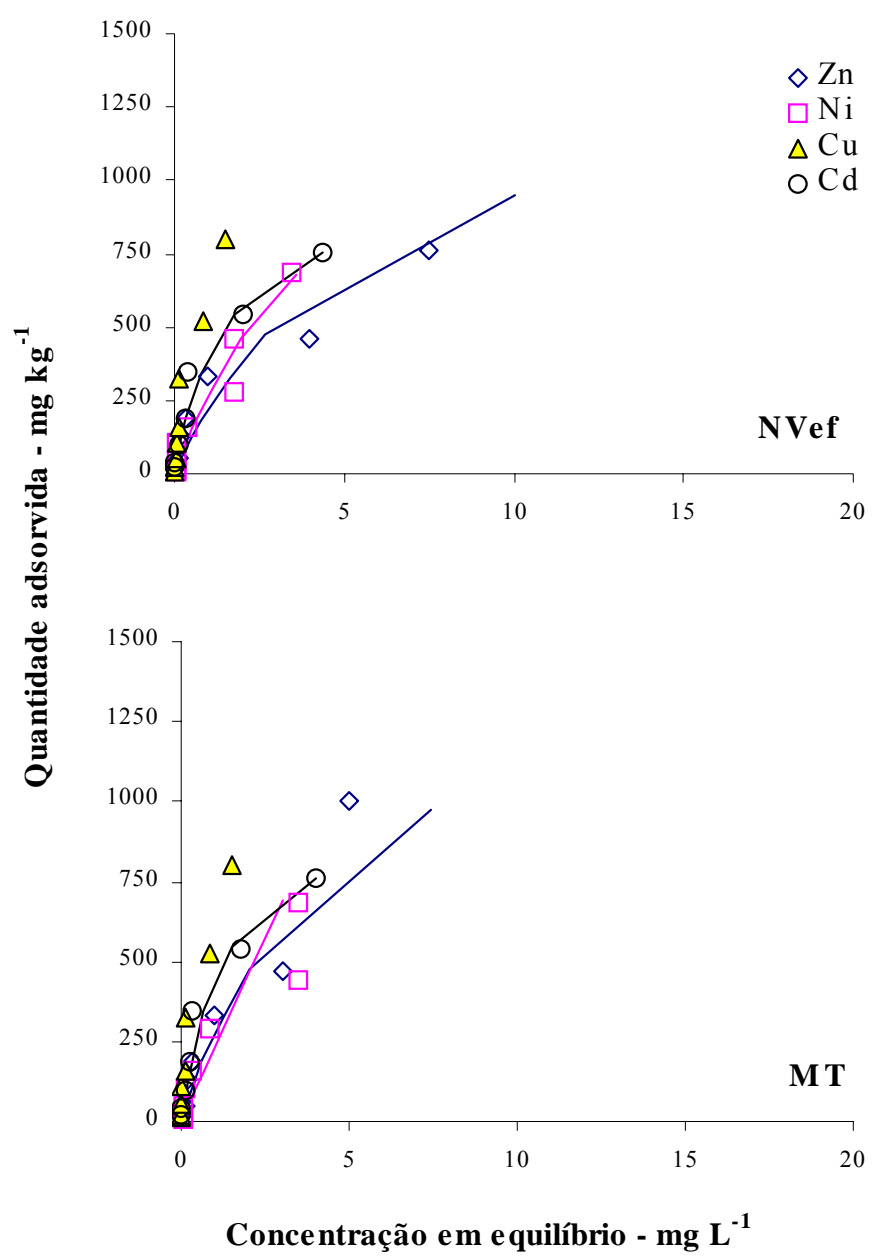

Figura 3 - Isotermas de adsorção de $\mathrm{Cd}, \mathrm{Cu}, \mathrm{Ni}$ e $\mathrm{Zn}$, no sistema não- competitivo, para Nitossolo Vermelho eutroférrico (NVef) e Chernossolo argilúvico (MT) 

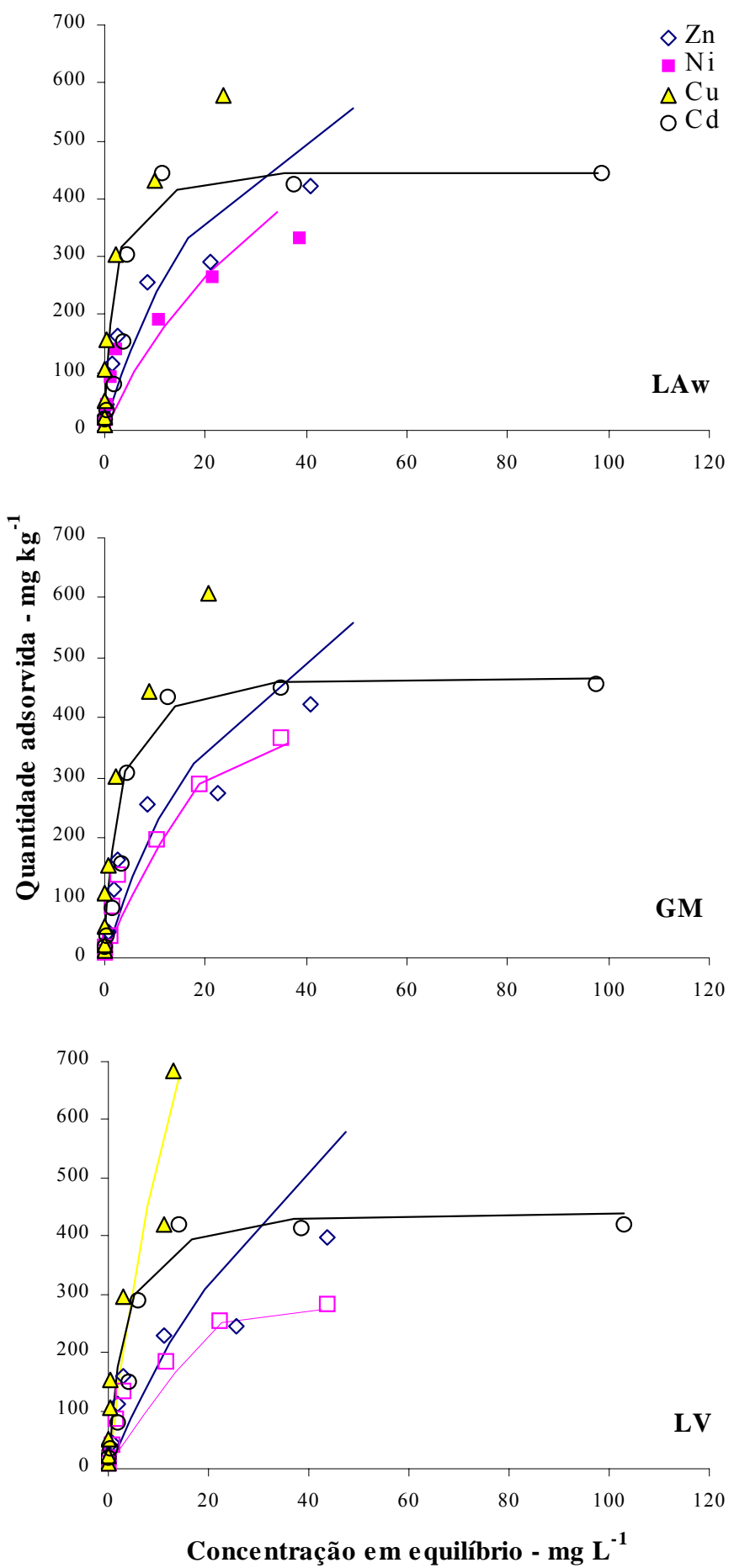

Figura 4 - Isotermas de adsorção de $\mathrm{Cd}, \mathrm{Cu}, \mathrm{Ni}$ e $\mathrm{Zn}$, no sistema não- competitivo, para Latossolo Amarelo ácrico (Law), Gleissolo Melânico (GM) e Latossolo Vermelho (LV) 

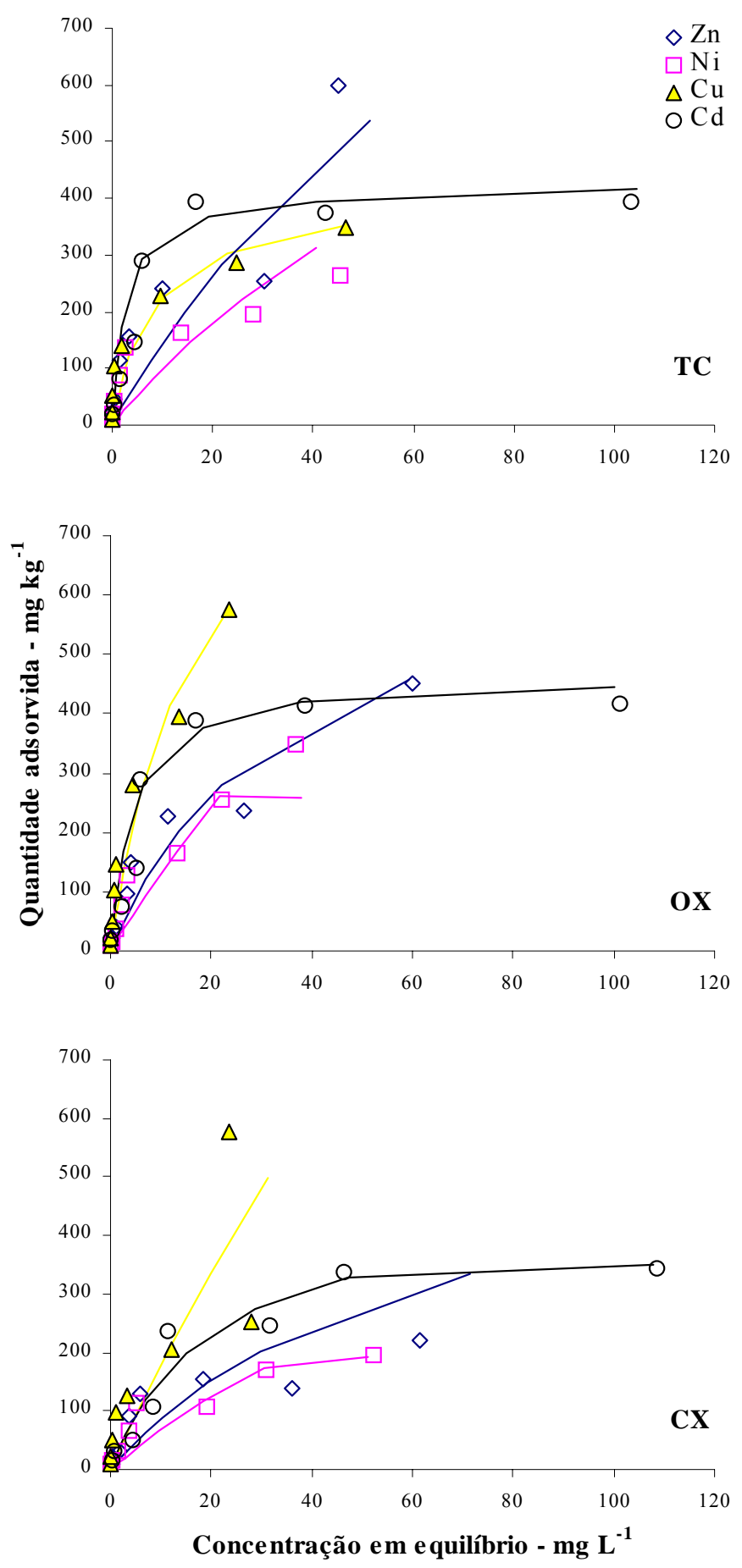

Figura 5 - Isotermas de adsorção de $\mathrm{Cd}, \mathrm{Cu}, \mathrm{Ni}$ e $\mathrm{Zn}$, no sistema não- competitivo, para Luvissolo Crômico (TC), Organossolo Háplico (OX) e Cambissolo Háplico (CX) 

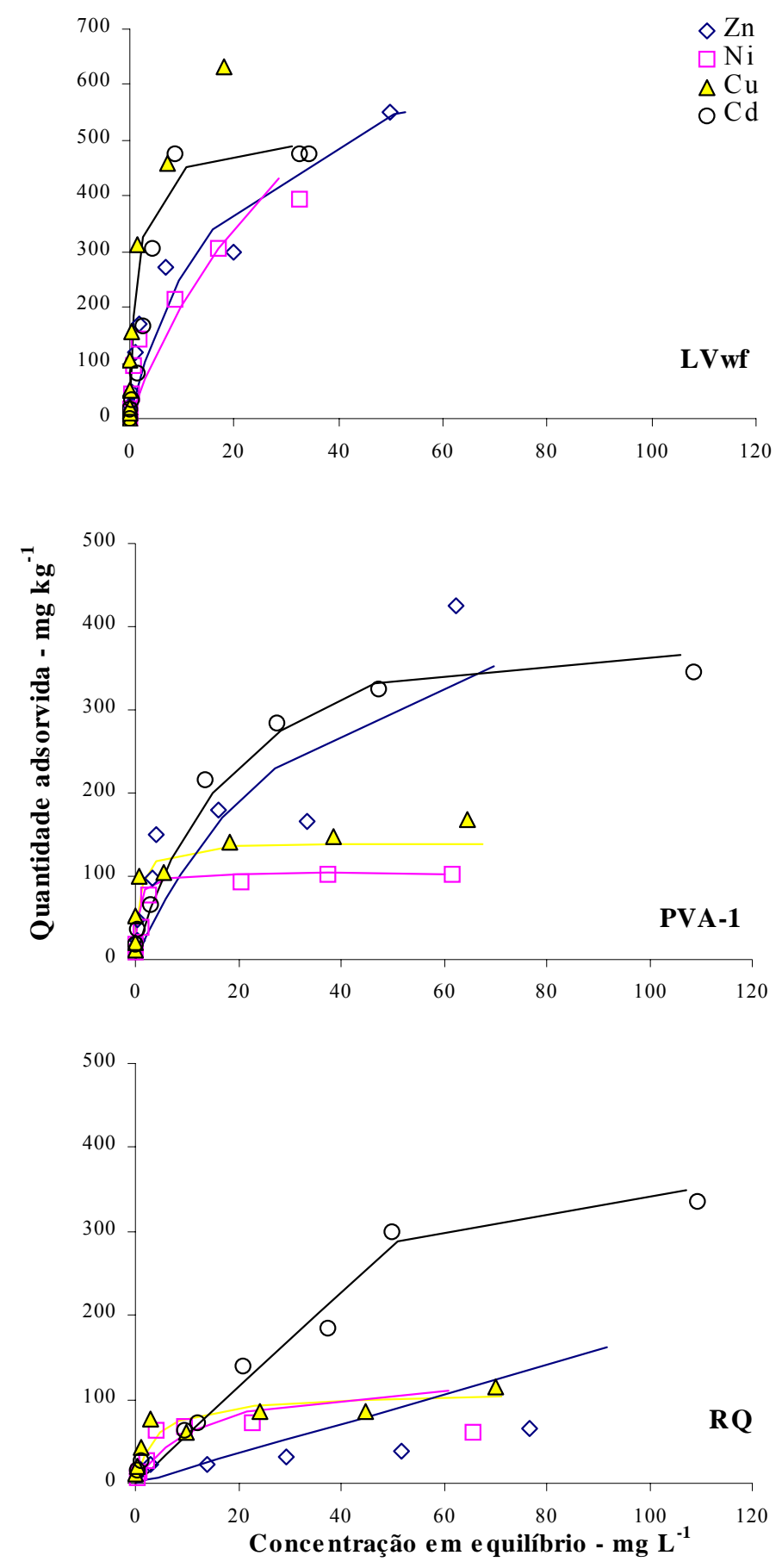

Figura 6 - Isotermas de adsorção de $\mathrm{Cd}, \mathrm{Cu}, \mathrm{Ni}$ e $\mathrm{Zn}$, no sistema não-competitivo, para Latossolo Vermelho eutroférrico (LVwf), Argissolo Vermelho-Amarelo (PVA1) e Neossolo Quartzarênico (RQ) 


\subsubsection{Sistema competitivo}

Para a adsorção no sistema competitivo, as quantidades de metais adsorvidas também aumentaram com o aumento das doses adicionadas. No entanto, houve menor inclinação da maioria das curvas, principalmente na parte inicial das isotermas. Com o aumento das concentrações adicionadas, teve início a competição entre os metais, o que afetou a adsorção de todos os metais, em diferentes proporções (Figuras 7 a 11). Tais resultados concordam com demais estudos de competição (Basta \& Tabatabai, 1992; Echeverría et al., 1998). Fontes \& Gomes (2003) estudaram a adsorção competitiva de metais em amostras de solos tropicais e observaram que com o aumento das concentrações adicionadas, alguns metais como $\mathrm{Cu}, \mathrm{Cr}$ e $\mathrm{Pb}$ mantiveram sua elevada afinidade com a superfície dos solos, enquanto $\mathrm{Ni}, \mathrm{Zn}$ e $\mathrm{Cd}$ foram deslocados das superfícies adsorventes dos mesmos.

Um dos fatores que explica o comportamento competitivo dos metais é o tipo de interação metal-superfície do solo, sendo a retenção de $\mathrm{Ni}, \mathrm{Zn}$ e $\mathrm{Cd}$ mais dependente de interações eletrostáticas com os sítios de troca da fase sólida, e a retenção de Cu mais dependente de interações covalentes com as estruturas dos minerais (McBride, 1994). Tais argumentos também são relacionados por Matos et al. (1996); Fontes et al. (2000); Gomes et al. (2001) e Fontes \& Gomes (2003).

Outra evidência do efeito da competição na adsorção dos metais pode ser observada ao compararmos as percentagens da máxima dose adicionada que foram retidas pelos solos, nos dois sistemas ( $\mathrm{SNC}$ e $\mathrm{SC}$ ). Considerando a dose máxima de $\mathrm{Zn}$ adicionada, ou seja, 105,0 $\mathrm{mg} \mathrm{dm}^{-3}\left(1,60 \mathrm{mmol} \mathrm{kg}^{-1}\right)$ o solo que adsorveu a maior quantidade do metal, em termos de porcentagem em relação a essa dose, foi o LVef com 96,6\%. Houve, portanto, decréscimo de apenas 2,9\% em relação à mesma dose adicionada no SNC. Essa pequena diferença indica que, apesar da presença de íons competidores no sistema, a adsorção de Zn não foi muito afetada. Os demais solos apresentaram maiores decréscimos nesse valor, sendo que os solos cujas porcentagens de adsorção referentes às máximas doses adicionadas mais se alteraram foram MT, TC, PVA-2, PVA-1 e LVwf (com decréscimos de 57,4; 41,0; 35,6; 30,6 e 23,8\%, 
respectivamente). Os menores percentuais de adsorção de $\mathrm{Zn}$ foram encontrados para os solos PVA-1 (9,9\%), RQ (12,5\%) e LV (19,1\%). Apesar disso, para o RQ, esse valor foi um pouco maior do que o obtido no $\mathrm{SNC}(5,1 \%)$. Os resultados corroboram os obtidos por Fontes \& Gomes (2003) para Oxisols, Ultisols e um Alfisol.

Para o $\mathrm{Ni}$, considerando a dose máxima adicionada de $71,76 \mathrm{mg} \mathrm{dm}^{-3}(1,529$ mmol kg-1 $)$ o LVef adsorveu a maior quantidade relativa $(54,66 \%)$, seguidos pelos solos MT (53,4\%), PVA-2 (48,0\%) e PVA-3 (41,7\%). Os menores percentuais de adsorção de Ni foram encontrados para os solos RQ (5,7\%), PVA-1 (7,8\%) e CX (8,1\%). Em relação à dose máxima adicionada de $\mathrm{Cu}$, ou seja $108,40 \mathrm{mg} \mathrm{dm}^{-3}\left(1,28 \mathrm{mmol} \mathrm{kg}^{-1}\right)$, os maiores percentuais de adsorção foram encontrados para os solos LVef $(97,6 \%)$, MT $(95,0 \%)$, NVef (93,8\%), PVA-3 (92,5\%) e PVA-2 (88,8\%). Os menores percentuais de adsorção, em relação à máxima dose adicionada, foram encontrados para os solos PVA-1 (11,3\%) e RQ $(12,5 \%)$.

Para o Cd, na dose máxima adicionada de $143,0 \mathrm{mg} \mathrm{dm}^{-3}\left(1,272 \mathrm{mmol} \mathrm{kg}^{-1}\right)$, os solos que adsorveram as maiores quantidades percentuais do metal foram o LVef $(97,6 \%)$ e o MT $(79,9 \%)$. Da mesma como ocorreu com os outros metais, a diferença entre a retenção de $\mathrm{Cd}$ pelo LVef na máxima dose foi pequena $(1,8 \%)$, reforçando o potencial adsortivo desse solo. Para os demais solos, as diferenças entre os dois sistemas estudados (SNC e SC) foram maiores. Os solos PVA-1 e RQ apresentaram os menores percentuais de adsorção em relação à máxima dose adicionada (10,30 e 13,23\%, respectivamente). 

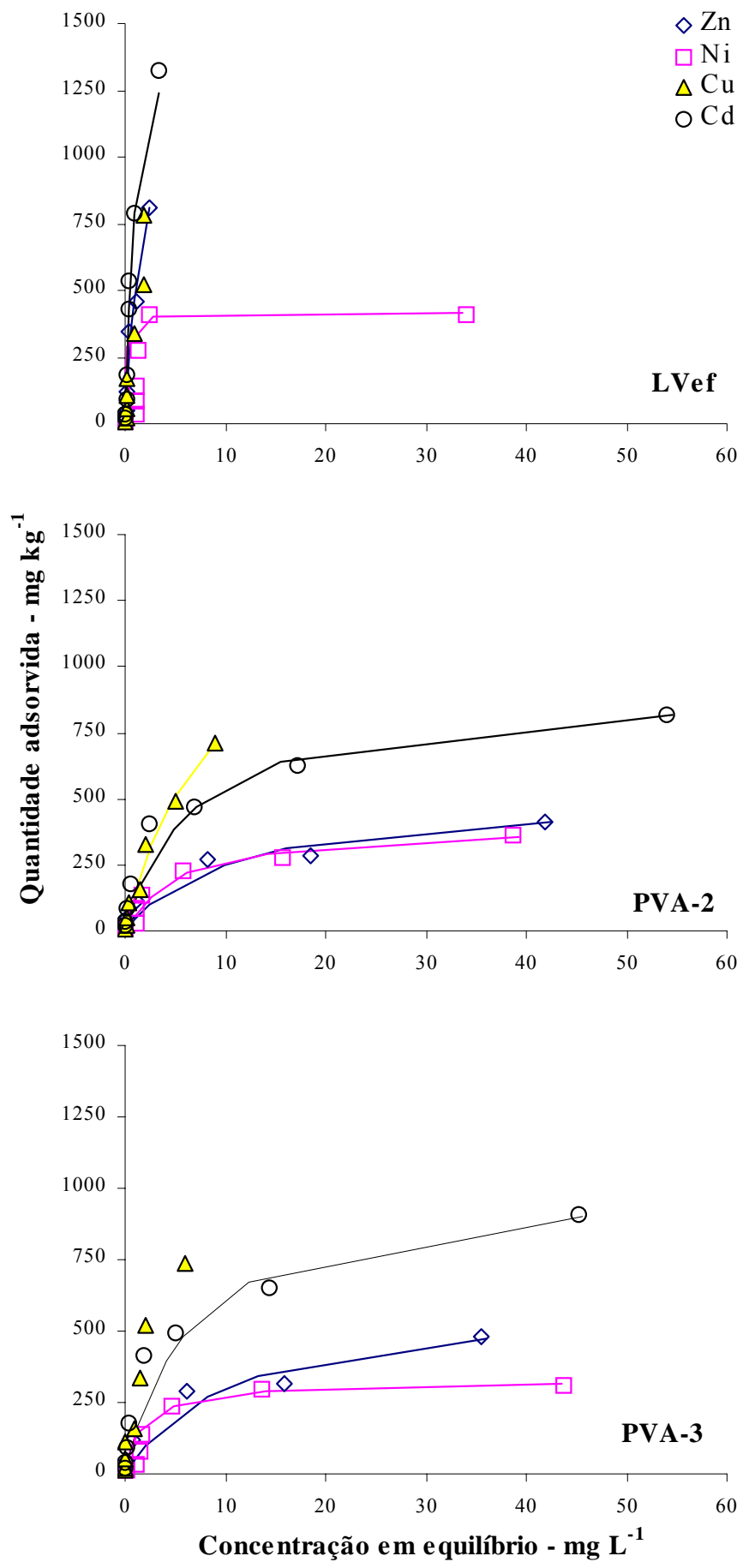

Figura 7 - Isotermas de adsorção de $\mathrm{Cd}, \mathrm{Cu}$, $\mathrm{Ni}$ e $\mathrm{Zn}$, no sistema competitivo, para Latossolo Vermelho eutroférrico (LVef), Argissolo Vermelho-Amarelo (PVA-2) e Argissolo Vermelho-Amarelo (PVA-3) 


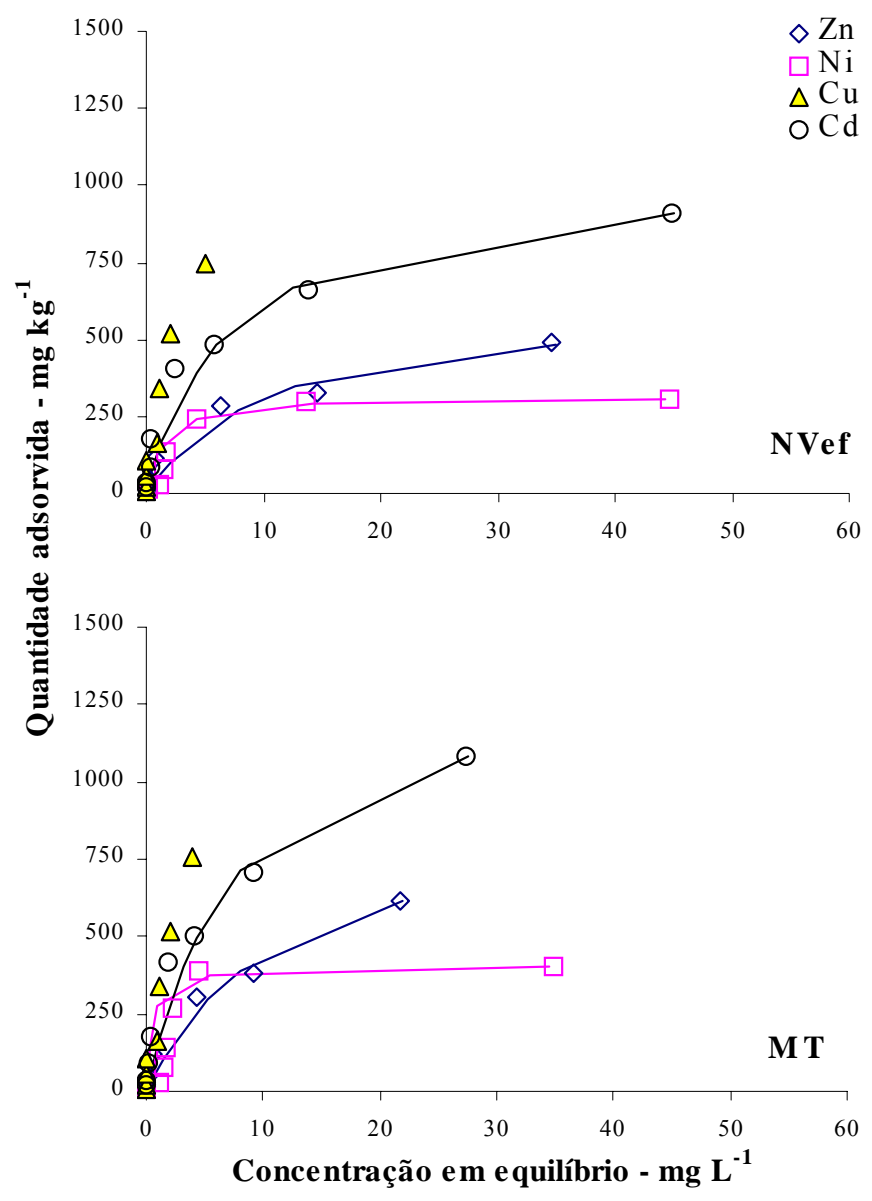

Figura 8 - Isotermas de adsorção de $\mathrm{Cd}, \mathrm{Cu}$, Ni e $\mathrm{Zn}$, no sistema competitivo, para Nitossolo Vermelho eutroférrico (NVef) e Chernossolo Argilúvico (MT) 

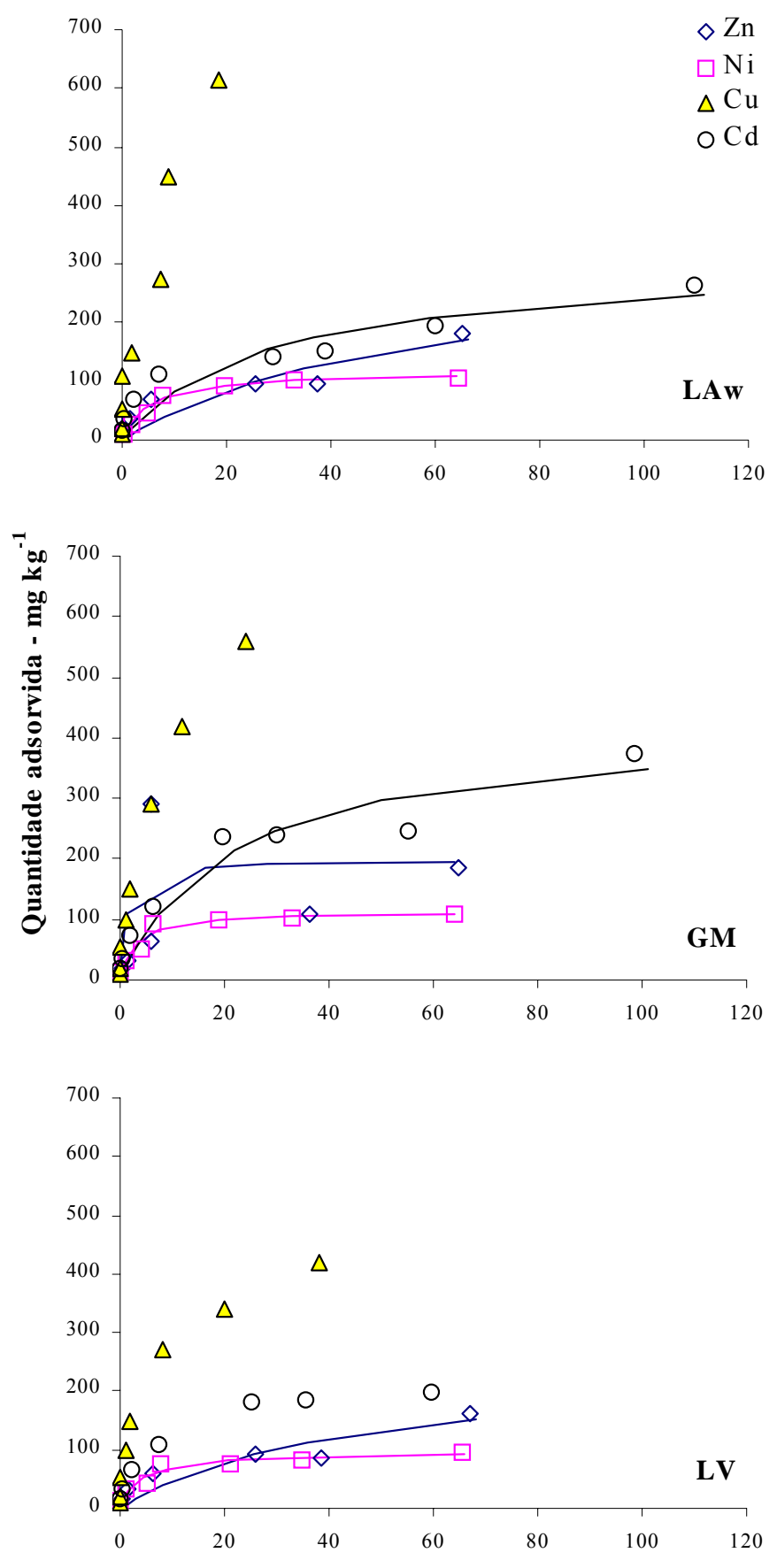

Concentração em equilíbrio - $\mathrm{mg} \mathrm{L}^{-1}$

Figura 9 - Isotermas de adsorção de $\mathrm{Cd}, \mathrm{Cu}, \mathrm{Ni}$ e $\mathrm{Zn}$, no sistema competitivo, para Latossolo Amarelo acriférrico (LAw), Gleissolo Melânico (GM) e Latossolo Vermelho (LV) 

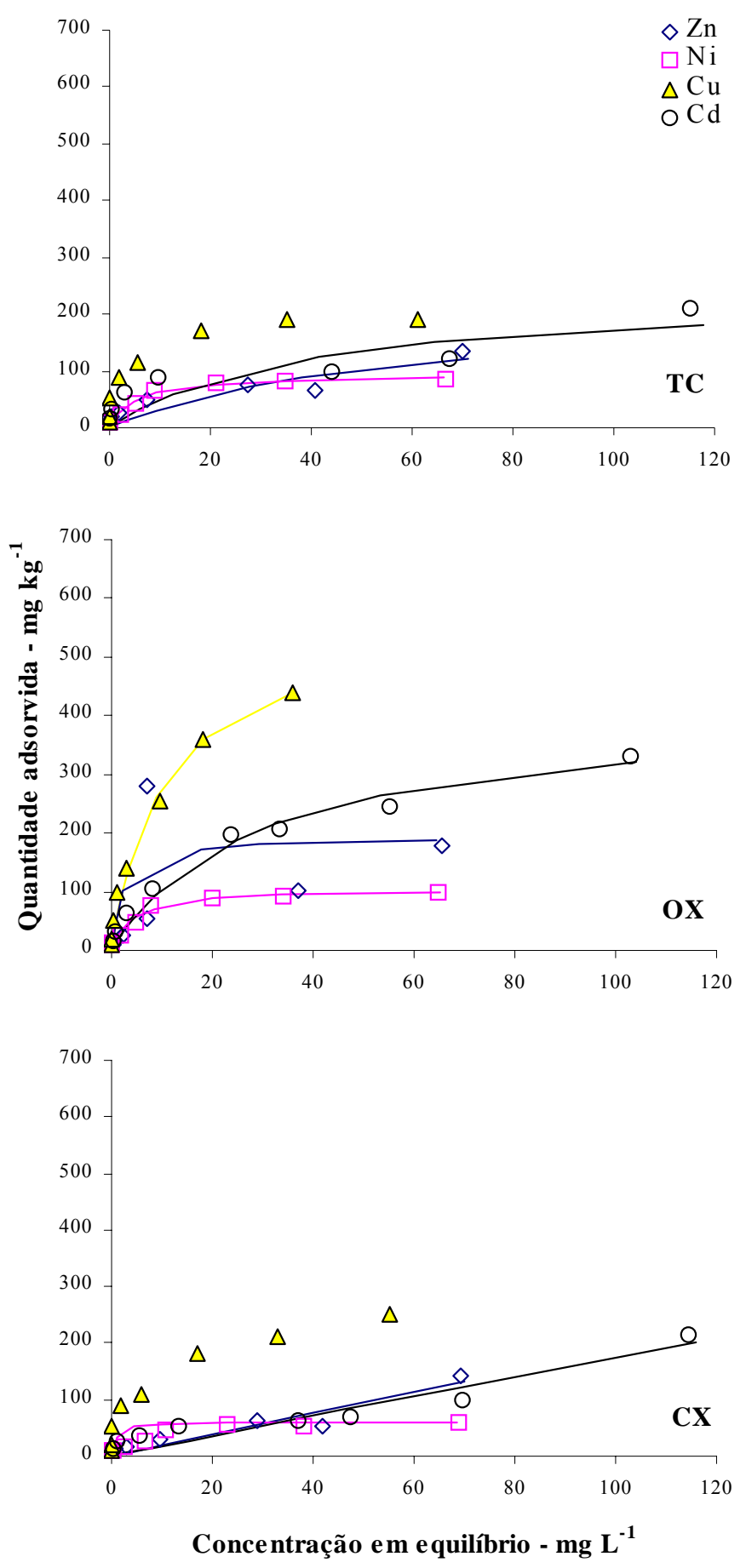

Figura 10 - Isotermas de adsorção de $\mathrm{Cd}, \mathrm{Cu}, \mathrm{Ni}$ e $\mathrm{Zn}$, no sistema competitivo, para Luvissolo Crômico (TC), Organossolo Háplico (OX) e Cambissolo Háplico $(\mathrm{CX})$ 

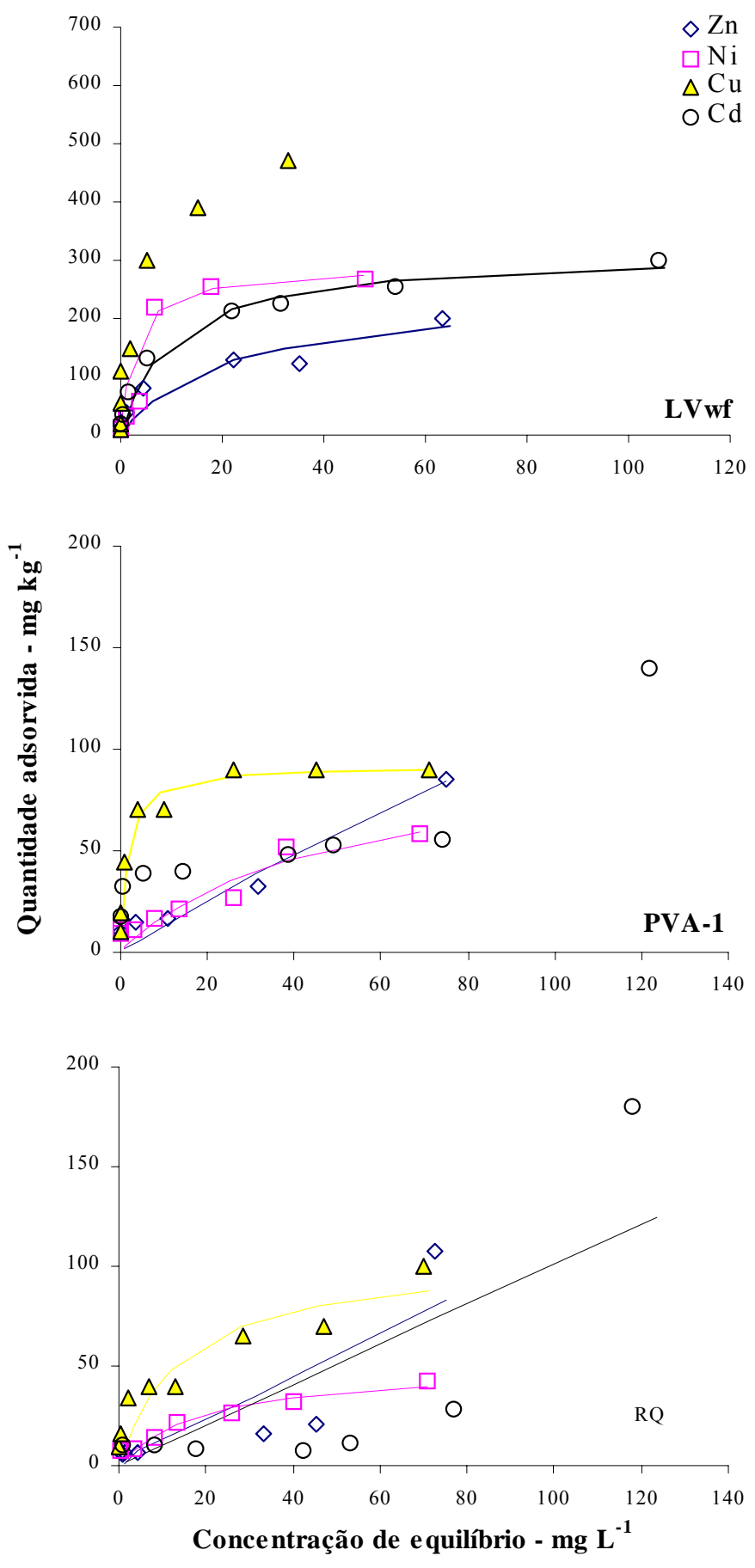

Figura 11 - Isotermas de adsorção de $\mathrm{Cd}, \mathrm{Cu}, \mathrm{Ni}$ e $\mathrm{Zn}$, no sistema competitivo, para Latossolo Vermelho eutroférrico (LVwf), Argissolo Vermelho-Amarelo (PVA-1) e Neossolo Quartzarênico (RQ) 
Os valores de adsorção máxima (b) dos metais, obtidos a partir da linearização dos dados experimentais, no sistema competitivo, estão na Tabela 7. Para o Cd no RQ, tais valores não são apresentados, devido a dificuldade de linearização das respectivas isotermas.

Tabela 7. Valores de adsorção máxima de $\mathrm{Zn}, \mathrm{Ni}, \mathrm{Cu}$ e $\mathrm{Cd}$, obtidos a partir das isotermas de adsorção dos metais em sistema competitivo, para os solos estudados

\begin{tabular}{|c|c|c|c|c|}
\hline Solos & $\mathrm{Zn}$ & $\mathrm{Ni}$ & $\mathrm{Cu}$ & $\mathrm{Cd}$ \\
\hline & 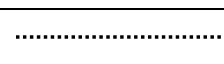 & 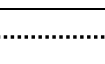 & $\overline{m m o l ~ k g}{ }^{-1}$ & \\
\hline LV & 2,22 & 1,48 & 6,55 & 2,22 \\
\hline LVef & 21,85 & 7,74 & 15,73 & 17,79 \\
\hline LVwf & 2,83 & 5,16 & 7,49 & 2,69 \\
\hline LAw & 2,43 & 1,89 & 9,25 & 2,28 \\
\hline PVA - 1 & 1,31 & 1,09 & 2,28 & 0,96 \\
\hline PVA - 2 & 6,12 & 6,85 & 14,30 & 7,41 \\
\hline PVA - 3 & 7,28 & 5,87 & 12,10 & 8,08 \\
\hline RQ & 0,32 & 0,76 & 1,49 & - \\
\hline NVef & 7,28 & 5,68 & 13,11 & 8,08 \\
\hline GM & 2,83 & 1,87 & 9,25 & 3,29 \\
\hline $\mathrm{OX}$ & 2,89 & 1,75 & 12,10 & 3,06 \\
\hline $\mathrm{CX}$ & 2,15 & 1,07 & 5,42 & 1,67 \\
\hline $\mathrm{TC}$ & 1,78 & 1,52 & 3,02 & 1,64 \\
\hline MT & 9,56 & 7,74 & 13,11 & 9,88 \\
\hline
\end{tabular}

Os valores de adsorção máxima obtidos para os solos evidenciam a superioridade do $\mathrm{Cu}$ no complexo adsortivo dos solos, principalmente para LVef, PVA2, MT, NVef, PVA-3 e OX. A elevada capacidade de retenção de Cu apresentada por esses solos, que apresentam alta CTC, indica que além do mecanismo de adsorção específica, envolvendo ligações do tipo covalente entre o metal e os colóides do solo, a 
adsorção de $\mathrm{Cu}$ também é favorecida pelas cargas elétricas do solo, apresentado ligações iônicas.

Com o objetivo de elucidar ainda mais o efeito da competição entre os metais, foram calculadas as proporções de acréscimo ou decréscimo na adsorção máxima dos metais no SC em relação ao SNC (Tabela 8). A proporção de variação da adsorção máxima para o LVef e para o $\mathrm{Cd}$ no RQ, não são apresentados, devido a dificuldade de linearização das respectivas isotermas.

As proporções de variação da adsorção máxima, entretanto, não devem ser interpretadas de forma isolada, a fim de estabelecer a afinidade dos metais pelos solos, já que um solo com alta capacidade de adsorver $\mathrm{Cu}$, por exemplo, tendo apresentado valores de adsorção máxima elevados em ambos os sistemas, teria uma pequena porcentagem de variação da adsorção máxima. Com isso, o $\mathrm{Cu}$ estaria subestimado em determinada seqüência de afinidade metálica. A principal vantagem em se conhecer a proporção de aumento ou decréscimo na adsorção máxima dos metais consiste, portanto, na obtenção da extensão com que a competição entre os íons afetou a adsorção de determinado metal, em um solo específico.

A maioria dos solos apresentou decréscimo na adsorção máxima dos metais, exceção feita para os solos PVA-2, PVA-3, NVef e MT, no caso da adsorção máxima de $\mathrm{Cd}$, e para os solos LAw e $\mathrm{OX}$, em relação à adsorção de $\mathrm{Cu}$ (Tabela 8). Para esses solos, a competição entre os metais, além de não ter afetado o comportamento adsortivo dos metais em questão, favoreceu de alguma forma sua retenção preferencial pelos solos. Resultado semelhante foi obtido para $\mathrm{Cu}$ em solos tropicais (Fontes \& Gomes, 2003) e para outros tipos de solos (Basta \& Tabatabai, 1992; Echeverría et al., 1998). Segundo os autores, a presença de $\mathrm{Cu}$ no sistema depreciou mais a adsorção de $\mathrm{Cd}, \mathrm{Zn}$ e Ni do que o inverso. Além disso, os parâmetros relacionados à capacidade adsortiva dos solos (adsorção máxima e coeficiente de distribuição) foram maiores no sistema nãocompetitivo do que no competitivo.

Para a maioria dos solos, a adsorção de $\mathrm{Cu}$ foi a que menos sofreu variação entre os dois sistemas, evidenciando que a competição iônica não impede sua ligação preferencial nos sítios de adsorção do solo. Apesar de os solos RQ, LAw, PVA-1 e 
LVwf terem apresentado baixos valores de $\mathrm{CTC}_{\mathrm{e}}$, eles apresentaram as menores reduções na adsorção máxima de $\mathrm{Cu}$ no $\mathrm{SC}$. Esse comportamento poderia estar relacionado à adsorção preferencial do $\mathrm{Cu}$, principalmente em condições em que há número reduzido de sítios de adsorção. Nos solos onde a CTC foi mais elevada, a competição entre os metais foi maior, porém a elevada afinidade entre o $\mathrm{Cu}$ e os colóides do solo parece ter sido decisiva para a maior retenção do metal.

Tabela 8. Proporção de acréscimo ou decréscimo na adsorção máxima de $\mathrm{Zn}, \mathrm{Ni}, \mathrm{Cu}$ e Cd no sistema competitivo em relação ao sistema não-competitivo

\begin{tabular}{|c|c|c|c|c|}
\hline Solo & $\mathrm{Zn}$ & $\mathrm{Ni}$ & $\mathrm{Cu}$ & $\mathrm{Cd}$ \\
\hline & & ………...... & & \\
\hline LV & $-62,3$ & $-69,5$ & $-29,1$ & $-42,5$ \\
\hline LVwf & $-66,6$ & $-27,3$ & $-23,8$ & $-39,4$ \\
\hline LAw & $-61,9$ & $-67,8$ & 0,0 & $-43,6$ \\
\hline PVA - 1 & $-76,0$ & $-38,4$ & $-13,0$ & $-70,6$ \\
\hline PVA - 2 & $-60,0$ & $-52,0$ & $-54,5$ & 25,0 \\
\hline PVA - 3 & $-47,6$ & $-62,0$ & $-53,9$ & 18,2 \\
\hline RQ & $-75,0$ & $-41,5$ & $-10,5$ & - \\
\hline NVef & $-42,8$ & $-60,0$ & $-33,3$ & 18,2 \\
\hline GM & $-57,4$ & $-73,6$ & $-5,9$ & $-22,2$ \\
\hline OX & $-60,4$ & $-73,2$ & 30,7 & $-24,1$ \\
\hline $\mathrm{CX}$ & $-76,0$ & $-69,8$ & $-13,8$ & $-52,8$ \\
\hline $\mathrm{LT}$ & $-82,5$ & $-65,2$ & $-44,2$ & $-55,5$ \\
\hline MT & $-37,5$ & $-36,3$ & $-25,0$ & 44,4 \\
\hline
\end{tabular}

Os solos que apresentaram menor decréscimo na adsorção máxima de $\mathrm{Cu}$ foram LAw, OX e GM. Já os solos PVA-2 e PVA-3 apresentaram os maiores decréscimos na adsorção de $\mathrm{Cu}$. Apesar disso, tais solos apresentaram elevada capacidade de adsorção do elemento. 


\subsection{Seqüências de afinidade metálica}

A seqüência de afinidade metálica mais comum no $\mathrm{SNC}$ foi $\mathrm{Cu}>\mathrm{Zn}>\mathrm{Ni}>\mathrm{Cd}$ (Tabela 9). Para os $\mathrm{SC}$, a seqüência de afinidade mais comum foi $\mathrm{Cu}>\mathrm{Cd}>\mathrm{Zn}>\mathrm{Ni}$, havendo portanto, inversão entre os metais $\mathrm{Cd}, \mathrm{Zn}$ e Ni, com predominância do Cd sobre Zn e Ni.

Tabela 9. Seqüências de afinidade de $\mathrm{Cd}, \mathrm{Cu}, \mathrm{Ni}$ e $\mathrm{Zn}$, baseada nos valores de adsorção máxima dos metais (em mmol kg ${ }^{-1}$ ), nos sistemas não-competitivo (SNC) e competitivo (SC), para os solos estudados

\begin{tabular}{ccc}
\hline Solo & $\mathrm{SNC}$ & $\mathrm{SC}$ \\
\hline LV & $\mathrm{Cu}>\mathrm{Zn}>\mathrm{Ni}>\mathrm{Cd}$ & $\mathrm{Cu}>\mathrm{Cd}>\mathrm{Zn}>\mathrm{Ni}$ \\
LVef & $\mathrm{Cu} \cong \mathrm{Zn} \cong \mathrm{Cd} \cong \mathrm{Ni}^{*}$ & $\mathrm{Zn}>\mathrm{Cd}>\mathrm{Cu}>\mathrm{Ni}$ \\
LVwf & $\mathrm{Cu}>\mathrm{Zn}>\mathrm{Ni}>\mathrm{Cd}$ & $\mathrm{Cu}>\mathrm{Ni}>\mathrm{Zn}>\mathrm{Cd}$ \\
LAw & $\mathrm{Cu}>\mathrm{Zn}>\mathrm{Ni}>\mathrm{Cd}$ & $\mathrm{Cu}>\mathrm{Zn}>\mathrm{Cd}>\mathrm{Ni}$ \\
PVA -1 & $\mathrm{Zn}>\mathrm{Cd}>\mathrm{Cu}>\mathrm{Ni}$ & $\mathrm{Cu}>\mathrm{Zn}>\mathrm{Ni}>\mathrm{Cd}$ \\
PVA -2 & $\mathrm{Cu}>\mathrm{Zn}>\mathrm{Ni}>\mathrm{Cd}$ & $\mathrm{Cu}>\mathrm{Cd}>\mathrm{Ni}>\mathrm{Zn}$ \\
PVA -3 & $\mathrm{Cu}>\mathrm{Ni}>\mathrm{Zn}>\mathrm{Cd}$ & $\mathrm{Cu}>\mathrm{Cd}>\mathrm{Zn}>\mathrm{Ni}$ \\
RQ & $\mathrm{Cd}>\mathrm{Cu}>\mathrm{Ni}>\mathrm{Zn}$ & $\mathrm{Cu}>\mathrm{Zn} \cong \mathrm{Cd}>\mathrm{Ni} *$ \\
NVef & $\mathrm{Cu}>\mathrm{Ni}>\mathrm{Zn}>\mathrm{Cd}$ & $\mathrm{Cu}>\mathrm{Cd}>\mathrm{Zn}>\mathrm{Ni}$ \\
GM & $\mathrm{Cu}>\mathrm{Ni}>\mathrm{Zn}>\mathrm{Cd}$ & $\mathrm{Cu}>\mathrm{Cd}>\mathrm{Zn}>\mathrm{Ni}$ \\
OX & $\mathrm{Cu}>\mathrm{Zn}>\mathrm{Ni}>\mathrm{Cd}$ & $\mathrm{Cu}>\mathrm{Cd}>\mathrm{Zn}>\mathrm{Ni}$ \\
$\mathrm{CX}$ & $\mathrm{Zn}>\mathrm{Cu}>\mathrm{Cd} \cong \mathrm{Ni}$ & $\mathrm{Cu}>\mathrm{Zn}>\mathrm{Cd}>\mathrm{Ni}$ \\
TC & $\mathrm{Zn}>\mathrm{Cu}>\mathrm{Ni}>\mathrm{Cd}$ & $\mathrm{Cu}>\mathrm{Zn}>\mathrm{Cd}>\mathrm{Ni}$ \\
MT & $\mathrm{Cu}>\mathrm{Zn}>\mathrm{Ni}>\mathrm{Cd}$ & $\mathrm{Cu}>\mathrm{Cd}>\mathrm{Zn}>\mathrm{Ni}$ \\
\hline
\end{tabular}

*seqüências de afinidade baseadas em observações visuais das isotermas de adsorção

A seqüência obtida no $\mathrm{SNC}(\mathrm{Cu}>\mathrm{Zn}>\mathrm{Ni}>\mathrm{Cd})$ foi consistente com os valores de constante de hidrólise apresentados no Quadro 2. Neste tipo de seqüência, a ligação 
covalente seria o principal mecanismo de retenção metálica e ocorreria mediante adsorção dos produtos de hidrólise metálica (Basta \& Tabatabai, 1992b, McBride, 1989). Seqüências de afinidade semelhantes, baseadas na constante de hidrólise, foram obtidas para solos contendo altos teores de argila e de óxidos de ferro (Tyler \& McBride, 1982; Tiller, et al., 1984). Para os Latossolos em estudo, com exceção do Lvef, que apresentou elevada afinidade pelos quatro metais, a seqüência metálica corrobora os resultados obtidos para metais em óxidos de ferro e alumínio (Kinninburgh et al., 1976). Tais resultados reforçam a importância da mineralogia oxídica dos Latossolos nos fenômenos de retenção dos metais. Além dos Latossolos, os solos PVA-2, OX e MT também apresentaram a seqüência $\mathrm{Cu}>\mathrm{Zn}>\mathrm{Ni}>\mathrm{Cd}$, coincidente com aquela obtida a partir das constantes de hidrólise dos metais.

Exceto para o Cd, os solos PVA-3, RQ, NVef e GM, apresentaram seqüências de afinidade metálica concordantes com o grau de "dureza" dos metais (Quadro 2). Esse parâmetro, derivado da teoria de ácidos e bases fortes e fracos de Pearson (1963), fornece uma medida do grau de ligações covalentes envolvidos na adsorção de metais pelo solo.

Com exceção do $\mathrm{Zn}$, houve correspondência entre os parâmetros eletronegatividade (Quadro 2) dos metais e a seqüência obtida no SNC, o que demonstra a participação de ligações covalentes no fenômeno adsortivo. Houve correspondência entre o potencial iônico, parâmetro que indica a participação de ligações eletrostáticas entre os metais e os colóides do solo (Quadro 2), e a seqüência de afinidade metálica obtida no SNC, com exceção do Ni, para a maioria dos solos.

No SC, observou-se menor variação entre as seqüências obtidas pelos solos, além de menores diferenças nos valores de adsorção máxima dos metais entre os solos, o que realça o efeito da competição no comportamento dos metais. A seqüência de afinidade metálica obtida no SC está de acordo com diversos estudos (Basta \& Tabatabai, 1992b; Fontes et al., 2000; Gomes et al., 2001; Fontes \& Gomes, 2003; Agbenin \& Olojo, 2004).

O predomínio do $\mathrm{Cu}$ na maioria das seqüências de afinidade dos solos está em conformidade com sua constante de hidrólise, evidenciando a participação de 
mecanismos específicos de ligação, nos quais há formação de complexos estáveis com elevada energia de ligação (James \& Healy, 1972). As seqüências Zn $>$ Ni, obtidas para a maioria dos solos, também estão de acordo com a constante de hidrólise dos metais.

Embora os solos tenham apresentado maior afinidade por $\mathrm{Cu}$ e $\mathrm{Cd}$ que por $\mathrm{Zn}$ e $\mathrm{Ni}$, as seqüências obtidas para os quatro metais no SC não concordaram com o grau de “dureza" dos elementos. Em relação à eletronegatividade, somente houve concordância para a seqüência $\mathrm{Cu}>\mathrm{Cd}>\mathrm{Zn}$ nos solos LV, PVA-2, NVef, OX e MT. Exceto para o $\mathrm{Ni}$, tais resultados estão de acordo com os obtidos por Basta \& Tabatabai (1992b), que observaram para dois solos (Haplaquoll e Hapludol) a seqüência de afinidade: $\mathrm{Pb}>\mathrm{Cu}>$ $\mathrm{Ni} \geq \mathrm{Cd} \sim$ Zn. Para McBride (1989), a contribuição das ligações do tipo covalente relacionada a eletronegatividade e ao grau de "dureza" não pode ser considerada o principal fator que comanda as ligações de cátions metálicos.

A respeito do potencial iônico dos metais, nenhum solo apresentou seqüências de afinidades concordantes com esse parâmetro, para os quatro metais. As baixas relações entre os resultados obtidos experimentalmente para os metais, com aqueles previstos pelo potencial iônico, parecem evidenciar que, em condições de elevada competição, as ligações metálicas nos solos não são predominantemente de natureza eletrostática ou coulômbica. Apesar disso, houve concordância entre o potencial iônico dos metais e a seqüência $\mathrm{Cu}>\mathrm{Zn}>\mathrm{Cd}$ para os solos LVwf, Law, PVA-1, RQ, CX e TC.

\subsection{Correlações entre adsorção máxima de Cd, $\mathrm{Cu}$, Ni e Zn e os atributos dos solos}

Os atributos $\mathrm{pH}, \mathrm{CTC}$ efetiva e $\mathrm{Mn}_{\mathrm{ds}}$ apresentaram correlação positiva com os valores de $b$ dos quatro metais (Tabela 10). Da mesma forma, o conteúdo de areia dos solos correlacionou-se negativamente com a $b$ dos mesmos. 
Tabela 10. Coeficientes de correlação simples entre a adsorção máxima de $\mathrm{Zn}, \mathrm{Ni}, \mathrm{Cu}$ e $\mathrm{Cd}$, no sistema não competitivo, e atributos dos solos

\begin{tabular}{ccccc}
\hline Atributo do solo & $\mathrm{Zn}$ & $\mathrm{Ni}$ & $\mathrm{Cu}$ & $\mathrm{Cd}$ \\
\hline $\mathrm{pH} \mathrm{H} \mathrm{H}_{2} \mathrm{O}$ & $0,69^{*}$ & $0,65^{*}$ & $0,63^{*}$ & $0,66^{*}$ \\
$\mathrm{CTC}$ efetiva & $0,64^{*}$ & $0,71^{*}$ & $0,58^{*}$ & $0,77^{*}$ \\
$\mathrm{CTC}$ potencial $^{*}$ & 0,41 & $0,56^{*}$ & 0,41 & $0,56^{*}$ \\
$\mathrm{Fe}_{\mathrm{as}}$ & 0,33 & 0,39 & 0,25 & 0,47 \\
$\mathrm{Fe}_{\mathrm{d}}$ & 0,32 & 0,39 & 0,24 & 0,45 \\
$\mathrm{Fe}_{\mathrm{o}}$ & 0,41 & 0,34 & 0,19 & 0,47 \\
$\mathrm{Al}_{\mathrm{as}}$ & 0,03 & 0,20 & 0,096 & 0,16 \\
$\mathrm{Mn}_{\mathrm{ds}}$ & $0,66^{*}$ & $0,83^{*}$ & $0,72^{*}$ & $0,86^{*}$ \\
$\mathrm{Argila}_{\text {Silte }}$ & 0,29 & 0,45 & 0,33 & 0,48 \\
Areia & $0,52^{*}$ & $0,63^{*}$ & 0,48 & $0,57^{*}$ \\
Carbono & $-0,46^{*}$ & $-0,66^{*}$ & $-0,48^{*}$ & $-0,64^{*}$ \\
& $-0,10$ & 0,08 & $-0,008$ & $-0,02$
\end{tabular}

*parâmetros significativos a 5\%

Além desses atributos, foi encontrada correlação positiva entre a CTC potencial e os valores de $b$ de $\mathrm{Ni}$ e $\mathrm{Cd}$, e correlação positiva entre o conteúdo de silte os valores de $b$ de $\mathrm{Zn}$, Ni e $\mathrm{Cd}$. Os resultados evidenciam alta correlação entre o teor de $\mathrm{Mn}_{\mathrm{ds}}$ e das cargas elétricas do solo nas reações de adsorção dos metais, uma vez que a CTC efetiva esteve sempre correlacionada com o comportamento adsortivo dos metais.

A adsorção máxima de $\mathrm{Cu}$ correlacionou-se mais acentuadamente com o conteúdo de $\mathrm{Mn}_{\mathrm{ds}}(\mathrm{r}=0,72)$ e o $\mathrm{pH}(\mathrm{r}=0,63)$ dos solos. $\mathrm{O}$ menor coeficiente de correlação obtido para a CTC $(\mathrm{r}=0,58)$ evidencia que a adsorção específica seria o mecanismo preferencial de retenção de Cu. Silveira (1999) obteve para o índice Ki e para a CTC os maiores coeficientes de correlação com a $b$ de cobre ( $r=0,96$ e $\mathrm{r}=0,89$, respectivamente), seguido do conteúdo de $\mathrm{MnO}(\mathrm{r}=0,88)$ e do parâmetro $\mathrm{Kr}(\mathrm{r}=0,82)$. Discordando desses resultados, Sadiq (1981), estudando vinte e sete solos minerais, com características distintas e CTC variando entre 20 e $710 \mathrm{mmol}_{\mathrm{c}} \mathrm{kg}^{-1}$, não encontrou correlação entre a 
adsorção de $\mathrm{Cu}$ e CTC $(\mathrm{r}=-0,11)$. Embora os fenômenos de adsorção de $\mathrm{Cu}$ envolvam reações de adsorção específica, as reações de troca iônica podem ocorrer concomitantemente (Guilherme \& Anderson, 1998), o que reforça a importância da capacidade de retenção de cátions em ambos os processos. Araújo et al. (2002) utilizaram análise de trilha para demonstrar a relação entre os parâmetros de adsorção obtidos para alguns metais, entre eles o $\mathrm{Cu}$, e os atributos de uma série de solos tropicais. Para os autores, as variáveis do solo que apresentaram coeficientes de correlação simples significativos com a adsorção de Cu foram Corg, CTC efetiva, teores de argila e de óxido de alumínio. Apesar de os coeficientes de correlação variarem em função dos tipos de solos e das condições de experimentais, muitos estudos relacionam a adsorção de Cu com CTC (Sidle \& Kardos, 1977; Basta \& Tabatabai, 1992b; Alva \& Obreza, 1994), pH (Tyler \& McBride, 1982; Harter, 1983; Msaky \& Calvet, 1990) e MnO (McLaren \& Crawford, 1973; Fu et al., 1991; Silveira, 1999).

Da mesma forma como ocorreu para o $\mathrm{Cu}$, a adsorção máxima de $\mathrm{Zn}$ correlacionou-se mais acentuadamente com o $\mathrm{pH}(\mathrm{r}=0,69)$ e com o conteúdo de $\mathrm{Mn}_{\mathrm{ds}}$ $(\mathrm{r}=0,66)$ dos solos. Resultados semelhantes foram encontrados para o $\mathrm{pH}$ (Harter, 1983; King, 1988) e para a CTC (Sidle \& Kardos, 1977, Araújo et al., 2002).

As adsorções máximas de $\mathrm{Cd}$ e $\mathrm{Ni}$ correlacionaram-se mais acentuadamente com o conteúdo de $\mathrm{Mn}_{\mathrm{ds}}(\mathrm{r}=0,86$ e $\mathrm{r}=0,83$, respectivamente) e com a CTC efetiva $(\mathrm{r}=0,77$ e $\mathrm{r}=0,71$, respectivamente) dos solos. A influência das cargas elétricas dos solos nas reações de adsorção dos metais foi maior para $\mathrm{Ni}$ e $\mathrm{Cd}$ do que para $\mathrm{Cu}$ e $\mathrm{Zn}$, indicando mecanismo de troca iônica ou adsorção não-específica (Matos et al., 2001). A adsorção dos metais, entre eles o $\mathrm{Cu}$, não pode ser caracterizada por uma única constante, uma vez que os atributos do solo estão relacionados, afetando as características adsortivas do solo (Silveira, 1999).

Por meio de regressões múltiplas foram selecionados os atributos dos solos que tinham maior efeito na adsorção máxima dos metais, no SNC (Tabela 11). Os resultados evidenciam a influência da CTC efetiva e $\mathrm{MnO}$ no comportamento adsortivo do $\mathrm{Zn}, \mathrm{Ni}$ e Cd. Para o $\mathrm{Cu}$, no entanto, somente a CTC efetiva afetou a adsorção máxima do metal nos solos. 
Tabela 11. Análises de regressão entre os atributos dos solos e a adsorção máxima de $\mathrm{Zn}, \mathrm{Cd}, \mathrm{Cu}$ e Ni no sistema não competitivo

\begin{tabular}{cc}
\hline Metal & Equação de regressão* \\
\hline $\mathrm{Zn}$ & $\mathrm{Ads} \mathrm{Zn}=174,8+3,0(\mathrm{CTCe})+15,9\left(\mathrm{Mn}_{\mathrm{ds}}\right)$ \\
$\mathrm{Cd}$ & $\mathrm{Ads} \mathrm{Cd}=369,1+2,2(\mathrm{CTCe})+8,8\left(\mathrm{Mn}_{\mathrm{ds}}\right)$ \\
$\mathrm{Cu}$ & $\mathrm{Ads} \mathrm{Cu}=504,1+36,7\left(\mathrm{Mn} \mathrm{ds}^{2}\right)$ \\
$\mathrm{Ni}$ & $\mathrm{Ads} \mathrm{Ni}=174,8+3,1(\mathrm{CTCe})+15,9\left(\mathrm{Mn}_{\mathrm{ds}}\right)$ \\
\hline
\end{tabular}

*parâmetros significativos a 5\%

Os resultados apresentados para $\mathrm{Zn}$, Ni e $\mathrm{Cd}$ realçam, mais uma vez, a importância das cargas elétricas nas reações de retenção dos metais, o que pode ser indício do mecanismo de adsorção não-específica ou troca iônica, não descartando, porém, a participação de adsorção específica com o $\mathrm{Mn}_{\mathrm{ds}}$ (Uren, 1992; Naidu, et al., 1994; Ross, 1994; Sauvé et al., 2000; Matos et al., 2001).

Para o $\mathrm{Cu}$, a adsorção específica em $\mathrm{Mn}_{\mathrm{ds}}$ seria o principal mecanismo de retenção do metal nos solos. Esse resultado difere do encontrado por Silveira (1999), que obteve, em análise conjunta, correlação entre a adsorção de $\mathrm{Cu}$ em Latossolos ácricos paulistas e os atributos $\mathrm{CTC}, \mathrm{Ki}, \mathrm{Kr}$, argila e ferro mal cristalizado.

A afinidade entre metais pesados e óxidos de $\mathrm{Mn}$ em solos e sedimentos já foi relatada em muitos estudos (Loganathan \& Burau, 1973; Whitney, 1981; Cole \& Rose, 1984; Zasoski \& Burau, 1988; Chen et al., 2000; Dong et al., 2000). Tal comportamento baseia-se na elevada superfície específica desses minerais microcristalinos e em suas estruturas cristalinas e características de carga (Childs, 1975; McKenzie, 1975; Gilkes, 1988). Pelo fato de os óxidos de Mn apresentarem cargas dependentes do $\mathrm{pH}$ e ponto de carga zero (PCZ) variando de 1,5 a 4,6, desenvolvem elevado potencial de carga negativo em uma faixa normal de $\mathrm{pH}$ dos solos $(>5)$. A adsorção específica de cátions metálicos por óxidos de $\mathrm{Mn}$ segue a ordem: $\mathrm{Pb}>\mathrm{Cu}>\mathrm{Mn}>\mathrm{Co}>\mathrm{Zn}>\mathrm{Ni}$, gerando acúmulo de tais íons em concentrações relativamente elevadas nos solos (McKenzie, 1972, 1980). 
Embora os solos com maior conteúdo de MO tenham apresentado maior adsorção de metais, principalmente $\mathrm{Cu}$, não foi obtida correlação entre adsorção máxima e o conteúdo de $\mathrm{MO}$ dos solos, estando de acordo com os resultados obtidos por Silveira (1999) para a adsorção máxima de Cu. Essa mesma conclusão foi obtida por Harter $(1979,1983)$ e estaria relacionada ao fato de que o conteúdo de MO de um conjunto de solos pode não expressar todo seu potencial de geração de carga negativa. Por exemplo, o pH baixo da maioria dos solos estudados pode não ter favorecido a disponibilização das cargas negativas da matéria orgânica. 


\section{CONCLUSÕES}

- O modelo de Langmuir simulou de maneira satisfatória a adsorção dos metais, na maioria dos solos estudados;

- A competição entre os metais afetou a magnitude da adsorção de todos os metais, com diminuição, no geral, da adsorção máxima dos mesmos;

- A seqüência de afinidade mais comum encontrada no sistema nãocompetitivo foi $\mathrm{Cu}>\mathrm{Zn}>\mathrm{Ni}>\mathrm{Cd}$. No sistema competitivo, a seqüência mais comum foi $\mathrm{Cu}>\mathrm{Cd}>\mathrm{Zn}>\mathrm{Ni}$;

- Os solos LVef, NVef, PVA-2, PVA-3 e MT foram os que apresentaram maior capacidade de adsorção dos metais, no sistema competitivo, ocorrendo o inverso para os solos RQ e PVA-1;

- Os atributos que apresentaram correlação simples positiva com a adsorção máxima dos metais foram $\mathrm{pH}, \mathrm{Mn}_{\mathrm{ds}}$, CTC efetiva e silte. A correlação foi negativa com os teores de areia dos solos. Na regressão múltipla, as adsorções máximas de Zn, Cd e Ni estiveram relacionadas com CTC efetiva e $\mathrm{Mn}_{\mathrm{ds}}$. Para o $\mathrm{Cu}$, somente o conteúdo de $\mathrm{Mn}_{\mathrm{ds}}$ relacionou-se com a adsorção máxima;

- O comportamento distinto dos metais, em ambos os sistemas analisados, evidenciou que a adsorção competitiva deve ser considerada para se avaliar, de maneira mais realística, a biodisponibilidade, a toxicidade e o potencial de lixiviação dos metais pesados em solos. 
ANEXO 
Tabela 3. Resultados das análises químicas dos solos estudados

\begin{tabular}{|c|c|c|c|c|c|c|c|c|c|c|c|c|c|c|c|c|}
\hline \multirow{3}{*}{$\begin{array}{l}\text { Solo } \\
\text { LV }\end{array}$} & \multicolumn{3}{|c|}{$\mathrm{pH}$} & \multirow[t]{2}{*}{$\Delta \mathrm{pH}$} & \multirow{2}{*}{$\begin{array}{c}\mathrm{C} \\
\mathrm{g} \mathrm{kg}^{-1}\end{array}$} & \multirow{2}{*}{$\begin{array}{c}\mathrm{P} \\
\mathrm{mg} \mathrm{kg}^{-1}\end{array}$} & \multirow[t]{2}{*}{$\mathrm{Ca}$} & \multirow[t]{2}{*}{$\mathrm{Mg}$} & \multirow[t]{2}{*}{$\mathrm{K}$} & \multirow{2}{*}{\multicolumn{2}{|c|}{$\mathrm{mmol}_{\mathrm{e}} \cdot \mathrm{kg}^{-1}$}} & \multirow[t]{2}{*}{$\mathrm{Al}^{+3}$} & \multirow[t]{2}{*}{$\mathrm{CTC}_{\mathrm{e}}$} & \multirow[t]{2}{*}{$\mathrm{CTC}_{\mathrm{pH} 7}$} & \multirow{2}{*}{\multicolumn{2}{|c|}{$\begin{array}{l}\mathrm{V} \\
\%\end{array}$}} \\
\hline & $\mathrm{H}_{2} \mathrm{O}$ & $\mathrm{CaCl}_{2}$ & $\mathrm{KCl}$ & & & & & & & & & & & & & \\
\hline & 4,60 & 4,20 & 4,10 & $-0,50$ & 23,94 & 4,29 & 10,80 & 9,00 & 2,04 & 21,84 & 44,88 & 14,20 & 36,04 & 66,72 & 32,73 & 39,40 \\
\hline LVef & 7,80 & 7,30 & 7,30 & $-0,50$ & 64,87 & 43,89 & 30,22 & 24,25 & 5,03 & 59,50 & 4,56 & 1,00 & 60,50 & 64,06 & 92,88 & 1,65 \\
\hline LVwf & 5,10 & 4,50 & 4,30 & $-0,80$ & 35,55 & 12,21 & 12,37 & 6,05 & 3,20 & 21,62 & 44,98 & 7,50 & 29,12 & 66,60 & 32,46 & 25,76 \\
\hline LAw & 5,00 & 4,50 & 4,20 & $-0,80$ & 25,54 & 4,95 & 6,75 & 4,56 & 1,78 & 13,09 & 40,28 & 8,80 & 21,89 & 53,37 & 24,52 & 40,21 \\
\hline PVA-1 & 5,85 & 5,00 & 4,90 & $-0,95$ & 4,23 & 1,32 & 3,24 & 1,56 & 0,37 & 5,17 & 4,87 & 0,80 & 5,97 & 10,04 & 51,49 & 13,40 \\
\hline PVA-2 & 6,00 & 5,50 & 5,30 & $-0,70$ & 19,15 & 24,42 & 34,00 & 7,78 & 3,32 & 45,10 & 16,51 & 0,92 & 46,02 & 61,61 & 73,20 & 2,00 \\
\hline PVA-3 & 6,30 & 5,80 & 5,60 & $-0,70$ & 20,75 & 22,11 & 48,98 & 16,32 & 3,65 & 68,95 & 16,96 & 0,90 & 69,85 & 85,91 & 80,26 & 1,29 \\
\hline RQ & 4,35 & 4,00 & 4,00 & $-0,35$ & 4,88 & 1,65 & 3,00 & 1,00 & 0,36 & 4,36 & 10,24 & 3,90 & 8,26 & 14,60 & 29,86 & 47,22 \\
\hline NVef & 5,80 & 5,20 & 4,90 & $-0,90$ & 35,72 & 11,55 & 39,00 & 13,88 & 5,18 & 58,06 & 38,99 & 1,10 & 59,16 & 97,05 & 59,83 & 1,86 \\
\hline GM & 4,85 & 4,10 & 3,95 & $-0,90$ & 130,7 & 18,15 & 6,35 & 4,00 & 1,45 & 11,80 & 132,2 & 46,00 & 57,80 & 143,98 & 8,20 & 79,58 \\
\hline OX & 4,10 & 3,80 & 3,60 & $-0,50$ & 119,1 & 70,95 & 14,48 & 4,00 & 1,47 & 19,95 & 104,8 & 46,90 & 66,85 & 124,72 & 16,00 & 70,16 \\
\hline CX & 4,30 & 4,00 & 3,85 & $-0,45$ & 17,56 & 5,28 & 4,00 & 2,00 & 1,30 & 7,30 & 32,30 & 17,20 & 24,50 & 39,60 & 18,43 & 70,20 \\
\hline $\mathrm{TC}$ & 5,60 & 4,80 & 4,50 & $-1,10$ & 6,38 & 1,65 & 4,20 & 2,00 & 1,28 & 7,48 & 6,00 & 1,50 & 8,98 & 13,48 & 55,49 & 16,70 \\
\hline MT & 5,70 & 5,30 & 4,70 & $-1,00$ & 28,75 & 18,86 & 90,63 & 23,80 & 2,48 & 116,9 & 36,66 & 1,52 & 118,1 & 153,57 & 76,13 & 1,06 \\
\hline
\end{tabular}


Tabela 4. Teores de óxidos e índices $\mathrm{Ki}$ e $\mathrm{Kr}$

\begin{tabular}{|c|c|c|c|c|c|c|c|c|c|}
\hline Solo & $\mathrm{SiO}_{2}$ & $\mathrm{Al}_{2} \mathrm{O}_{3}$ & $\mathrm{Fe}_{2} \mathrm{O}_{3}$ & $\mathrm{Fe}_{\mathrm{d}}$ & $\mathrm{Fe}_{\mathrm{o}}$ & $\mathrm{MnO}_{\mathrm{as}}$ & $\mathrm{MnO}$ & $\mathrm{Ki}$ & $\mathrm{Kr}$ \\
\hline & & & \multicolumn{3}{|c|}{$\mathrm{g} \mathrm{kg}^{-1}$} & \multicolumn{4}{|c|}{$\mathrm{mg} \mathrm{L}^{-1}$} \\
\hline LV & 147,50 & 211,60 & 120,70 & 33,20 & 3,15 & 0,40 & 1,63 & 1,19 & 0,87 \\
\hline LVef & 127,50 & 201,30 & 299,00 & 152,33 & 14,00 & 2,00 & 13,08 & 1,08 & 0,55 \\
\hline LVwf & 141,50 & 247,90 & 331,00 & 150,52 & 12,87 & 2,11 & 5,64 & 0,97 & 0,52 \\
\hline Law & 124,00 & 222,10 & 192,00 & 69,84 & 2,81 & 0,50 & 1,19 & 0,95 & 0,61 \\
\hline PVA-1 & 13,50 & 9,80 & 17,80 & 3,00 & 0,06 & 0,25 & 1,94 & 2,34 & 1,09 \\
\hline PVA-2 & 125,50 & 74,90 & 84,50 & 29,45 & 1,41 & 1,40 & 9,29 & 2,85 & 1,66 \\
\hline PVA-3 & 104,00 & 59,10 & 29,50 & 11,06 & 2,10 & 2,86 & 34,99 & 2,99 & 2,27 \\
\hline RQ & 24,50 & 17,40 & 11,70 & 2,32 & 0,21 & 0,03 & 0,05 & 2,39 & 1,68 \\
\hline NVef & 191,00 & 199,60 & 300,30 & 153,53 & 4,36 & 3,39 & 27,41 & 1,63 & 0,83 \\
\hline GM & 220,50 & 182,30 & 10,50 & 4,20 & 1,93 & 0,05 & 0,20 & 2,06 & 1,98 \\
\hline OX & 199,00 & 143,20 & 17,20 & 10,60 & 3,88 & 0,14 & 0,30 & 2,36 & 2,19 \\
\hline $\mathrm{CX}$ & 124,50 & 109,60 & 29,60 & 20,52 & 0,93 & 0,37 & 0,08 & 1,93 & 1,65 \\
\hline $\mathrm{TC}$ & 31,50 & 11,90 & 9,00 & 5,07 & 0,52 & 0,35 & 0,85 & 4,50 & 3,04 \\
\hline MT & 236,00 & 151,90 & 252,80 & 82,42 & 20,10 & 3,98 & 11,95 & 2,64 & 1,28 \\
\hline
\end{tabular}




\section{REFERÊNCIAS BIBLIOGRÁFICAS}

AGBENIN, J.O.; OLOJO, L.A. Competitive adsorption of copper and zinc by a Bt horizon of a savanna Alfisol as affected by $\mathrm{pH}$ and selective removal of hydrous oxides and organic matter. Geoderma, v.119, p.85-95, 2004.

ALLEONI, L.R.F.; CAMARGO, O.A. Solos ácricos: atributos e manejo. Boletim Informativo da Sociedade Brasileira de Ciência do Solo, v.20, p.9-17, 1995.

ALLOWAY, B.J. Soil processes and the behavior of metals. In: B.J. ALLOWAY (Ed.) Heavy metals in soils. London: Blackie Academic \& Professional, 1990. p.11-37.

ALLOWAY, B.J.; AYERS, D.C. Chemical principles of environmental pollution. 2. ed. CRC Press, 1996. 395p.

ALUMAA, P.; STEINESS, E.; KIRSO, U.; PETERSEL, L. Heavy metal sorption by different stonian soil types at low equilibrium solution concentrations. Proceedings Stonian Academy Science Chemistry, v.50, n.2, p.104-115, 2001.

ALVA A.K.; OBREZA, T.A. Reactions of copper and sulphate in sandy soils under citrus grove and in uncultivated conditions. Soil Science, v.158, p.56-64, 1994. 
ANDERSON, A. The distribution of heavy metals in soils and soil and soil material as influenced by the ionic radius. Swedish Journal of Agriculture Research, v.7, p.79-83, 1977.

ARAÚJO, W.S.; AMARAL SOBRINHO, N.M.B.; MAZUR, N.; GOMES, P.C. Relação entre adsorção de metais pesados e atributos químicos e físicos de classes de solo do Brasil. Revista Brasileira de Ciência do Solo, v. 26, p.17-27, 2002.

BARROW, N.J. Reactions with variable-charge soils. Dordrecht: Martinus Nijjhoff Publishers, 1987, 91 p.

BASTA, N.T.; TABATABAI, M.A. Effect of cropping systems on adsorption of metals by soils: II. Effect of pH. Soil Science, v.153, n.3, p.195-204, 1992a.

BASTA, N.T.; TABATABAI, M.A. Effect of cropping systems on adsorption of metals by soils: III. Competitive adsorption. Soil Science, v.153, n.4, p.331-337, $1992 b$.

BERTSCH, P.M.; BLOOM, P.R. Aluminum. In: BIGHAM, J.M. (Ed.). Methods of soil analysis. Part 3- Chemical methods. Madison: Soil Science Society of America; American Society of Agronomy, 1996. cap.18, p.517-550.

BRÜMMER, G.; TILLER, K.G.; HERMS, V.; CLAYTON, P.M. Adsorption/desorption and/or preciptation-dissolution process of zinc in soils. Geoderma, v.31, p.337-357, 1983.

CAMARGO, O. A.; AlLEONI, L. R. F.; CASAGRANDE, J. C. Reações dos micronutrientes e elementos tóxicos. In: FERREIRA, M. E.; CRUZ, M. C. P. da; RAIJ, B. van; ABREU, C. A. de (Ed.) Micronutrientes e elementos tóxicos na agricultura. Jaboticabal: CNPq/FAPESP/ POTAFOS, 2001. cap.5, p. 89-124. 
CAMARGO, O. A.; ROVERS, H.; VALADARES, J.M.A.S. Adsorção de níquel em Latossolos paulistas. Revista Brasileira de Ciência do Solo, v.13, p.125-129, 1989.

CASAGRANDE, J. C. Avaliação de um modelo de complexação de superfície para adsorção de fosfato em solos ácricos do norte paulista. Piracicaba, 1993. 97p. Tese (Doutorado) - Escola Superior de Agricultura “Luiz de Queiroz”, Universidade de São Paulo.

CASAGRANDE, J. C. Adsorção de fosfato em solo com caráter ácrico avaliada por um modelo de complexação de superfície. Revista Brasileira de Ciência do Solo, v.21, n.3, p.353-360, 1997.

CASAGRANDE, J.C.; ALLEONI, L.R.F; CAMARGO, O.A. Utilização do modelo de capacitância constante para avaliação de adsorção de boro em solos ácricos. In: REUNIÃO BRASILEIRA DE FERTILIDADE DO SOLO E NUTRIÇÃO DE PLANTAS - FERTBIO, 23., Caxambu, 1998. Resumos. Caxambu: 1998. p.689.

CHANG, T.W.; WANG, M.K.; LIN, C. Adsorption of cooper in the different sorbent/water ratios of soil systems. Water, Air, and Soil Pollution, v.138, p.199209, 2002.

CHEN, Z.S.; LEE, G.J.; LIU, J.C. The effects of chemical remediation treatments on the extractability and speciation of cadmium and lead in contaminted soils. Chemosphere, v.41, n1\&2, p.235-342, 2000.

CHILDS, C.W. Composition of iron-manganese concretions from some New Zealand soils. Geoderma, v.13, n.2, p.141-152. 
CLARK, C.J.; McBRIDE, M.B. Chemisorption of Cu (II) and Co(II) on allophane and inogolite. Clays and Clay Minerals, v.32, p.300-310, 1984.

COLE, D.R.; ROSE, A.W. Distribution and model of occurence of zinc and lead in glacial soils. Journal of Geochemical Exploration, v.20, n.2, 137-160, 1984.

COMPANHIA DE TECNOLOGIA DE SANEAMENTO AMBIENTAL. Relatório de estabelecimento de valores orientadores para solos e água subterrâneas no Estado de São Paulo. São Paulo, 2001. 247p.

CORNELL, R.M.; SCHWERTMANN, U. The iron oxides: structure, properties, reactions, occurrence and uses. Weinheim: VCH, 1996. 573p.

CRITER, S.A.M. Troca iônica, calorimetria, análise térmica e microbiológica aplicadas a um Latossolo Roxo. Campinas, 1996. 150p. Tese (Doutorado) - Unicamp.

CUNHA, R.C. de A.; CAMARGO, O.A.; KINJO, T. Aplicação de três isotermas na adsorção de zinco em Oxissolos, Alfissolos e Ultissolos. Revista Brasileira de Ciência do Solo, v.18, p.15-20, 1994.

DIAS, N.M.; ALLEONI, L.R.F.; CASAGRANDE, J.C.; CAMARGO, O.A. Adsorção de cádmio em dois Latossolos ácricos e um Nitossolo. Revista Brasileira de Ciência do Solo, v.25, p.297-304, 2001.

DONG, D.; NELSON, Y.M.; SHULER, L.W.M.; GHIORSE, W.C. Adsorption of Pb and Cd onto metal oxides and organic material in natural saurface coatings as determined by selective extrations: new evidence for the importance of $\mathrm{Mn}$ and Fe oxides. Water Research, v.34, n.2, p.427-436, 2000. 
ECHEVERRÍA, J.C.; MORERA, M.T.; MAZKIARÁN, C.; GARRIDO, J.J. Competitive sorption of heavy metal by soils. Isotherms and fractional factorial experiments. Environmental Pollution, v.101, n.275-284, 1998.

EMPRESA BRASILEIRA DE PESQUISA AGROPECUÁRIA - Centro Nacional de Pesquisa de Solos. Manual de métodos de análise de solo. 2. ed. Rio de Janeiro, 1997. 212p.

EMPRESA BRASILEIRA DE PESQUISA AGROPECUÁRIA. Sistema Brasileiro de Classificação de Solos. Brasília: Embrapa, 1999. 412p.

FERREIRA, M.E.; CRUZ, M.C.P. Micronutrientes na agricultura. Piracicaba: POTAFOS; CNPq, 1991. 734p.

FONTES, M.P.F.; GOMES, P.C. Simultaneous competitive adsorption of heavy metals by the mineral matrix of tropical soils. Applied Geochemistry, v.18, p.795-804, 2003.

FONTES, M.P.F.; MATOS, A.T.; COSTA, L.M.; NEVES, J.C.L. Competitive adsorption of zinc, cadmium, copper and lead in three highly-weathered Brazilian soils. Communications of Soil Science and Plant Analysis, v.31, n.17/18, p.2939-2958, 2000.

FONTES, M.P.F.; WEED, S.B. Phosphate adsorption by clays from Brazilian Oxisols: relationship with specific area and mineralogy. Geoderma, v.72, n.1, p.37-51, 1996.

FORBES, E.A.; POSNER, Q.M.; QUIRK, J.P. The specific adsorption of divalent Cd, Co, $\mathrm{Cu}, \mathrm{Pb}$ and $\mathrm{Zn}$ on goethite. Journal of Soil Science, v.27, p.154-166, 1976. 
FORD, R.G.; SCHEINOST, A.C.; SPARKS, D.L. Frontiers in metal sorption/precipitation mechanisms on soil mineral surfaces. Advances in Agronomy, v.74, p.41-62, 2001.

FU, G.; ALLEN, H.E.; COWAN, C.E. Adsorption of cadmium and copper by manganese oxide. Soil Science, v.152, p.72-81, 1991.

GAMBRELL, R. P. Manganese. In: BIGHAM, J.M. (Ed.). Methods of soil analysis. Part 3- Chemical methods. Madison: Soil Science Society of America; American Society of Agronomy, 1996. cap.24, p.665-682.

GILES, C.H.; SMITH, D.; HUÍTSON, A. A general treatment and classification of solute adsorption isotherm. I: Theoretical. Journal of Colloid Interface Science, v.47, p.755-765, 1974.

GILKES, R.J. Geochemistry and mineralogy of manganese in soils. In: GRAHAM, R.D.; HANNAM, K.J. (Eds.) Manganese in Soil and Plants. Netherlands: Kluwer Academic Publishers, 1988, p.23-35

GOLDBERG, S. A chemical model for phosphate adsorption on oxide mineral and soils. Riverside, 1983. 149 p. Thesis (Ph.D.) - University of California.

GOLDBERG, S. Use of complexation models in soil chemical systems. Advances in Agronomy, v.47, p.323-329, 1992.

GOLDBERG, S. Adsorption models incorporated into chemical equilibrium models. In: Chemical equilibrium and reaction models. Soil Science Society of American Proceedings, v.42, p.75-95, 1995. 
GOMES, P.C.; FONTES, M.P.F.; da SILVA, A.G.; MENDONÇA, E.S.; NETTO, A.R. Selectivity sequence and competitive adsorption of heavy metals by Brazilian soils. Soil Science Society of America Journal, v.65, p.1115-1121, 2001.

GUILHERME, L.R.G.; ANDERSON, S.J. Copper sorption kinetics and sorption hysteresis in two oxide-rich soils (Oxisols). In: VENNE, E.A. (Ed). Adsorption of metals by geomedia: variables, mechanisms and model applications. San Diego: Academic Press, 1998. Cap.9, p. 209-228.

HARTER, R.D. Effect of soil pH on adsorption of lead, cooper, zinc and nickel. Soil Science Society of America Journal, v.47, p.47-51, 1983.

HARTER, R.D. Competitive sorption of cobalt, copper, and nickel. Soil Science Society of America Journal, v.56, p.444-449, 1992.

HARTER, R.D.; NAIDU, R. An assessment of environmental and solution parameter impact on trace-metal sorption by soils. Soil Science Society of America Journal, v.65, n.3, p.597-612, 2001.

HINZ, C. Description of sorption data with isotherm equations. Geoderma, v.99, p.225-243, 2001.

HUHEEY, J.E. Inorganic chemistry: principles of structure and reactivity. New York: Harper \& Row, 1972. 737p.

JACKSON, M.L. Soil chemical analysis: advanced course. Madison: University of Wisconsin, 1969. 991p. 
JAMES, R.O.; HEALY, T.W. Adsorption of hydrolysable metals at the oxide-water interface. III. A thermodynamic model of adsorption. Journal of Colloid Interface Science, v.40, p.65-80,1972.

JI G.L.; LI, H.Y. Electrostatic adsorption of cations. In: YU, T.R. Chemistry of variable charge soils. New York: Oxford University Press, 1997, p.65-79.

JORDÃO, C.P.; ALVES, N.M.; PEREIRA, J.L.; BELLATO, C.R. Adsorção de íons $\mathrm{Cu}^{2+}$ em Latossolo Vermelho-Amarelo húmico. Química Nova, v.23, n.1, p.5-11, 2000.

KABATA-PENDIA, A.; PENDIAS, H. Soil constituents. In: Trace elements in soils and plants. Florida: CRC Press, 1984, p.33-50.

KALBASI, M.; RACZ, G.J.; LOEWEN-RUDGERS, L.A. Mechanism of zinc adsorption by iron and aluminum oxides. Soil Science, v.125, n.3, p.146-150, 1978.

KÄMPF, N.; SCHWERTMANN, U. The 5M - NaOH concentration treatment for iron oxides in soils. Clays and Clay Minerals,v.30, p.401-408, 1982.

KING, L.D. Retention of cadmium by several soils of southeastern United States. Journal of Environmental Quality, v.17, p.246-250, 1988.

KINNINBURG, D.G.; JACKSON, M.L..; SYERS, J.K. Adsorption of alkaline earth, transition and heavy metal cations by hidrous oxide gels of iron and aluminum. Soil Science Society of America Journal, v.40, p.746-749, 1976.

KUO, S.; BAKER, A.S. Sorption of copper, zinc, and cadmium by some acid soils. Soil Science Society of America Journal, v.44, p.969-974, 1980. 
LOEPPERT, R.L.; INSKEEP, W.P. Iron. In: BIGHAM, J.M. (Ed.). Methods of soil analysis. Part 3- Chemical methods. Madison: Soil Science Society of America; American Society of Agronomy, 1996. cap.23, p.639-664.

LOGANATHAN, P.; BURAU, R.G. Sorption of heavy metal ions by a hydrous manganese oxide. Geochimica et Cosmochimica Acta, v.37, n.5, p.1277-1293, 1973.

MATOS, A.T.; FONTES, M.P.F.; COSTA, L.M.; MARTINEZ, M.A. Mobility of heavy metals as related to soil chemical and mineralogical characteristics of Brazilian soils. Environmental Pollution, v.111, p.429-435, 2001.

MATOS, A.T.; FONTES, M.P.F.; JORDÃO, C.P.; da COSTA, L.M. Mobilidade e formas de retenção de metais pesados em Latossolo Vermelho-Amarelo. Revista Brasileira de Ciência do Solo, v.20, p.379-386, 1996.

McBRIDE, M. B. Environmental Chemistry of Soils. New York: Oxford University Press, 1994. 415p.

McBRIDE, M.B. Reactions controlling heavy metal solubility in soils. Advances in Soil Science, v.10, p.1-47, 1989.

McBRIDE, M.B.; BLASIAK, J.J. Zinc and copper solubility as a function of $\mathrm{pH}$ in an acid soil. Soil Science Society of America Journal, v.43, p.866-870, 1979.

McKENZIE, R.M. An electron microprobe study of the relationships between heavy metals and manganese and iron in soils and ocean floor nodules. Australian Journal of Soil Research, v.13, p.177-188, 1975. 
McKENZIE, R.M. The adsorption of lead and other heavy metals on oxides of manganese and iron. Australian Journal of Soil Research, v.18, p.61-73, 1980.

McKENZIE, R.M. The sorption of some heavy metals by lower oxides and hydroxides of manganese. Geoderma, v.8, p.29-35, 1972.

McLAREN, R.G.; CRAWFORD, D.V. Studies on soil copper II. The specific adsorption of copper by soils. Journal of Soil Science, v.24, p.443-452, 1973.

MEAD, J.A. A comparison of the Langmuir, Freundlich and Temkim equations to describe phosphate adsorption properties. Australian Journal of Soil Research, v.19, p.333-342, 1981.

MESQUITA, M.E.; SILVA, J.M.V. Preliminary study of $\mathrm{pH}$ effect in application of Langmuir and Freundlich isotherms to $\mathrm{Cu}-\mathrm{Zn}$ competitive adsorption. Geoderma, v.106, p.219-234, 2002.

MEURER, E.J. Fundamentos de química do solo. Porto Alegre: Genesis, 2000. 173p.

MORERA, M.T.; ECHEVERRÍA, J.C.; MAZKIARÁN, C.; GARRIDO, J.J. Isotherms and sequential extraction procedures for evaluating sorption and distribution of heavy metals in soils. Environmental Pollution, v.113, p.135-144, 2001.

MSAKY, J.J.; CALVET, R. Adsorption behavior of copper and zinc in soils - Influence of pH on adsorption characteristics. Soil Science, v.150, n.2, p.513-521, 1990.

MURALI, V.; AYLMORE, L.A.G. Competitive adsorption during solute transport in soils. 2. Simulations of competitive adsorption. Soil Science, v.135, p.203-213, 1983. 
NAIDU, R.; BOLAN, N.S.; KOOKANA, R.S.; TILLER, K.G. Ionic-strength and pH effects on the sorption of cadmium and the surface charge of soils. European Journal of Soil Science, v.45, p.419-429, 1994.

OLSEN S.R.; WATANABE, F.S. A method to determine a phosphorus adsorption maximum of soils as measured by the Langmuir isotherm. Soil Science Society of America Journal, v.21, p.144-149, 1957.

PARTIFF, R.L.; CHILDS, C.W. Estimation of forms of $\mathrm{Fe}$ and $\mathrm{Al}$ : A review, and analysis of contrasting soils by dissolution and Mössbauer methods. Australian Journal of Soil Research, v.26, n.1, p.121-144, 1988.

PHILLIPS, I.R. Copper, lead, cadmium, and zinc sorption by waterlogged and air-dry soil. Journal of Soil Contamination, v., n.3, p.343-364, 1999.

POMBO, L.C.A. Sorção de cádmio em solos do estado do Rio Grande do Sul. Revista Brasileira de Ciência do Solo, v.19, p.19-24, 1995.

POMBO, L.C.A.; SALGADO, V.; VOLKWEISS, S.; KLAMT, E. Adsorção de níquel por dois solos: Terra Bruna estruturada similar e Podozólico Vermelho-Amarelo. Pesquisa Agropecuária Brasileira, v.24, n.5, p.593-598, 1989.

RAIJ, B. van; ANDRADE, J.C. de; CANTARELLA, H.; QUAGGIO, J.A. Análise química para avaliação da fertilidade de solos tropicais. Campinas: Instituto Agronômico, 2001. 285p.

ROSS, S.M. Retention, transformation and mobility of toxic metals in soils. In: ROSS, S.M. (Ed.) Toxic Metals in Soil-Plant Systems, New York: Wiley, 1994. p. 63152. 
SADIQ, M. The adsorption characteristics of soil and sorption of copper, manganese e zinc. Communications of Soil Science and Plant Analysis, v.12, p.631-642, 1981.

SAS INSTITUTE. SAS user's guide: release 6.03. Cary, 1988. 1028p.

SAUVÉ, S.; HENDERSHOT, W.; ALLEN, H.E. Solid-solution partitioning of metals in contaminated soils: dependence on $\mathrm{pH}$ and total metal burden. Environmental Science andTechnology, v.34, p.1125-1131, 2000.

SCHULTHESS, C.P.; HUANG, C.P. Adsorption of heavy metal by silicon and aluminum oxide surfaces on clay minerals. Soil Science Society of Ames ${ }^{76}$ Journal, v.54, p.679-688, 1990.

SCHULZE, D.G. The influence of aluminum on iron oxides. VIII. Unit-cell dimensions of $\mathrm{Al}$-substituted goethites and estimation of $\mathrm{Al}$ from them. Clays and Clay Minerals, v.32, n.1, p.36-44, 1984.

SCHWERTMANN, U.; FITZPATRICK, R.W.; TAYLOR, R.M.; LEWIS, D.G. The influence of aluminum on iron oxides. Part II. Preparation and properties of Alsubstituted hematites. Clays and Clay Minerals, v.27, n.2, p.105-112, 1979.

SCHWERTMANN, U.; CORNELL R.M. Iron oxides in laboratory: preparation and characterization. Weinheim: VCH, 1991. 137p.

SHANI, U.; DUDLEY, L.M.; HANKS, R.J. Model of boron movement in soils. Soil Science Society of America Journal, v.56, p.1365-1370, 1992.

SIDLE, R.C.; KARDOS, L.T. Transport of heavy metals in a sludge-treated forested area. Journal of Environmental Quality, v.6, p.431-437, 1977. 
SILVEIRA, M.L.A. Adsorção de cobre em Latossolos ácricos paulistas. Piracicaba, 1999. 91p. Dissertação (M.S.) - Escola Superior de Agricultura “Luiz de Queiroz”, Universidade de São Paulo.

SILVEIRA, M.L.A.; ALLEONI, L.R.F.; CAMARGO, O.A.; CASAGRANDE, J.C. Copper adsorption in oxidic soils after removal of organic matter and iron oxides. Communications of Soil Science and Plant Analysis, v.33, n.19/20, p.3581-3592, 2002.

SINGH, B. R.; STEINNES, E. Soil and water contamination by heavy metals. In: LAI, R; STEWART, B. A. (Ed). Advances in soil science: soil process and water quality. Boca Raton: Lewis Publishers, 1994. p.233-237.

SINGH, B.; GILKES, R.J. Properties and distribution of iron oxides and their association with minor elements in the soils of South-Western Australia. Journal of Soil Science, v.43, p.77-98, 1992.

SINGH, M. Retention of addedcopper by two soils as affected by organic matter, $\mathrm{CaCO}_{3}$ and exchangeable ions. Geoderma, v.5, p.219-227, 1971.

SPOSITO, G. The chemistry of soils. New York: Oxford University Press, 1989. 277p.

SPOSITO, G. The operational definition of zero point of charge in soils. Soil Science Society of America Journal, v.45, p.292-297, 1981.

STEVENSON, F.L.; ARDAKANI,C. Organic matter reactions involving micronutrients in soils. In: MORTVEDT, J.J.; GIORDANO, P.M.; LINDSAY, W.L. (Eds.) Micronutrients in agriculture. Madison: Wis., 1972. p. 79-114. 
STUMM, W.; MORGAN. Aquatic chemistry. New York: John Willey, 1981. 47p.

SULLIVAN, P.J. The principles of had and soft acids and bases as applied to exchangeable cation selectivity in soils. Soil Science, v.124, p.117-121, 1977.

TAN, K.H.; HAJEK, B.F.; BARSHAD, I. Thermal analysis techniques. In: KLUTE, A. (Ed.). Methods of soil analysis. Part 1- Physical and mineralogical methods. 2 ed. Madison: Soil Science Society of America/ American Society of Agronomy, 1986. cap.7, p151-183.

TILLER, K.G; GERTH, J.; BRÜMMER, G. The relative affinities of Cd, Ni and Zn for different soil clay fractions and goethite. Geoderma, v.34, p.17-35, 1984.

TYLER, L.D.; McBRIDE, M.B. Influence of Ca, $\mathrm{pH}$ and humic acid on Cd uptake. Plant and Soil, v.64, p.259-262.

UEHARA, G. Acric properties and their significance to soil classification. In: INTERNATIONAL SOIL CLASSIFICATION WORSHOP, 8., Rio de Janeiro, 1986. Proceedings. Rio de Janeiro: EMBRAPA, SNLCS, 1988. p.19-22.

UREN, N. C. Forms, reactions, and availability of nickel in soils. Advances in Agronomy. v. 48, p.141-203, 1992.

WHITNEY, P.R. Heavy metals and manganese oxides in the genese watershed, New York state: effects of geology and land use. Journal of Geochemical Exploration, v.14, p.95-117, 1981. 
WHITTIG, L. D.; ALLARDACE, W.R. X-ray diffraction techniques. In: KLUTE, A. (Ed.). Methods of soil analysis. Part 1- Physical and mineralogical methods. 2 ed. Madison: Soil Science Society of America/ American Society of Agronomy, 1986. cap.12, p331-382.

YONG, R.N.; MOHAMED, A.M.O.; WARKENTIN, B.P. Principles of contaminant transport in soils. Elsevier. 1992. 342p.

YU, T.R. Chemistry of variable charge soils. New York: Oxford University Press, 1997. 505p.

ZASOSKI, R.J.; BURAU, R.G. Sorption and sorptive interactions of cadmium and zinc on hydrous manganese oxide. Soil Science Society of America Journal, v.52, p.81-87.

ZHU, B.; ALVA, K. Differential adsorption of trace metals by soils as influenced by exchangeable cations and ionic strength. Soil Science, v.155, n.1, p.61-66, 1993. 


\section{APÊNDICES}


Tabela A1. Concentração de inicial (CI), concentração de equilíbrio (Ceq.), quantidade adsorvida, equação de Langmuir, adsorção máxima (b) e constante de afinidade (Kaf) obtidos a partir das isotermas de adsorção de $\mathrm{Zn}, \mathrm{Ni}$, Cu e Cd, em sistema não-competitivo para o Latossolo Vermelho (LV)

\begin{tabular}{|c|c|c|c|c|c|c|}
\hline \multirow[t]{2}{*}{ Metais } & CI & Ceq & \multirow{2}{*}{$\begin{array}{c}\text { Quantidade } \\
\text { adsorvida } \\
\mathrm{mg} \mathrm{kg}^{-1}\end{array}$} & \multirow[t]{2}{*}{ Equação de Langmuir } & \multirow{2}{*}{$\frac{\mathrm{b}}{\mathrm{mg} \mathrm{kg}}$} & \multirow{2}{*}{$\begin{array}{c}\text { Kaf } \\
\mathrm{L} \mathrm{mg}^{-1}\end{array}$} \\
\hline & \multicolumn{2}{|c|}{$\ldots \ldots \ldots \ldots \ldots$} & & & & \\
\hline \multirow{8}{*}{$\mathrm{Zn}$} & 1,30 & 0,05 & 12,50 & $y=84,03 x /(1+0,21 x)$ & 384,61 & 0,218 \\
\hline & 2,50 & 0,10 & 24,00 & & & \\
\hline & 5,10 & 0,60 & 45,00 & & & \\
\hline & 13,00 & 2,00 & 110,00 & & & \\
\hline & 19,00 & 3,10 & 159,00 & & & \\
\hline & 34,00 & 10,95 & 230,50 & & & \\
\hline & 50,00 & 25,45 & 245,50 & & & \\
\hline & 105,00 & 43,55 & 614,50 & & & \\
\hline \multirow{8}{*}{$\mathrm{Ni}$} & 1,03 & 0,09 & 9,42 & $y=90,85 x /(1+0,31 x)$ & 285,71 & 0,318 \\
\hline & 1,97 & 0,09 & 18,82 & & & \\
\hline & 4,78 & 0,56 & 42,22 & & & \\
\hline & 10,27 & 1,58 & 86,88 & & & \\
\hline & 16,25 & 2,99 & 132,60 & & & \\
\hline & 29,90 & 11,55 & 183,48 & & & \\
\hline & 47,86 & 22,25 & 256,09 & & & \\
\hline & 71,76 & 43,59 & 281,70 & & & \\
\hline \multirow{8}{*}{$\mathrm{Cu}$} & 1,10 & 0,01 & 10,95 & $y=434,76 x /(1+0,73 x)$ & 588,23 & 0,739 \\
\hline & 2,17 & 0,04 & 21,30 & & & \\
\hline & 5,30 & 0,10 & 52,00 & & & \\
\hline & 10,83 & 0,23 & 106,05 & & & \\
\hline & 15,90 & 0,50 & 154,00 & & & \\
\hline & 32,50 & 2,80 & 297,00 & & & \\
\hline & 53,20 & 11,15 & 420,50 & & & \\
\hline & 81,40 & 13,00 & 684,00 & & & \\
\hline \multirow{8}{*}{ Cd } & 1,91 & 0,00 & 19,10 & $y=117,39 x /(1+0,27 x)$ & 434,78 & 0,273 \\
\hline & 3,82 & 0,30 & 35,20 & & & \\
\hline & 9,55 & 1,75 & 78,00 & & & \\
\hline & 19,10 & 4,20 & 149,00 & & & \\
\hline & 35,00 & 5,90 & 291,00 & & & \\
\hline & 56,00 & 13,90 & 421,00 & & & \\
\hline & 80,00 & 38,65 & 413,50 & & & \\
\hline & 143,00 & 103,00 & 400,00 & & & \\
\hline
\end{tabular}


Tabela A2. Concentração de inicial (CI), concentração de equilíbrio (Ceq.), quantidade adsorvida, equação de Langmuir, adsorção máxima (b) e constante de afinidade (Kaf) obtidos a partir das isotermas de adsorção de $\mathrm{Zn}, \mathrm{Ni}$, Cu e Cd, em sistema não-competitivo para o Latossolo Vermelho Eutroférrico (LVef)

\begin{tabular}{|c|c|c|c|c|c|c|}
\hline \multirow[t]{2}{*}{ Metais } & CI & Ceq & \multirow{2}{*}{$\begin{array}{c}\begin{array}{c}\text { Quantidad } \\
\text { e adsorvida }\end{array} \\
\mathrm{mg} \mathrm{kg}^{-1} \\
\end{array}$} & \multirow{2}{*}{ Equação de Langmuir } & \multirow{2}{*}{$\frac{\mathrm{b}}{\mathrm{mg} \mathrm{kg}^{-1}}$} & \multirow{2}{*}{$\frac{\mathrm{Kaf}}{\mathrm{L} \mathrm{mg}^{-1}}$} \\
\hline & $\cdots \cdots \cdots \cdots \cdots \cdots$ & ${ }^{-3} \cdots \ldots \ldots \ldots \ldots \ldots \ldots$ & & & & \\
\hline \multirow{7}{*}{$\mathrm{Zn}$} & 1,30 & 0,05 & 12,55 & - & - & - \\
\hline & 2,50 & 0,07 & 24,30 & & & \\
\hline & 5,10 & 0,12 & 49,80 & & & \\
\hline & 13,00 & 0,17 & 128,30 & & & \\
\hline & 19,00 & 0,22 & 187,80 & & & \\
\hline & 83,33 & 0,42 & 829,10 & & & \\
\hline & 107,80 & 0,52 & 1072,80 & & & \\
\hline \multirow{8}{*}{$\mathrm{Ni}$} & 1,03 & 0,09 & 9,42 & - & - & - \\
\hline & 1,97 & 0,17 & 17,96 & & & \\
\hline & 4,78 & 0,17 & 46,06 & & & \\
\hline & 10,27 & 0,17 & 100,96 & & & \\
\hline & 16,25 & 0,30 & 159,48 & & & \\
\hline & 29,90 & 1,31 & 285,91 & & & \\
\hline & 47,86 & 1,77 & 460,95 & & & \\
\hline & 71,76 & 1,77 & 699,95 & & & \\
\hline \multirow{7}{*}{$\mathrm{Cu}$} & 1,10 & 0,12 & 9,80 & - & - & - \\
\hline & 2,17 & 0,16 & 20,15 & & & \\
\hline & 5,30 & 0,31 & 49,95 & & & \\
\hline & 10,83 & 0,47 & 103,60 & & & \\
\hline & 15,90 & 0,50 & 154,00 & & & \\
\hline & 53,20 & 1,15 & 520,50 & & & \\
\hline & 81,40 & 1,50 & 799,00 & & & \\
\hline \multirow{8}{*}{ Cd } & 1,91 & 0,10 & 18,10 & - & - & - \\
\hline & 3,82 & 0,30 & 35,20 & & & \\
\hline & 9,55 & 0,30 & 92,50 & & & \\
\hline & 19,10 & 0,90 & 182,00 & & & \\
\hline & 35,00 & 0,90 & 341,00 & & & \\
\hline & 56,00 & 0,85 & 551,50 & & & \\
\hline & 80,00 & 0,85 & 791,50 & & & \\
\hline & 143,00 & 0,90 & 1421,00 & & & \\
\hline
\end{tabular}


Tabela A3. Concentração de inicial (CI), concentração de equilíbrio (Ceq.), quantidade adsorvida, equação de Langmuir, adsorção máxima (b) e constante de afinidade (Kaf) obtidos a partir das isotermas de adsorção de $\mathrm{Zn}$, Ni, Cu e Cd, em sistema não-competitivo para o Latossolo Vermelho acriférrico (LVwf)

\begin{tabular}{|c|c|c|c|c|c|c|}
\hline \multirow[t]{2}{*}{ Metais } & CI & Ceq & \multirow{2}{*}{$\begin{array}{r}\text { Quantidad } \\
\text { e adsorvida } \\
\text { mg kg }^{-1}\end{array}$} & \multirow{2}{*}{ Equação de Langmuir } & \multirow{2}{*}{$\frac{\mathrm{b}}{\mathrm{mg} \mathrm{kg}^{-1}}$} & \multirow{2}{*}{$\frac{\text { Kaf }}{\mathrm{L} \mathrm{mg}^{-1}}$} \\
\hline & 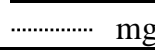 & $\mathrm{1}^{-3} \ldots \ldots \ldots \ldots \ldots \ldots$ & & & & \\
\hline \multirow{8}{*}{$\mathrm{Zn}$} & 1,30 & 0,01 & 12,90 & $y=114,94 x /(1+0,207 x)$ & 555,56 & 0,206 \\
\hline & 2,50 & 0,08 & 24,20 & & & \\
\hline & 5,10 & 0,38 & 47,20 & & & \\
\hline & 13,00 & 1,18 & 118,20 & & & \\
\hline & 19,00 & 1,88 & 171,20 & & & \\
\hline & 34,00 & 6,98 & 270,20 & & & \\
\hline & 50,00 & 19,98 & 300,20 & & & \\
\hline & 105,00 & 49,98 & 550,20 & & & \\
\hline \multirow{8}{*}{$\mathrm{Ni}$} & 1,03 & 0,09 & 9,42 & $y=99,99 x /(1+0,24 x)$ & 416,66 & 0,240 \\
\hline & 1,97 & 0,17 & 17,96 & & & \\
\hline & 4,78 & 0,30 & 44,78 & & & \\
\hline & 10,27 & 0,86 & 94,14 & & & \\
\hline & 16,25 & 1,84 & 144,12 & & & \\
\hline & 29,90 & 8,56 & 213,35 & & & \\
\hline & 47,86 & 17,13 & 307,31 & & & \\
\hline & 71,76 & 32,49 & 392,67 & & & \\
\hline \multirow{8}{*}{$\mathrm{Cu}$} & 1,10 & 0,02 & 10,85 & $y=666,68 x /(1+1,06 x)$ & 625,00 & 1,060 \\
\hline & 2,17 & 0,01 & 21,60 & & & \\
\hline & 5,30 & 0,04 & 52,60 & & & \\
\hline & 10,83 & 0,15 & 106,80 & & & \\
\hline & 15,90 & 0,25 & 156,50 & & & \\
\hline & 32,50 & 1,40 & 311,00 & & & \\
\hline & 53,20 & 7,30 & 459,00 & & & \\
\hline & 81,40 & 18,10 & 633,00 & & & \\
\hline \multirow{8}{*}{$\mathrm{Cd}$} & 1,91 & 0,1 & 18,10 & $y=137,0 x /(1+0,27 x)$ & 500,00 & 0,274 \\
\hline & 3,82 & 0,35 & 34,70 & & & \\
\hline & 9,55 & 1,4 & 81,50 & & & \\
\hline & 19,10 & 2,6 & 165,00 & & & \\
\hline & 35,00 & 4,4 & 306,00 & & & \\
\hline & 56,00 & 8,5 & 475,00 & & & \\
\hline & 80,00 & 32,5 & 475,00 & & & \\
\hline & 143,00 & 34,21 & 1087,90 & & & \\
\hline
\end{tabular}


Tabela A4. Concentração de inicial (CI), concentração de equilíbrio (Ceq.), quantidade adsorvida, equação de Langmuir, adsorção máxima (b) e constante de afinidade (Kaf) obtidos a partir das isotermas de adsorção de $\mathrm{Zn}$, Ni, Cu e Cd, em sistema não-competitivo para o Latossolo Amarelo ácrico (LAw)

\begin{tabular}{|c|c|c|c|c|c|c|}
\hline \multirow[t]{2}{*}{ Metais } & CI & Ceq & \multirow{2}{*}{$\begin{array}{c}\begin{array}{c}\text { Quantidad } \\
\text { e adsorvida }\end{array} \\
\mathrm{mg} \mathrm{kg}^{-1} \\
\end{array}$} & \multirow{2}{*}{ Equação de Langmuir } & $\mathrm{b}$ & \multirow{2}{*}{$\frac{\mathrm{Kaf}}{\mathrm{L} \mathrm{mg}^{-1}}$} \\
\hline & $\ldots \cdots \cdots \cdots \cdots \cdots$ & $\mathrm{h}^{-3} \cdots \cdots \cdots \cdots \cdots \cdots$ & & & $\mathrm{mg} \mathrm{kg}^{-1}$ & \\
\hline \multirow{8}{*}{ Zn } & 1,30 & 0,01 & 12,90 & \multirow[t]{8}{*}{$y=113,62 x /(1+0,27 x)$} & 416,67 & \multirow[t]{8}{*}{0,270} \\
\hline & 2,50 & 0,10 & 24,00 & & & \\
\hline & 5,10 & 0,50 & 46,00 & & & \\
\hline & 13,00 & 1,45 & 115,50 & & & \\
\hline & 19,00 & 2,60 & 164,00 & & & \\
\hline & 34,00 & 8,50 & 255,00 & & & \\
\hline & 50,00 & 21,00 & 290,00 & & & \\
\hline & 105,00 & 41,00 & 640,00 & & & \\
\hline \multirow{8}{*}{$\mathrm{Ni}$} & 1,03 & 0,09 & 9,42 & \multirow[t]{8}{*}{$y=95,85 x /(1+0,27 x)$} & 344,82 & \multirow[t]{8}{*}{0,278} \\
\hline & 1,97 & 0,13 & 18,39 & & & \\
\hline & 4,78 & 0,30 & 44,78 & & & \\
\hline & 10,27 & 0,94 & 93,28 & & & \\
\hline & 16,25 & 2,22 & 140,28 & & & \\
\hline & 29,90 & 10,70 & 192,02 & & & \\
\hline & 47,86 & 21,40 & 264,63 & & & \\
\hline & 71,76 & 38,47 & 332,92 & & & \\
\hline \multirow{8}{*}{$\mathrm{Cu}$} & 1,10 & 0,01 & 10,90 & \multirow[t]{8}{*}{$y=588,23 x /(1+x)$} & 588,23 & \multirow[t]{8}{*}{1,00} \\
\hline & 2,17 & 0,02 & 21,50 & & & \\
\hline & 5,30 & 0,04 & 52,60 & & & \\
\hline & 10,83 & 0,14 & 106,90 & & & \\
\hline & 15,90 & 0,30 & 156,00 & & & \\
\hline & 32,50 & 2,10 & 304,00 & & & \\
\hline & 53,20 & 9,95 & 432,50 & & & \\
\hline & 81,40 & 23,50 & 579,00 & & & \\
\hline \multirow{8}{*}{$\mathrm{Cd}$} & 1,91 & 0,10 & 18,10 & \multirow[t]{8}{*}{$y=111,09 x /(1+0,26 x)$} & 454,54 & \multirow[t]{8}{*}{0,261} \\
\hline & 3,82 & 0,20 & 36,20 & & & \\
\hline & 9,55 & 1,70 & 78,50 & & & \\
\hline & 19,10 & 3,70 & 154,00 & & & \\
\hline & 35,00 & 4,50 & 305,00 & & & \\
\hline & 56,00 & 11,50 & 445,00 & & & \\
\hline & 80,00 & 37,50 & 425,00 & & & \\
\hline & 143,00 & 98,50 & 445,00 & & & \\
\hline
\end{tabular}


Tabela A5. Concentração de inicial (CI), concentração de equilíbrio (Ceq.), quantidade adsorvida, equação de Langmuir, adsorção máxima (b) e constante de afinidade (Kaf) obtidos a partir das isotermas de adsorção de $\mathrm{Zn}$, Ni, Cu e Cd, em sistema não-competitivo para o Argissolo Vermelho-Amarelo (PVA-1)

\begin{tabular}{|c|c|c|c|c|c|c|}
\hline \multirow[t]{2}{*}{ Metais } & CI & Ceq & \multirow{2}{*}{$\begin{array}{r}\begin{array}{c}\text { Quantidad } \\
\text { e adsorvida }\end{array} \\
\mathrm{mg} \mathrm{kg}^{-1}\end{array}$} & \multirow{2}{*}{ Equação de Langmuir } & $\mathrm{b}$ & \multirow{2}{*}{$\frac{\mathrm{Kaf}}{\mathrm{L} \mathrm{mg}^{-1}}$} \\
\hline & ............... mg & $\mathrm{n}^{-3} \ldots \ldots \ldots \ldots \ldots \ldots . \cdots \cdots \cdot \ldots$ & & & $\mathrm{mg} \mathrm{kg}^{-1}$ & \\
\hline \multirow{8}{*}{$\mathrm{Zn}$} & 1,30 & 0,10 & 12,00 & $y=42,85 x /(1+0,12 x)$ & 357,14 & 0,117 \\
\hline & 2,50 & 0,20 & 23,00 & & & \\
\hline & 5,10 & 0,40 & 47,00 & & & \\
\hline & 13,00 & 3,25 & 97,50 & & & \\
\hline & 19,00 & 4,00 & 150,00 & & & \\
\hline & 34,00 & 16,00 & 180,00 & & & \\
\hline & 50,00 & 33,50 & 165,00 & & & \\
\hline & 105,00 & 62,50 & 425,00 & & & \\
\hline \multirow{7}{*}{$\mathrm{Ni}$} & 1,03 & 0,09 & 9,42 & $y=86,45 x /(1+0,83 x)$ & 104,16 & 0,827 \\
\hline & 1,97 & 0,17 & 17,96 & & & \\
\hline & 4,78 & 0,98 & 37,96 & & & \\
\hline & 10,27 & 2,52 & 77,49 & & & \\
\hline & 29,90 & 20,51 & 93,86 & & & \\
\hline & 47,86 & 37,61 & 102,45 & & & \\
\hline & 71,76 & 61,51 & 102,46 & & & \\
\hline \multirow{8}{*}{$\mathrm{Cu}$} & 1,10 & 0,01 & 10,90 & $y=121,94 x /(1+0,73 x)$ & 166,66 & 0,731 \\
\hline & 2,17 & 0,05 & 21,25 & & & \\
\hline & 5,30 & 0,16 & 51,45 & & & \\
\hline & 10,83 & 0,84 & 99,90 & & & \\
\hline & 15,90 & 5,40 & 105,00 & & & \\
\hline & 32,50 & 18,30 & 142,00 & & & \\
\hline & 53,20 & 38,35 & 148,50 & & & \\
\hline & 81,40 & 64,60 & 168,00 & & & \\
\hline \multirow{7}{*}{$\mathrm{Cd}$} & 1,91 & 0,10 & 18,10 & $y=54,62 x /(1+0,14 x)$ & 370,37 & 0,147 \\
\hline & 3,82 & 0,20 & 36,20 & & & \\
\hline & 19,10 & 3,00 & 161,00 & & & \\
\hline & 35,00 & 13,50 & 215,00 & & & \\
\hline & 56,00 & 27,50 & 285,00 & & & \\
\hline & 80,00 & 47,50 & 325,00 & & & \\
\hline & 143,00 & 108,45 & 345,50 & & & \\
\hline
\end{tabular}


Tabela A6. Concentração de inicial (CI), concentração de equilíbrio (Ceq.), quantidade adsorvida, equação de Langmuir, adsorção máxima (b) e constante de afinidade (Kaf) obtidos a partir das isotermas de adsorção de $\mathrm{Zn}, \mathrm{Ni}$, $\mathrm{Cu}$ e $\mathrm{Cd}$, em sistema não-competitivo para o Argissolo Vermelho-Amarelo (PVA-2)

\begin{tabular}{|c|c|c|c|c|c|c|}
\hline \multirow[t]{2}{*}{ Metais } & CI & Ceq & \multirow{2}{*}{$\begin{array}{c}\text { Quantidade } \\
\text { adsorvida }\end{array}$} & \multirow[t]{2}{*}{ Equação de Langmuir } & \multirow{2}{*}{$\frac{\mathrm{b}}{\mathrm{mg} \mathrm{kg}^{-1}}$} & \multirow{2}{*}{$\frac{\mathrm{Kaf}}{\mathrm{L} \mathrm{mg}^{-1}}$} \\
\hline & $\ldots \ldots \ldots \ldots \ldots \ldots$ & 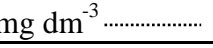 & & & & \\
\hline \multirow{8}{*}{$\mathrm{Zn}$} & 1,30 & 0,00 & 13,00 & $\mathrm{y}=400,0 \mathrm{x} /(1+0,4 \mathrm{x})$ & 1000,00 & 0,400 \\
\hline & 2,50 & 0,04 & 24,60 & & & \\
\hline & 5,10 & 0,14 & 49,60 & & & \\
\hline & 13,00 & 0,24 & 127,60 & & & \\
\hline & 19,00 & 0,44 & 185,60 & & & \\
\hline & 34,00 & 1,94 & 320,60 & & & \\
\hline & 50,00 & 4,94 & 450,60 & & & \\
\hline & 83,33 & 9,44 & 738,90 & & & \\
\hline \multirow{7}{*}{$\mathrm{Ni}$} & 1,97 & 0,09 & 18,82 & $y=274,99 x /(1+0,33 x)$ & 833,33 & 0,330 \\
\hline & 4,78 & 0,26 & 45,21 & & & \\
\hline & 10,27 & 0,22 & 100,54 & & & \\
\hline & 16,25 & 0,39 & 158,63 & & & \\
\hline & 29,90 & 1,31 & 285,91 & & & \\
\hline & 47,86 & 3,47 & 443,88 & & & \\
\hline & 71,76 & 8,59 & 631,66 & & & \\
\hline \multirow{8}{*}{$\mathrm{Cu}$} & 1,10 & 0,03 & 10,70 & $y=357,2 x /(1+0,17 x)$ & 2000,00 & 0,179 \\
\hline & 2,17 & 0,08 & 20,95 & & & \\
\hline & 5,30 & 0,14 & 51,65 & & & \\
\hline & 10,83 & 0,27 & 105,60 & & & \\
\hline & 15,90 & 0,40 & 155,00 & & & \\
\hline & 32,50 & 0,90 & 316,00 & & & \\
\hline & 53,20 & 2,30 & 509,00 & & & \\
\hline & 81,40 & 3,40 & 780,00 & & & \\
\hline \multirow{8}{*}{$\mathrm{Cd}$} & 1,91 & 0,00 & 19,10 & $y=909,12 x /(1+1,36 x)$ & 666,66 & 1.367 \\
\hline & 3,82 & 0,00 & 38,20 & & & \\
\hline & 9,55 & 0,35 & 92,00 & & & \\
\hline & 19,10 & 0,35 & 187,50 & & & \\
\hline & 35,00 & 0,65 & 343,50 & & & \\
\hline & 56,00 & 1,45 & 545,50 & & & \\
\hline & 80,00 & 12,50 & 675,00 & & & \\
\hline & 143,00 & 75,50 & 675,00 & & & \\
\hline
\end{tabular}


Tabela A7. Concentração de inicial (CI), concentração de equilíbrio (Ceq.), quantidade adsorvida, equação de Langmuir, adsorção máxima (b) e constante de afinidade (Kaf) obtidos a partir das isotermas de adsorção de $\mathrm{Zn}, \mathrm{Ni}$, Cu e Cd, em sistema não-competitivo para o Argissolo Vermelho-Amarelo (PVA-3)

\begin{tabular}{|c|c|c|c|c|c|c|}
\hline \multirow[t]{2}{*}{ Metais } & CI & Ceq & \multirow{2}{*}{$\begin{array}{c}\begin{array}{c}\text { Quantidade } \\
\text { adsorvida }\end{array} \\
\mathrm{mg} \mathrm{kg}^{-1} \\
\end{array}$} & \multirow[t]{2}{*}{ Equação de Langmuir } & \multirow{2}{*}{$\frac{\mathrm{b}}{\mathrm{mg} \mathrm{kg}^{-1}}$} & \multirow{2}{*}{$\frac{\text { Kaf }}{\mathrm{L} \mathrm{mg}^{-1}}$} \\
\hline & ............ $\mathrm{mg} \mathrm{dm}$ & $-3 \ldots \ldots \ldots \ldots \ldots \ldots$ & & & & \\
\hline \multirow{8}{*}{$\mathrm{Zn}$} & 1,30 & 0,01 & 12,90 & \multirow[t]{8}{*}{$y=454,54 x /(1+0,5 x)$} & 909,09 & \multirow[t]{8}{*}{0,500} \\
\hline & 2,50 & 0,05 & 24,50 & & & \\
\hline & 5,10 & 0,15 & 49,50 & & & \\
\hline & 13,00 & 0,30 & 127,00 & & & \\
\hline & 19,00 & 0,45 & 185,50 & & & \\
\hline & 34,00 & 1,50 & 325,00 & & & \\
\hline & 50,00 & 3,00 & 470,00 & & & \\
\hline & 105,00 & 7,60 & 974,00 & & & \\
\hline \multirow{8}{*}{$\mathrm{Ni}$} & 1,03 & 0,09 & 9,42 & \multirow[t]{8}{*}{$y=4356,36 x /(1+0,39 x)$} & 909,09 & \multirow[t]{8}{*}{0,392} \\
\hline & 1,97 & 0,09 & 18,82 & & & \\
\hline & 4,78 & 0,17 & 46,06 & & & \\
\hline & 10,27 & 0,09 & 101,82 & & & \\
\hline & 16,25 & 0,34 & 159,06 & & & \\
\hline & 29,90 & 0,88 & 290,17 & & & \\
\hline & 47,86 & 1,77 & 460,95 & & & \\
\hline & 71,76 & 6,89 & 648,74 & & & \\
\hline \multirow{6}{*}{$\mathrm{Cu}$} & 1,10 & 0,00 & 11,00 & \multirow[t]{6}{*}{$y=666,66 x /(1+0,40 x)$} & \multirow[t]{6}{*}{1666,67} & \multirow[t]{6}{*}{0,460} \\
\hline & 2,17 & 0,04 & 21,35 & & & \\
\hline & 5,30 & 0,09 & 52,15 & & & \\
\hline & 10,83 & 0,19 & 106,45 & & & \\
\hline & 53,20 & 1,40 & 518,00 & & & \\
\hline & 81,40 & 2,10 & 793,00 & & & \\
\hline \multirow{8}{*}{$\mathrm{Cd}$} & 1,91 & 0,01 & 19,00 & \multirow[t]{8}{*}{$y=2000,0 x /(1+2,60 x)$} & \multirow[t]{8}{*}{769,23} & \multirow[t]{8}{*}{2,600} \\
\hline & 3,82 & 0,02 & 38,00 & & & \\
\hline & 9,55 & 0,03 & 95,20 & & & \\
\hline & 19,10 & 0,15 & 189,50 & & & \\
\hline & 35,00 & 0,25 & 347,50 & & & \\
\hline & 56,00 & 1,65 & 543,50 & & & \\
\hline & 80,00 & 3,90 & 761,00 & & & \\
\hline & 143,00 & 64,10 & 789,00 & & & \\
\hline
\end{tabular}


Tabela A8. Concentração de inicial (CI), concentração de equilíbrio (Ceq.), quantidade adsorvida, equação de Langmuir, adsorção máxima (b) e constante de afinidade (Kaf) obtidos a partir das isotermas de adsorção de $\mathrm{Zn}, \mathrm{Ni}$, Cu e Cd, em sistema não-competitivo para o Neossolo Quartzarênico (RQ)

\begin{tabular}{|c|c|c|c|c|c|c|}
\hline \multirow[t]{2}{*}{ Metais } & CI & Ceq & \multirow{2}{*}{$\begin{array}{c}\begin{array}{c}\text { Quantidade } \\
\text { adsorvida }\end{array} \\
\mathrm{mg} \mathrm{kg}^{-1} \\
\end{array}$} & \multirow[t]{2}{*}{ Equação de Langmuir } & \multirow{2}{*}{$\frac{\mathrm{b}}{\mathrm{mg} \mathrm{kg}^{-1}}$} & \multirow{2}{*}{$\begin{array}{c}\text { Kaf } \\
\mathrm{L} \mathrm{mg}^{-1} \\
\end{array}$} \\
\hline & 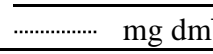 & $1^{-3} \ldots \ldots \ldots \ldots \ldots \ldots$ & & & & \\
\hline \multirow{7}{*}{$\mathrm{Zn}$} & 1,30 & 0,27 & 10,30 & $y=4,74 x /(1+0,05 x)$ & 83,33 & 0,057 \\
\hline & 2,50 & 0,72 & 17,80 & & & \\
\hline & 5,10 & 2,92 & 21,80 & & & \\
\hline & 16,00 & 13,77 & 22,30 & & & \\
\hline & 32,50 & 29,32 & 31,80 & & & \\
\hline & 55,60 & 51,67 & 39,30 & & & \\
\hline & 83,33 & 76,77 & 65,60 & & & \\
\hline \multirow{7}{*}{$\mathrm{Ni}$} & 1,03 & 0,30 & 7,28 & $y=33,61 x /(1+0,43 x)$ & 76,92 & 0,437 \\
\hline & 1,97 & 0,56 & 14,12 & & & \\
\hline & 4,78 & 2,18 & 26,01 & & & \\
\hline & 10,27 & 4,06 & 62,13 & & & \\
\hline & 16,25 & 9,48 & 67,70 & & & \\
\hline & 29,90 & 22,65 & 72,52 & & & \\
\hline & 71,76 & 65,78 & 59,78 & & & \\
\hline \multirow{8}{*}{$\mathrm{Cu}$} & 1,10 & 0,06 & 10,40 & $y=23,50 x /(1+0,22 x)$ & 106,38 & 0,221 \\
\hline & 2,17 & 0,20 & 19,75 & & & \\
\hline & 5,30 & 1,01 & 42,95 & & & \\
\hline & 10,83 & 3,09 & 77,45 & & & \\
\hline & 15,90 & 9,90 & 60,00 & & & \\
\hline & 32,50 & 24,05 & 84,50 & & & \\
\hline & 53,20 & 44,75 & 84,50 & & & \\
\hline & 81,40 & 70,00 & 114,00 & & & \\
\hline \multirow{8}{*}{$\mathrm{Cd}$} & 1,91 & 0,40 & 15,10 & $y=17,19 x /(1+0,04 x)$ & 384,61 & 0,044 \\
\hline & 3,82 & 1,15 & 26,70 & & & \\
\hline & 9,55 & 9,50 & 0,50 & & & \\
\hline & 19,10 & 12,00 & 71,00 & & & \\
\hline & 35,00 & 21,00 & 140,00 & & & \\
\hline & 56,00 & 37,50 & 185,00 & & & \\
\hline & 80,00 & 50,00 & 300,00 & & & \\
\hline & 143,00 & 109,50 & 335,00 & & & \\
\hline
\end{tabular}


Tabela A9. Concentração de inicial (CI), concentração de equilíbrio (Ceq.), quantidade adsorvida, equação de Langmuir, adsorção máxima (b) e constante de afinidade (Kaf) obtidos a partir das isotermas de adsorção de $\mathrm{Zn}, \mathrm{Ni}$, Cu e Cd, em sistema não-competitivo para o Nitossolo Vermelho eutroférrico (NVef)

\begin{tabular}{|c|c|c|c|c|c|c|}
\hline \multirow[t]{2}{*}{ Metais } & CI & Ceq & \multirow{2}{*}{$\begin{array}{c}\begin{array}{c}\text { Quantidade } \\
\text { adsorvida }\end{array} \\
\mathrm{mg} \mathrm{kg}^{-1}\end{array}$} & \multirow[t]{2}{*}{ Equação de Langmuir } & \multirow{2}{*}{$\frac{\mathrm{b}}{\mathrm{mg} \mathrm{kg}^{-1}}$} & \multirow{2}{*}{$\frac{\mathrm{Kaf}}{\mathrm{L} \mathrm{mg}^{-1}}$} \\
\hline & $\ldots \ldots \cdots \cdots \cdots \cdots \mathrm{mg} \mathrm{dm}^{-3}$ & ${ }^{3 \ldots \ldots \ldots \ldots \ldots \ldots \ldots}$ & & & & \\
\hline \multirow{8}{*}{$\mathrm{Zn}$} & 1,30 & 0,00 & 13,00 & $y=591,66 x /(1+0,71 x)$ & 833,33 & 0,710 \\
\hline & 2,50 & 0,00 & 25,00 & & & \\
\hline & 5,10 & 0,10 & 50,00 & & & \\
\hline & 13,00 & 0,20 & 128,00 & & & \\
\hline & 19,00 & 0,30 & 187,00 & & & \\
\hline & 34,00 & 1,00 & 330,00 & & & \\
\hline & 50,00 & 4,00 & 460,00 & & & \\
\hline & 105,00 & 7,50 & 975,00 & & & \\
\hline \multirow{8}{*}{$\mathrm{Ni}$} & 1,03 & 0,09 & 9,42 & $y=833,33 x /(1+x)$ & 833,33 & 1,000 \\
\hline & 1,97 & 0,09 & 18,82 & & & \\
\hline & 4,78 & 0,09 & 46,92 & & & \\
\hline & 10,27 & 0,09 & 101,82 & & & \\
\hline & 16,25 & 0,39 & 158,63 & & & \\
\hline & 29,90 & 1,74 & 281,64 & & & \\
\hline & 47,86 & 1,77 & 460,95 & & & \\
\hline & 71,76 & 3,47 & 682,88 & & & \\
\hline \multirow{8}{*}{$\mathrm{Cu}$} & 1,10 & 0,00 & 11,00 & $y=1428,62 x /(1+1,14 x)$ & 1250,00 & 1,142 \\
\hline & 2,17 & 0,02 & 21,55 & & & \\
\hline & 5,30 & 0,04 & 52,65 & & & \\
\hline & 10,83 & 0,08 & 107,55 & & & \\
\hline & 15,90 & 0,10 & 158,00 & & & \\
\hline & 32,50 & 0,15 & 323,50 & & & \\
\hline & 53,20 & 0,85 & 523,50 & & & \\
\hline & 81,40 & 1,50 & 799,00 & & & \\
\hline \multirow{8}{*}{$\mathrm{Cd}$} & 1,91 & 0,01 & 19,00 & $y=1428,53 x /(1+1,85 x)$ & 769,23 & 1,850 \\
\hline & 3,82 & 0,02 & 38,00 & & & \\
\hline & 9,55 & 0,10 & 94,50 & & & \\
\hline & 19,10 & 0,30 & 188,00 & & & \\
\hline & 35,00 & 0,40 & 346,00 & & & \\
\hline & 56,00 & 2,05 & 539,50 & & & \\
\hline & 80,00 & 4,35 & 756,50 & & & \\
\hline & 143,00 & 66,40 & 766,00 & & & \\
\hline
\end{tabular}


Tabela A10. Concentração de inicial (CI), concentração de equilíbrio (Ceq.), quantidade adsorvida, equação de Langmuir, adsorção máxima (b) e constante de afinidade (Kaf) obtidos a partir das isotermas de adsorção de $\mathrm{Zn}, \mathrm{Ni}$, Cu e Cd, em sistema não-competitivo para o Gleissolo Melânico (GM)

\begin{tabular}{|c|c|c|c|c|c|c|}
\hline \multirow[t]{2}{*}{ Metais } & CI & Ceq & \multirow{2}{*}{$\begin{array}{c}\text { Quantidade } \\
\text { adsorvida }\end{array}$} & \multirow[t]{2}{*}{ Equação de Langmuir } & \multirow{2}{*}{$\frac{\mathrm{b}}{\mathrm{mg} \mathrm{kg}}$} & \multirow{2}{*}{$\frac{\mathrm{Kaf}}{\mathrm{L} \mathrm{mg}^{-1}}$} \\
\hline & ............... m & $-3 \ldots \ldots \ldots \ldots \ldots \ldots$ & & & & \\
\hline \multirow{8}{*}{$\mathrm{Zn}$} & 1,30 & 0,10 & 12,00 & \multirow[t]{8}{*}{$y=82,60 x /(1+0,19 x)$} & \multirow[t]{8}{*}{434,78} & \multirow[t]{8}{*}{0,193} \\
\hline & 2,50 & 0,10 & 24,00 & & & \\
\hline & 5,10 & 0,70 & 44,00 & & & \\
\hline & 13,00 & 1,70 & 113,00 & & & \\
\hline & 19,00 & 2,70 & 163,00 & & & \\
\hline & 34,00 & 8,50 & 255,00 & & & \\
\hline & 50,00 & 22,50 & 275,00 & & & \\
\hline & 105,00 & 41,00 & 640,00 & & & \\
\hline \multirow{8}{*}{$\mathrm{Ni}$} & 1,03 & 0,09 & 9,42 & \multirow[t]{8}{*}{$y=63,33 x /(1+0,15 x)$} & \multirow[t]{8}{*}{416,66} & \multirow[t]{8}{*}{0,152} \\
\hline & 1,97 & 0,17 & 17,96 & & & \\
\hline & 4,78 & 0,98 & 37,96 & & & \\
\hline & 10,27 & 1,58 & 86,88 & & & \\
\hline & 16,25 & 2,52 & 137,29 & & & \\
\hline & 29,90 & 10,27 & 196,28 & & & \\
\hline & 47,86 & 18,84 & 290,24 & & & \\
\hline & 71,76 & 35,05 & 367,06 & & & \\
\hline \multirow{8}{*}{$\mathrm{Cu}$} & 1,10 & 0,00 & 11,00 & \multirow[t]{8}{*}{$y=500,0 x /(1+0,8 x)$} & \multirow[t]{8}{*}{625,00} & \multirow[t]{8}{*}{0,800} \\
\hline & 2,17 & 0,01 & 21,60 & & & \\
\hline & 5,30 & 0,05 & 52,50 & & & \\
\hline & 10,83 & 0,13 & 107,05 & & & \\
\hline & 15,90 & 0,60 & 153,00 & & & \\
\hline & 32,50 & 2,15 & 303,50 & & & \\
\hline & 53,20 & 8,80 & 444,00 & & & \\
\hline & 81,40 & 20,70 & 607,00 & & & \\
\hline \multirow{8}{*}{$\mathrm{Cd}$} & 1,91 & 0,01 & 19,00 & \multirow[t]{8}{*}{$y=153,85 x /(1+0,32 x)$} & \multirow[t]{8}{*}{476,19} & \multirow[t]{8}{*}{0,323} \\
\hline & 3,82 & 0,20 & 36,20 & & & \\
\hline & 9,55 & 1,30 & 82,50 & & & \\
\hline & 19,10 & 3,45 & 156,50 & & & \\
\hline & 35,00 & 4,30 & 307,00 & & & \\
\hline & 56,00 & 12,50 & 435,00 & & & \\
\hline & 80,00 & 35,00 & 450,00 & & & \\
\hline & 143,00 & 97,50 & 455,00 & & & \\
\hline
\end{tabular}


Tabela A11. Concentração de inicial (CI), concentração de equilíbrio (Ceq.), quantidade adsorvida, equação de Langmuir, adsorção máxima (b) e constante de afinidade (Kaf) obtidos a partir das isotermas de adsorção de $\mathrm{Zn}, \mathrm{Ni}$, $\mathrm{Cu}$ e Cd, em sistema não-competitivo para o Cambissolo Háplico (CX)

\begin{tabular}{|c|c|c|c|c|c|c|}
\hline \multirow[t]{2}{*}{ Metais } & CI & Ceq & \multirow{2}{*}{$\begin{array}{c}\begin{array}{c}\text { Quantidade } \\
\text { adsorvida }\end{array} \\
\mathrm{mg} \mathrm{kg}^{-1}\end{array}$} & \multirow{2}{*}{ Equação de Langmuir } & \multirow{2}{*}{$\frac{\mathrm{b}}{\mathrm{mg} \mathrm{kg}^{-1}}$} & \multirow{2}{*}{$\frac{\mathrm{Kaf}}{\mathrm{L} \mathrm{mg}^{-1}}$} \\
\hline & $\ldots \ldots \ldots \ldots \ldots \ldots . . . \quad \mathrm{mg}$ & $\mathrm{n}^{-3} \ldots \ldots \ldots \ldots \ldots \ldots$ & & & & \\
\hline \multirow{8}{*}{$\mathrm{Zn}$} & 1,30 & 0,27 & 10,30 & $y=9,88 x /(1+0,016 x)$ & 588,23 & 0,016 \\
\hline & 2,50 & 0,37 & 21,30 & & & \\
\hline & 5,10 & 1,92 & 31,80 & & & \\
\hline & 13,00 & 3,72 & 92,80 & & & \\
\hline & 19,00 & 5,92 & 130,80 & & & \\
\hline & 34,00 & 18,42 & 155,80 & & & \\
\hline & 50,00 & 35,97 & 140,30 & & & \\
\hline & 105,00 & 61,37 & 436,30 & & & \\
\hline \multirow{8}{*}{$\mathrm{Ni}$} & 1,03 & 0,09 & 9,42 & $y=28,95 x /(1+0,13 x)$ & 208,33 & 0,14 \\
\hline & 1,97 & 0,52 & 14,55 & & & \\
\hline & 4,78 & 1,54 & 32,41 & & & \\
\hline & 10,27 & 3,50 & 67,68 & & & \\
\hline & 16,25 & 5,00 & 112,54 & & & \\
\hline & 29,90 & 19,23 & 106,66 & & & \\
\hline & 47,86 & 30,79 & 170,74 & & & \\
\hline & 71,76 & 52,13 & 196,35 & & & \\
\hline \multirow{8}{*}{$\mathrm{Cu}$} & 1,10 & 0,01 & 10,90 & $y=104,16 x /(1+0,26 x)$ & 400,00 & 0,260 \\
\hline & 2,17 & 0,05 & 21,20 & & & \\
\hline & 5,30 & 0,25 & 50,50 & & & \\
\hline & 10,83 & 1,05 & 97,80 & & & \\
\hline & 15,90 & 3,40 & 125,00 & & & \\
\hline & 32,50 & 12,05 & 204,50 & & & \\
\hline & 53,20 & 27,95 & 252,50 & & & \\
\hline & 81,40 & 23,70 & 577,00 & & & \\
\hline \multirow{8}{*}{$\mathrm{Cd}$} & 1,91 & 0,40 & 15,10 & $y=24,2 x /(1+0,06 x)$ & 454,55 & 0,166 \\
\hline & 3,82 & 0,80 & 30,20 & & & \\
\hline & 9,55 & 4,60 & 49,50 & & & \\
\hline & 19,10 & 8,50 & 106,00 & & & \\
\hline & 35,00 & 11,50 & 235,00 & & & \\
\hline & 56,00 & 31,50 & 245,00 & & & \\
\hline & 80,00 & 46,25 & 337,50 & & & \\
\hline & 143,00 & 108,50 & 345,00 & & & \\
\hline
\end{tabular}


Tabela A12. Concentração de inicial (CI), concentração de equilíbrio (Ceq.), quantidade adsorvida, equação de Langmuir, adsorção máxima (b) e constante de afinidade (Kaf) obtidos a partir das isotermas de adsorção de $\mathrm{Zn}, \mathrm{Ni}$, Cu e Cd, em sistema não-competitivo para o Organossolo Háplico (OX)

\begin{tabular}{|c|c|c|c|c|c|c|}
\hline \multirow{2}{*}{ Metais } & CI & Ceq & \multirow{2}{*}{$\begin{array}{c}\begin{array}{c}\text { Quantidade } \\
\text { adsorvida }\end{array} \\
\mathrm{mg} \mathrm{kg}^{-1}\end{array}$} & \multirow{2}{*}{ Equação de Langmuir } & \multirow{2}{*}{$\frac{\mathrm{b}}{\mathrm{mg} \mathrm{kg}}$} & \multirow{2}{*}{$\frac{\mathrm{Kaf}}{\mathrm{L} \mathrm{mg}^{-1}}$} \\
\hline & ............... m & $\mathrm{n}^{-3} \ldots \ldots \ldots \ldots \ldots \ldots$ & & & & \\
\hline \multirow{8}{*}{$\mathrm{Zn}$} & 1,30 & 0,16 & 11,40 & $y=42,85 x /(1+0,09 x)$ & 476,19 & 0,090 \\
\hline & 2,50 & 0,31 & 21,90 & & & \\
\hline & 5,10 & 1,21 & 38,90 & & & \\
\hline & 13,00 & 3,31 & 96,90 & & & \\
\hline & 19,00 & 4,21 & 147,90 & & & \\
\hline & 34,00 & 11,41 & 225,90 & & & \\
\hline & 50,00 & 26,41 & 235,90 & & & \\
\hline & 105,00 & 59,91 & 450,90 & & & \\
\hline \multirow{8}{*}{$\mathrm{Ni}$} & 1,03 & 0,09 & 9,42 & $y=53,19 x /(1+0,18 x)$ & 384,61 & 0,116 \\
\hline & 1,97 & 0,34 & 16,26 & & & \\
\hline & 4,78 & 0,98 & 37,96 & & & \\
\hline & 10,27 & 2,35 & 79,20 & & & \\
\hline & 16,25 & 3,42 & 128,33 & & & \\
\hline & 29,90 & 13,26 & 166,41 & & & \\
\hline & 47,86 & 22,25 & 256,09 & & & \\
\hline & 71,76 & 36,76 & 349,99 & & & \\
\hline \multirow{8}{*}{$\mathrm{Cu}$} & 1,10 & 0,02 & 10,80 & $y=194,11 x /(1+0,33 x)$ & 588,23 & 0,330 \\
\hline & 2,17 & 0,08 & 20,90 & & & \\
\hline & 5,30 & 0,20 & 51,00 & & & \\
\hline & 10,83 & 0,62 & 102,10 & & & \\
\hline & 15,90 & 1,20 & 147,00 & & & \\
\hline & 32,50 & 4,35 & 281,50 & & & \\
\hline & 53,20 & 13,80 & 394,00 & & & \\
\hline & 81,40 & 23,70 & 577,00 & & & \\
\hline \multirow{8}{*}{$\mathrm{Cd}$} & 1,91 & 0,15 & 17,60 & $y=75,77 x /(1+0,16 x)$ & 454,54 & 0,166 \\
\hline & 3,82 & 0,45 & 33,70 & & & \\
\hline & 9,55 & 2,15 & 74,00 & & & \\
\hline & 19,10 & 5,10 & 140,00 & & & \\
\hline & 35,00 & 6,00 & 290,00 & & & \\
\hline & 56,00 & 17,00 & 390,00 & & & \\
\hline & 80,00 & 38,75 & 412,50 & & & \\
\hline & 143,00 & 101,41 & 415,90 & & & \\
\hline
\end{tabular}


Tabela A13. Concentração de inicial (CI), concentração de equilíbrio (Ceq.), quantidade adsorvida, equação de Langmuir, adsorção máxima (b) e constante de afinidade (Kaf) obtidos a partir das isotermas de adsorção de Zn, Ni, Cu e Cd, em sistema não-competitivo para o Luvissolo Crômico (TC)

\begin{tabular}{|c|c|c|c|c|c|c|}
\hline \multirow[t]{2}{*}{ Metais } & CI & Ceq & \multirow{2}{*}{$\begin{array}{c}\begin{array}{c}\text { Quantidade } \\
\text { adsorvida }\end{array} \\
\mathrm{mg} \mathrm{kg}^{-1}\end{array}$} & \multirow[t]{2}{*}{ Equação de Langmuir } & \multirow{2}{*}{$\frac{\mathrm{b}}{\mathrm{mg} \mathrm{kg}^{-1}}$} & \multirow{2}{*}{$\frac{\mathrm{Kaf}}{\mathrm{L} \mathrm{mg}^{-1}}$} \\
\hline & $\ldots \ldots \ldots \ldots \ldots$ & $\mathrm{n}^{-3} \ldots \ldots \ldots \ldots \ldots \ldots \ldots$ & & & & \\
\hline \multirow{8}{*}{$\mathrm{Zn}$} & 1,30 & 0,07 & 12,30 & \multirow[t]{8}{*}{$y=79,99 x /(1+0,12 x)$} & 666,66 & \multirow[t]{8}{*}{0,120} \\
\hline & 2,50 & 0,17 & 23,30 & & & \\
\hline & 5,10 & 0,52 & 45,80 & & & \\
\hline & 13,00 & 1,62 & 113,80 & & & \\
\hline & 19,00 & 3,37 & 156,30 & & & \\
\hline & 34,00 & 9,97 & 240,30 & & & \\
\hline & 50,00 & 30,27 & 197,30 & & & \\
\hline & 105,00 & 44,97 & 600,30 & & & \\
\hline \multirow{8}{*}{$\mathrm{Ni}$} & 1,03 & 0,09 & 9,42 & \multirow[t]{8}{*}{$y=73,84 x /(1+0,53 x)$} & 256,41 & \multirow[t]{8}{*}{0,288} \\
\hline & 1,97 & 0,13 & 18,39 & & & \\
\hline & 4,78 & 0,52 & 42,65 & & & \\
\hline & 10,27 & 1,58 & 86,88 & & & \\
\hline & 16,25 & 2,61 & 136,44 & & & \\
\hline & 29,90 & 13,69 & 162,14 & & & \\
\hline & 47,86 & 28,23 & 196,35 & & & \\
\hline & 71,76 & 45,30 & 264,63 & & & \\
\hline \multirow{8}{*}{$\mathrm{Cu}$} & 1,10 & 0,01 & 10,95 & \multirow[t]{8}{*}{$y=182,75 x /(1+0,53 x)$} & 344,82 & \multirow[t]{8}{*}{0,537} \\
\hline & 2,17 & 0,05 & 21,20 & & & \\
\hline & 5,30 & 0,11 & 51,95 & & & \\
\hline & 10,83 & 0,47 & 103,60 & & & \\
\hline & 15,90 & 1,80 & 141,00 & & & \\
\hline & 32,50 & 9,75 & 227,50 & & & \\
\hline & 53,20 & 24,65 & 285,50 & & & \\
\hline & 81,40 & 46,50 & 349,00 & & & \\
\hline \multirow{8}{*}{$\mathrm{Cd}$} & 1,91 & 0,10 & 18,10 & \multirow[t]{8}{*}{$\mathrm{y}=112,08 \mathrm{x} /(1+0,26 \mathrm{x})$} & 416,67 & \multirow[t]{8}{*}{0,269} \\
\hline & 3,82 & 0,20 & 36,20 & & & \\
\hline & 9,55 & 1,50 & 80,50 & & & \\
\hline & 19,10 & 4,45 & 146,50 & & & \\
\hline & 35,00 & 6,00 & 290,00 & & & \\
\hline & 56,00 & 16,50 & 395,00 & & & \\
\hline & 80,00 & 42,50 & 375,00 & & & \\
\hline & 143,00 & 103,50 & 395,00 & & & \\
\hline
\end{tabular}


Tabela A14. Concentração de inicial (CI), concentração de equilíbrio (Ceq), quantidade adsorvida, equação de Langmuir, adsorção máxima (b) e constante de afinidade (Kaf) obtidos a partir das isotermas de adsorção de $\mathrm{Zn}, \mathrm{Ni}$, Cu e Cd, em sistema não-competitivo para o Chernossolo Argilúvico (MT)

\begin{tabular}{|c|c|c|c|c|c|c|}
\hline \multirow[t]{2}{*}{ Metais } & CI & Ceq & \multirow{2}{*}{$\begin{array}{c}\begin{array}{c}\text { Quantidade } \\
\text { adsorvida }\end{array} \\
\mathrm{mg} \mathrm{kg}^{-1} \\
\end{array}$} & \multirow{2}{*}{ Equação de Langmuir } & \multirow{2}{*}{$\frac{\mathrm{b}}{\mathrm{mg} \mathrm{kg}^{-1}}$} & \multirow{2}{*}{$\frac{\text { Kaf }}{\mathrm{L} \mathrm{mg}^{-1}}$} \\
\hline & $\ldots \ldots \ldots \ldots \ldots . . \quad \mathrm{mg} \mathrm{dm}$ & . & & & & \\
\hline \multirow{8}{*}{$\mathrm{Zn}$} & 1,30 & 0,00 & 13,00 & $y=666,7 x /(1+0,66 x)$ & 1000,00 & 0,660 \\
\hline & 2,50 & 0,00 & 25,00 & & & \\
\hline & 5,10 & 0,10 & 50,00 & & & \\
\hline & 13,00 & 0,20 & 128,00 & & & \\
\hline & 19,00 & 0,30 & 187,00 & & & \\
\hline & 34,00 & 1,00 & 330,00 & & & \\
\hline & 50,00 & 3,00 & 470,00 & & & \\
\hline & 105,00 & 5,00 & 1000,00 & & & \\
\hline \multirow{8}{*}{$\mathrm{Ni}$} & 1,03 & 0,09 & 9,42 & $y=588,23 x /(1+0,82 x)$ & 714,286 & 0,82 \\
\hline & 1,97 & 0,09 & 18,82 & & & \\
\hline & 4,78 & 0,09 & 46,92 & & & \\
\hline & 10,27 & 0,13 & 101,39 & & & \\
\hline & 16,25 & 0,34 & 159,06 & & & \\
\hline & 29,90 & 0,88 & 290,17 & & & \\
\hline & 47,86 & 3,47 & 443,88 & & & \\
\hline & 71,76 & 3,47 & 682,88 & & & \\
\hline \multirow{8}{*}{$\mathrm{Cu}$} & 1,10 & 0,00 & 11,00 & $y=1666,66 x /(1+1,5 x)$ & 1111,11 & 1,500 \\
\hline & 2,17 & 0,00 & 21,70 & & & \\
\hline & 5,30 & 0,01 & 52,95 & & & \\
\hline & 10,83 & 0,02 & 108,15 & & & \\
\hline & 15,90 & 0,10 & 158,00 & & & \\
\hline & 32,50 & 0,10 & 324,00 & & & \\
\hline & 53,20 & 0,85 & 523,50 & & & \\
\hline & 81,40 & 1,50 & 799,00 & & & \\
\hline \multirow{7}{*}{$\mathrm{Cd}$} & 1,91 & 0,01 & 19,00 & $y=1428,0 x /(1+1,85 x)$ & 769,23 & 1850,000 \\
\hline & 3,82 & 0,02 & 38,05 & & & \\
\hline & 9,55 & 0,15 & 94,00 & & & \\
\hline & 19,10 & 0,25 & 188,50 & & & \\
\hline & 35,00 & 0,35 & 346,50 & & & \\
\hline & 56,00 & 1,75 & 542,50 & & & \\
\hline & 80,00 & 4,00 & 760,00 & & & \\
\hline
\end{tabular}


Tabela A15. Concentração de inicial (CI), concentração de equilíbrio (Ceq.), quantidade adsorvida, equação de Langmuir, adsorção máxima (b) e constante de afinidade (Kaf) obtidos a partir das isotermas de adsorção de Zn, Ni, Cu e Cd, em sistema competitivo para o Latossolo Vermelho (LV)

\begin{tabular}{|c|c|c|c|c|c|c|}
\hline \multirow[t]{2}{*}{ Metais } & CI & Ceq & \multirow{2}{*}{$\begin{array}{c}\begin{array}{c}\text { Quantidade } \\
\text { adsorvida }\end{array} \\
\mathrm{mg} \mathrm{kg}^{-1}\end{array}$} & \multirow[t]{2}{*}{ Equação de Langmuir } & \multirow{2}{*}{$\frac{\mathrm{b}}{\mathrm{mg} \mathrm{kg}^{-1}}$} & \multirow{2}{*}{$\begin{array}{c}\text { Kaf } \\
\mathrm{L} \mathrm{mg}^{-1}\end{array}$} \\
\hline & \multicolumn{2}{|c|}{$\ldots \cdots \cdots \cdots \cdots \cdots \mathrm{mg} \mathrm{dm}^{-3} \ldots$} & & & & \\
\hline \multirow{7}{*}{$\mathrm{Zn}$} & 1,22 & 0,12 & 11,00 & \multirow[t]{7}{*}{$y=19,23 x /(1+0,13 x)$} & 144,93 & \multirow[t]{7}{*}{0,133} \\
\hline & 2,10 & 0,30 & 18,00 & & & \\
\hline & 4,81 & 1,60 & 32,10 & & & \\
\hline & 12,30 & 6,20 & 61,00 & & & \\
\hline & 35,00 & 25,80 & 92,00 & & & \\
\hline & 47,20 & 38,55 & 86,50 & & & \\
\hline & 83,33 & 67,05 & 162,80 & & & \\
\hline \multirow{8}{*}{$\mathrm{Ni}$} & 1,04 & 0,00 & 10,44 & \multirow[t]{8}{*}{$y=47,82 x /(1+0,55 x)$} & 86,95 & \multirow[t]{8}{*}{0,550} \\
\hline & 1,30 & 0,00 & 12,99 & & & \\
\hline & 4,35 & 1,17 & 31,77 & & & \\
\hline & 9,42 & 5,23 & 41,93 & & & \\
\hline & 15,52 & 7,77 & 77,48 & & & \\
\hline & 28,72 & 20,97 & 77,48 & & & \\
\hline & 43,23 & 34,97 & 82,55 & & & \\
\hline & 75,00 & 65,46 & 95,40 & & & \\
\hline \multirow{8}{*}{$\mathrm{Cu}$} & 1,00 & 0,01 & 9,90 & \multirow[t]{8}{*}{$y=200,0 x /(1+0,48 x)$} & 416,67 & \multirow[t]{8}{*}{0,480} \\
\hline & 2,00 & 0,01 & 19,90 & & & \\
\hline & 5,40 & 0,01 & 53,90 & & & \\
\hline & 11,00 & 1,00 & 100,00 & & & \\
\hline & 17,00 & 2,00 & 150,00 & & & \\
\hline & 35,00 & 8,00 & 270,00 & & & \\
\hline & 54,00 & 20,00 & 340,00 & & & \\
\hline & 80,00 & 38,00 & 420,00 & & & \\
\hline \multirow{8}{*}{$\mathrm{Cd}$} & 1,87 & 0,16 & 17,10 & \multirow[t]{8}{*}{$y=34,01 x /(1+00,13 x)$} & 250,00 & \multirow[t]{8}{*}{0,136} \\
\hline & 3,70 & 0,38 & 33,20 & & & \\
\hline & 9,10 & 2,35 & 67,50 & & & \\
\hline & 18,40 & 7,55 & 108,50 & & & \\
\hline & 43,30 & 25,00 & 183,00 & & & \\
\hline & 54,10 & 35,50 & 186,00 & & & \\
\hline & 79,60 & 59,80 & 198,00 & & & \\
\hline & 136,00 & 11,10 & 1249,00 & & & \\
\hline
\end{tabular}


Tabela A16. Concentração de inicial (CI), concentração de equilíbrio (Ceq.), quantidade adsorvida, equação de Langmuir, adsorção máxima (b) e constante de afinidade (Kaf) obtidos a partir das isotermas de adsorção de $\mathrm{Zn}, \mathrm{Ni}$, $\mathrm{Cu}$ e Cd, em sistema competitivo para o Latossolo Vermelho Eutroférrico (LVef)

\begin{tabular}{|c|c|c|c|c|c|c|}
\hline \multirow[t]{2}{*}{ Metais } & CI & Ceq & \multirow{2}{*}{$\begin{array}{c}\begin{array}{c}\text { Quantidade } \\
\text { adsorvida }\end{array} \\
\mathrm{mg} \mathrm{kg}^{-1}\end{array}$} & \multirow[t]{2}{*}{ Equação de Langmuir } & \multirow{2}{*}{$\frac{\mathrm{b}}{\mathrm{mg} \mathrm{kg}^{-1}}$} & \multirow{2}{*}{$\frac{\text { Kaf }}{\mathrm{L} \mathrm{mg}^{-1}}$} \\
\hline & \multicolumn{2}{|c|}{$\ldots \ldots \ldots \ldots \ldots \ldots \mathrm{mg} \mathrm{dm}^{-3} \ldots$} & & & & \\
\hline \multirow{7}{*}{$\mathrm{Zn}$} & 1,22 & 0,08 & 11,40 & $y=714,28 x /(1+0,5 x)$ & 1428,57 & 0,500 \\
\hline & 2,10 & 0,09 & 20,10 & & & \\
\hline & 4,81 & 0,10 & 47,10 & & & \\
\hline & 12,30 & 0,15 & 121,50 & & & \\
\hline & 35,00 & 0,40 & 346,00 & & & \\
\hline & 47,20 & 1,20 & 460,00 & & & \\
\hline & 83,33 & 2,50 & 808,30 & & & \\
\hline \multirow{8}{*}{$\mathrm{Ni}$} & 1,04 & 0,01 & 10,34 & $y=124,99 x /(1+0,27 x)$ & 454,54 & 0,275 \\
\hline & 1,30 & 0,02 & 12,84 & & & \\
\hline & 4,35 & 1,16 & 31,86 & & & \\
\hline & 9,42 & 1,19 & 82,34 & & & \\
\hline & 15,52 & 1,20 & 143,19 & & & \\
\hline & 28,72 & 1,30 & 274,23 & & & \\
\hline & 43,23 & 2,47 & 407,58 & & & \\
\hline & 75,00 & 34,00 & 410,00 & & & \\
\hline \multirow{8}{*}{$\mathrm{Cu}$} & 1,00 & 0,05 & 9,50 & $y=769,2 x /(1+0,76 x)$ & 1000,00 & 0,769 \\
\hline & 2,00 & 0,1 & 19,00 & & & \\
\hline & 5,40 & 0,11 & 52,90 & & & \\
\hline & 11,00 & 0,12 & 108,80 & & & \\
\hline & 17,00 & 0,13 & 168,70 & & & \\
\hline & 35,00 & 0,9 & 341,00 & & & \\
\hline & 54,00 & 1,9 & 521,00 & & & \\
\hline & 80,00 & 1,92 & 780,80 & & & \\
\hline \multirow{8}{*}{$\mathrm{Cd}$} & 1,87 & 0,02 & 18,50 & $y=(1250,0 x / 1+0,62 x)$ & 2000,00 & 0,625 \\
\hline & 3,70 & 0,04 & 36,60 & & & \\
\hline & 9,10 & 0,15 & 89,50 & & & \\
\hline & 18,40 & 0,20 & 182,00 & & & \\
\hline & 43,30 & 0,30 & 430,00 & & & \\
\hline & 54,10 & 0,31 & 537,90 & & & \\
\hline & 79,60 & 1,00 & 786,00 & & & \\
\hline & 136,00 & 3,30 & 1327,00 & & & \\
\hline
\end{tabular}


Tabela A17. Concentração de inicial (CI), concentração de equilíbrio (Ceq.), quantidade adsorvida, equação de Langmuir, adsorção máxima (b) e constante de afinidade (Kaf) obtidos a partir das isotermas de adsorção de $\mathrm{Zn}, \mathrm{Ni}$, $\mathrm{Cu}$ e Cd, em sistema competitivo para o Latossolo Vermelho acriférrico (LVwf)

\begin{tabular}{|c|c|c|c|c|c|c|}
\hline \multirow[t]{2}{*}{ Metais } & CI & Ceq & \multirow{2}{*}{$\begin{array}{c}\begin{array}{c}\text { Quantidade } \\
\text { adsorvida }\end{array} \\
\mathrm{mg} \mathrm{kg}^{-1} \\
\end{array}$} & \multirow{2}{*}{ Equação de Langmuir } & \multirow{2}{*}{$\frac{\mathrm{b}}{\mathrm{mg} \mathrm{kg}^{-1}}$} & \multirow{2}{*}{$\frac{\mathrm{Kaf}}{\mathrm{L} \mathrm{mg}^{-1}}$} \\
\hline & $\ldots \ldots \cdots \cdots \cdots \cdots \cdots$ & $1^{-3} \ldots \ldots \ldots \ldots \ldots \ldots$ & & & & \\
\hline \multirow{7}{*}{$\mathrm{Zn}$} & 1,22 & 0,07 & 11,50 & \multirow[t]{7}{*}{$y=34,72 x /(1+0,18 x)$} & 185,19 & \multirow[t]{7}{*}{0,187} \\
\hline & 2,10 & 0,17 & 19,30 & & & \\
\hline & 4,81 & 1,03 & 37,80 & & & \\
\hline & 12,30 & 4,33 & 79,70 & & & \\
\hline & 35,00 & 22,23 & 127,70 & & & \\
\hline & 47,20 & 35,08 & 121,20 & & & \\
\hline & 83,33 & 63,18 & 201,50 & & & \\
\hline \multirow{7}{*}{$\mathrm{Ni}$} & 1,04 & 0,00 & 10,44 & \multirow[t]{7}{*}{$y=40,9 x /(1+0,13 x)$} & 303,03 & \multirow[t]{7}{*}{0,14} \\
\hline & 1,30 & 0,05 & 12,49 & & & \\
\hline & 4,35 & 1,16 & 31,86 & & & \\
\hline & 9,42 & 3,70 & 57,24 & & & \\
\hline & 28,72 & 6,75 & 219,73 & & & \\
\hline & 43,23 & 17,88 & 253,45 & & & \\
\hline & 75,00 & 48,19 & 268,10 & & & \\
\hline \multirow{8}{*}{$\mathrm{Cu}$} & 1,00 & 0,00 & 9,99 & \multirow[t]{8}{*}{$y=357,14 x /(1+0,75 x)$} & 476,19 & \multirow[t]{8}{*}{0,750} \\
\hline & 2,00 & 0,00 & 19,99 & & & \\
\hline & 5,40 & 0,00 & 53,99 & & & \\
\hline & 11,00 & 0,00 & 109,99 & & & \\
\hline & 17,00 & 2,00 & 150,00 & & & \\
\hline & 35,00 & 5,00 & 300,00 & & & \\
\hline & 54,00 & 15,00 & 390,00 & & & \\
\hline & 80,00 & 33,00 & 470,00 & & & \\
\hline \multirow{8}{*}{$\mathrm{Cd}$} & 1,87 & 0,09 & 17,80 & \multirow[t]{8}{*}{$y=52,90 x /(1+0,17 x)$} & 303,03 & \multirow[t]{8}{*}{0,170} \\
\hline & 3,70 & 0,22 & 34,80 & & & \\
\hline & 9,10 & 1,54 & 75,60 & & & \\
\hline & 18,40 & 5,04 & 133,60 & & & \\
\hline & 43,30 & 21,99 & 213,10 & & & \\
\hline & 54,10 & 31,49 & 226,10 & & & \\
\hline & 79,60 & 53,99 & 256,10 & & & \\
\hline & 136,00 & 105,89 & 301,10 & & & \\
\hline
\end{tabular}


Tabela A18. Concentração de inicial (CI), concentração de equilíbrio (Ceq.), quantidade adsorvida, equação de Langmuir, adsorção máxima (b) e constante de afinidade (Kaf) obtidos a partir das isotermas de adsorção de $\mathrm{Zn}, \mathrm{Ni}$, Cu e Cd, em sistema competitivo para o Latossolo Amarelo ácrico (LAw)

\begin{tabular}{|c|c|c|c|c|c|c|}
\hline \multirow[t]{2}{*}{ Metais } & CI & Ceq & \multirow{2}{*}{$\begin{array}{c}\begin{array}{c}\text { Quantidade } \\
\text { adsorvida }\end{array} \\
\mathrm{mg} \mathrm{kg}^{-1} \\
\end{array}$} & \multirow[t]{2}{*}{ Equação de Langmuir } & \multirow{2}{*}{$\frac{\mathrm{b}}{\mathrm{mg} \mathrm{kg}}$} & \multirow{2}{*}{$\frac{\mathrm{Kaf}}{\mathrm{L} \mathrm{mg}^{-1}}$} \\
\hline & \multicolumn{2}{|c|}{$\ldots \ldots \cdots \cdots \cdots \cdot \mathrm{mg} \mathrm{dm}^{-3} \ldots \ldots \ldots$} & & & & \\
\hline \multirow{7}{*}{$\mathrm{Zn}$} & 1,22 & 0,07 & 11,50 & $y=22,99 x /(1+0,14 x)$ & 158,73 & 0,145 \\
\hline & 2,10 & 0,16 & 19,40 & & & \\
\hline & 4,81 & 1,33 & 34,80 & & & \\
\hline & 12,30 & 5,43 & 68,70 & & & \\
\hline & 35,00 & 25,48 & 95,20 & & & \\
\hline & 47,20 & 37,58 & 96,20 & & & \\
\hline & 83,33 & 65,08 & 182,50 & & & \\
\hline \multirow{8}{*}{$\mathrm{Ni}$} & 1,04 & 0,10 & 9,42 & $y=29,99 x /(1+0,27 x)$ & 111,11 & 0,270 \\
\hline & 1,30 & 0,25 & 10,45 & & & \\
\hline & 4,35 & 1,68 & 26,69 & & & \\
\hline & 9,42 & 4,72 & 47,01 & & & \\
\hline & 15,52 & 7,77 & 77,48 & & & \\
\hline & 28,72 & 19,45 & 92,71 & & & \\
\hline & 43,23 & 32,94 & 102,87 & & & \\
\hline & 75,00 & 64,49 & 105,10 & & & \\
\hline \multirow{8}{*}{$\mathrm{Cu}$} & 1,00 & 0,01 & 9,90 & $y=263,17 x /(1+0,44 x)$ & 588,24 & 0,447 \\
\hline & 2,00 & 0,02 & 19,80 & & & \\
\hline & 5,40 & 0,03 & 53,70 & & & \\
\hline & 11,00 & 0,04 & 109,60 & & & \\
\hline & 17,00 & 2,00 & 150,00 & & & \\
\hline & 35,00 & 7,50 & 275,00 & & & \\
\hline & 54,00 & 9,00 & 450,00 & & & \\
\hline & 80,00 & 18,50 & 615,00 & & & \\
\hline \multirow{8}{*}{ Cd } & 1,87 & 0,12 & 17,50 & $y=24,74 x /(1+0,09 x)$ & 256,41 & 0,097 \\
\hline & 3,70 & 0,23 & 34,70 & & & \\
\hline & 9,10 & 2,14 & 69,60 & & & \\
\hline & 18,40 & 7,04 & 113,60 & & & \\
\hline & 43,30 & 28,99 & 143,10 & & & \\
\hline & 54,10 & 38,79 & 153,10 & & & \\
\hline & 79,60 & 59,99 & 196,10 & & & \\
\hline & 136,00 & 109,49 & 265,10 & & & \\
\hline
\end{tabular}


Tabela A19. Concentração de inicial (CI), concentração de equilíbrio (Ceq.), quantidade adsorvida, equação de Langmuir, adsorção máxima (b) e constante de afinidade (Kaf) obtidos a partir das isotermas de adsorção de $\mathrm{Zn}, \mathrm{Ni}$, Cu e Cd, em sistema competitivo para o Argissolo Vermelho-Amarelo (PVA-1)

\begin{tabular}{|c|c|c|c|c|c|c|}
\hline \multirow[t]{2}{*}{ Metais } & CI & Ceq & \multirow{2}{*}{$\begin{array}{c}\begin{array}{c}\text { Quantidade } \\
\text { adsorvida }\end{array} \\
\mathrm{mg} \mathrm{kg}^{-1}\end{array}$} & \multirow{2}{*}{ Equação de Langmuir } & \multirow{2}{*}{$\frac{\mathrm{b}}{\mathrm{mg} \mathrm{kg}^{-1}}$} & \multirow{2}{*}{$\frac{\mathrm{Kaf}}{\mathrm{L} \mathrm{mg}^{-1}}$} \\
\hline & .................. $\mathrm{mg} \mathrm{dm}^{-}$ & $1^{-3} \ldots \ldots \ldots \ldots \ldots$ & & & & \\
\hline \multirow{6}{*}{$\mathrm{Zn}$} & 1,22 & 0,16 & 10,60 & $y=4,27 x /(1+0,05 x)$ & 85,47 & 0,051 \\
\hline & 2,10 & 0,48 & 16,20 & & & \\
\hline & 4,81 & 3,37 & 14,40 & & & \\
\hline & 12,30 & 10,62 & 16,80 & & & \\
\hline & 35,00 & 31,77 & 32,30 & & & \\
\hline & 83,33 & 74,77 & 85,60 & & & \\
\hline \multirow{8}{*}{$\mathrm{Ni}$} & 1,04 & 0,13 & 9,14 & $y=4,48 x /(1+0,07 x)$ & 64,10 & 0,070 \\
\hline & 1,30 & 0,16 & 11,43 & & & \\
\hline & 4,35 & 3,20 & 11,46 & & & \\
\hline & 9,42 & 7,77 & 16,53 & & & \\
\hline & 15,52 & 13,36 & 21,61 & & & \\
\hline & 28,72 & 26,05 & 26,69 & & & \\
\hline & 43,23 & 38,02 & 52,13 & & & \\
\hline & 75,00 & 69,13 & 58,70 & & & \\
\hline \multirow{8}{*}{$\mathrm{Cu}$} & 1,00 & 0,01 & 9,90 & $y=92,59 x /(1+0,64 x)$ & 144,93 & 0,639 \\
\hline & 2,00 & 0,05 & 19,50 & & & \\
\hline & 5,40 & 1,00 & 44,00 & & & \\
\hline & 11,00 & 4,00 & 70,00 & & & \\
\hline & 17,00 & 10,00 & 70,00 & & & \\
\hline & 35,00 & 26,00 & 90,00 & & & \\
\hline & 54,00 & 45,00 & 90,00 & & & \\
\hline & 80,00 & 71,00 & 90,00 & & & \\
\hline \multirow{8}{*}{$\mathrm{Cd}$} & 1,87 & 0,10 & 17,70 & $y=4,79 x /(1+0,04 x)$ & 108,69 & 0,044 \\
\hline & 3,70 & 0,47 & 32,30 & & & \\
\hline & 9,10 & 5,24 & 38,60 & & & \\
\hline & 18,40 & 14,39 & 40,10 & & & \\
\hline & 43,30 & 38,44 & 48,60 & & & \\
\hline & 54,10 & 48,84 & 52,60 & & & \\
\hline & 79,60 & 74,09 & 55,10 & & & \\
\hline & 136,00 & 121,99 & 140,10 & & & \\
\hline
\end{tabular}


Tabela A20. Concentração de inicial (CI), concentração de equilíbrio (Ceq.), quantidade adsorvida, equação de Langmuir, adsorção máxima (b) e constante de afinidade (Kaf) obtidos a partir das isotermas de adsorção de $\mathrm{Zn}, \mathrm{Ni}$, Cu e Cd, em sistema competitivo para o Argissolo Vermelho-Amarelo (PVA-2)

\begin{tabular}{|c|c|c|c|c|c|c|}
\hline \multirow[t]{2}{*}{ Metais } & CI & Ceq & $\begin{array}{l}\text { Quantidade } \\
\text { adsorvida }\end{array}$ & \multirow[t]{2}{*}{ Equação de Langmuir } & $\mathrm{b}$ & Kaf \\
\hline & $\ldots \ldots \cdots \cdots \cdots \cdots \cdots \cdot \mathrm{mg} \mathrm{dm}^{-}$ & $-3 \ldots \ldots \ldots \ldots \ldots$ & $\mathrm{mg} \mathrm{kg}^{-1}$ & & $\mathrm{mg} \mathrm{kg}^{-1}$ & $\mathrm{~L} \mathrm{mg}^{-1}$ \\
\hline \multirow{7}{*}{$\mathrm{Zn}$} & 1,22 & 0,01 & 12,10 & \multirow[t]{7}{*}{$y=176,0 x /(1+0,44 x)$} & 400,00 & \multirow[t]{7}{*}{0,439} \\
\hline & 2,10 & 0,03 & 20,70 & & & \\
\hline & 4,81 & 0,14 & 46,70 & & & \\
\hline & 12,30 & 1,04 & 112,60 & & & \\
\hline & 35,00 & 8,19 & 268,10 & & & \\
\hline & 47,20 & 18,54 & 286,60 & & & \\
\hline & 83,33 & 41,84 & 414,90 & & & \\
\hline \multirow{8}{*}{$\mathrm{Ni}$} & 1,04 & 0,01 & 10,34 & \multirow[t]{8}{*}{$y=86,8 x /(1+0,21 x)$} & 400,00 & \multirow[t]{8}{*}{0,217} \\
\hline & 1,30 & 0,02 & 12,79 & & & \\
\hline & 4,35 & 1,17 & 31,77 & & & \\
\hline & 9,42 & 1,17 & 82,55 & & & \\
\hline & 15,52 & 1,68 & 138,42 & & & \\
\hline & 28,72 & 5,74 & 229,83 & & & \\
\hline & 43,23 & 15,67 & 275,58 & & & \\
\hline & 75,00 & 38,77 & 362,30 & & & \\
\hline \multirow{8}{*}{$\mathrm{Cu}$} & 1,00 & 0,01 & 9,90 & \multirow[t]{8}{*}{$y=249,9 x /(1+0,27 x)$} & 909,09 & \multirow[t]{8}{*}{0,275} \\
\hline & 2,00 & 0,10 & 19,00 & & & \\
\hline & 5,40 & 0,20 & 52,00 & & & \\
\hline & 11,00 & 0,30 & 107,00 & & & \\
\hline & 17,00 & 1,50 & 155,00 & & & \\
\hline & 35,00 & 2,00 & 330,00 & & & \\
\hline & 54,00 & 5,00 & 490,00 & & & \\
\hline & 80,00 & 9,00 & 710,00 & & & \\
\hline \multirow{8}{*}{$\mathrm{Cd}$} & 1,87 & 0,01 & 18,60 & \multirow[t]{8}{*}{$\mathrm{y}=333,3 \mathrm{x} /(1+0,4 \mathrm{x})$} & 833,33 & \multirow[t]{8}{*}{0,400} \\
\hline & 3,70 & 0,04 & 36,60 & & & \\
\hline & 9,10 & 0,25 & 88,50 & & & \\
\hline & 18,40 & 0,50 & 179,00 & & & \\
\hline & 43,30 & 2,50 & 408,00 & & & \\
\hline & 54,10 & 7,00 & 471,00 & & & \\
\hline & 79,60 & 17,20 & 624,00 & & & \\
\hline & 136,00 & 54,10 & 819,00 & & & \\
\hline
\end{tabular}


Tabela A21. Concentração de inicial (CI), concentração de equilíbrio (Ceq.), quantidade adsorvida, equação de Langmuir, adsorção máxima (b) e constante de afinidade (Kaf) obtidos a partir das isotermas de adsorção de Zn, Ni, Cu e Cd, em sistema competitivo para o Argissolo Vermelho-Amarelo (PVA-3)

\begin{tabular}{|c|c|c|c|c|c|c|}
\hline \multirow[t]{2}{*}{ Metais } & CI & Ceq & \multirow{2}{*}{$\begin{array}{c}\text { Quantidade } \\
\text { adsorvida } \\
\mathrm{mg} \mathrm{kg}^{-1}\end{array}$} & \multirow[t]{2}{*}{ Equação de Langmuir } & \multirow{2}{*}{$\frac{\mathrm{b}}{\mathrm{mg} \mathrm{kg}}$} & \multirow{2}{*}{$\frac{\mathrm{Kaf}}{\mathrm{L} \mathrm{mg}^{-1}}$} \\
\hline & \multicolumn{2}{|c|}{$\ldots \ldots \ldots \ldots \ldots \ldots \mathrm{mg} \mathrm{dm}^{-3} \ldots \ldots \ldots \ldots \ldots \ldots$} & & & & \\
\hline \multirow{7}{*}{$\mathrm{Zn}$} & 1,22 & 0,01 & 12,10 & \multirow[t]{7}{*}{$y=219,04 x /(1+0,46 x)$} & 476,19 & \multirow[t]{7}{*}{0,457} \\
\hline & 2,10 & 0,02 & 20,80 & & & \\
\hline & 4,81 & 0,11 & 47,00 & & & \\
\hline & 12,30 & 0,76 & 115,40 & & & \\
\hline & 35,00 & 6,16 & 288,40 & & & \\
\hline & 47,20 & 15,86 & 313,40 & & & \\
\hline & 83,33 & 35,56 & 477,70 & & & \\
\hline \multirow{8}{*}{$\mathrm{Ni}$} & 1,04 & 0,05 & 9,93 & \multirow[t]{8}{*}{$y=85,17 x /(1+0,24 x)$} & 344,82 & \multirow[t]{8}{*}{0,247} \\
\hline & 1,30 & 0,10 & 11,97 & & & \\
\hline & 4,35 & 1,17 & 31,77 & & & \\
\hline & 9,42 & 1,42 & 80,02 & & & \\
\hline & 15,52 & 1,68 & 138,42 & & & \\
\hline & 28,72 & 4,72 & 239,99 & & & \\
\hline & 43,23 & 13,64 & 295,90 & & & \\
\hline & 75,00 & 43,80 & 312,00 & & & \\
\hline \multirow{8}{*}{$\mathrm{Cu}$} & 1,00 & 0,01 & 9,90 & \multirow[t]{8}{*}{$y=1000,0 x /(1+1,3 x)$} & 769,23 & \multirow[t]{8}{*}{1,300} \\
\hline & 2,00 & 0,02 & 19,80 & & & \\
\hline & 5,40 & 0,03 & 53,70 & & & \\
\hline & 11,00 & 0,04 & 109,60 & & & \\
\hline & 17,00 & 1,00 & 160,00 & & & \\
\hline & 35,00 & 1,50 & 335,00 & & & \\
\hline & 54,00 & 2,00 & 520,00 & & & \\
\hline & 80,00 & 6,00 & 740,00 & & & \\
\hline \multirow{8}{*}{$\mathrm{Cd}$} & 1,87 & 0,01 & 18,60 & \multirow[t]{8}{*}{$y=400,0 x /(1+0,44 x)$} & 909,09 & \multirow[t]{8}{*}{0,440} \\
\hline & 3,70 & 0,04 & 36,60 & & & \\
\hline & 9,10 & 0,20 & 89,00 & & & \\
\hline & 18,40 & 0,35 & 180,50 & & & \\
\hline & 43,30 & 1,95 & 413,50 & & & \\
\hline & 54,10 & 5,05 & 490,50 & & & \\
\hline & 79,60 & 14,30 & 653,00 & & & \\
\hline & 136,00 & 45,30 & 907,00 & & & \\
\hline
\end{tabular}


Tabela A22. Concentração de inicial (CI), concentração de equilíbrio (Ceq.), quantidade adsorvida, equação de Langmuir, adsorção máxima (b) e constante de afinidade (Kaf) obtidos a partir das isotermas de adsorção de $\mathrm{Zn}, \mathrm{Ni}$, Cu e Cd, em sistema competitivo para o Neossolo Quartzarênico (RQ)

\begin{tabular}{|c|c|c|c|c|c|c|}
\hline \multirow[t]{2}{*}{ Metais } & CI & Ceq & \multirow{2}{*}{$\begin{array}{c}\begin{array}{c}\text { Quantidade } \\
\text { adsorvida }\end{array} \\
\mathrm{mg} \mathrm{kg}^{-1}\end{array}$} & \multirow[t]{2}{*}{ Equação de Langmuir } & \multirow{2}{*}{$\begin{array}{c}\mathrm{b} \\
\mathrm{mg} \mathrm{kg}^{-1}\end{array}$} & \multirow{2}{*}{$\frac{\mathrm{Kaf}}{\mathrm{L} \mathrm{mg}^{-1}}$} \\
\hline & \multicolumn{2}{|c|}{$\ldots \ldots \ldots \ldots \ldots \ldots \ldots \mathrm{mg} \mathrm{dm}^{-3} \ldots$} & & & & \\
\hline \multirow{6}{*}{$\mathrm{Zn}$} & 1,22 & 0,66 & 5,60 & $y=3,95 x /(1+0,19 x)$ & 20,79 & 0,190 \\
\hline & 2,10 & 1,48 & 6,20 & & & \\
\hline & 4,81 & 4,17 & 6,40 & & & \\
\hline & 35,00 & 33,42 & 15,80 & & & \\
\hline & 47,20 & 45,17 & 20,30 & & & \\
\hline & 83,33 & 72,57 & 107,60 & & & \\
\hline \multirow{8}{*}{$\mathrm{Ni}$} & 1,04 & 0,41 & 6,38 & $y=3,60 x /(1+0,08 x)$ & 45,04 & 0,080 \\
\hline & 1,30 & 0,51 & 7,91 & & & \\
\hline & 4,35 & 3,45 & 8,92 & & & \\
\hline & 9,42 & 8,02 & 14,00 & & & \\
\hline & 15,52 & 13,36 & 21,61 & & & \\
\hline & 28,72 & 26,05 & 26,69 & & & \\
\hline & 43,23 & 40,05 & 31,82 & & & \\
\hline & 75,00 & 70,75 & 42,50 & & & \\
\hline \multirow{8}{*}{$\mathrm{Cu}$} & 1,00 & 0,01 & 9,90 & $y=12,68 x /(1+0,13 x)$ & 95,24 & 0,133 \\
\hline & 2,00 & 0,35 & 16,50 & & & \\
\hline & 5,40 & 2,00 & 34,00 & & & \\
\hline & 11,00 & 7,00 & 40,00 & & & \\
\hline & 17,00 & 13,00 & 40,00 & & & \\
\hline & 35,00 & 28,50 & 65,00 & & & \\
\hline & 54,00 & 47,00 & 70,00 & & & \\
\hline & 80,00 & 70,00 & 100,00 & & & \\
\hline \multirow{7}{*}{$\mathrm{Cd}$} & 1,87 & 0,83 & 10,40 & - & - & - \\
\hline & 9,10 & 8,05 & 10,50 & & & \\
\hline & 18,40 & 17,55 & 8,50 & & & \\
\hline & 43,30 & 42,55 & 7,50 & & & \\
\hline & 54,10 & 53,00 & 11,00 & & & \\
\hline & 79,60 & 76,80 & 28,00 & & & \\
\hline & 136,00 & 118,00 & 180,00 & & & \\
\hline
\end{tabular}


Tabela A23. Concentração de inicial (CI), concentração de equilíbrio (Ceq.), quantidade adsorvida, equação de Langmuir, adsorção máxima (b) e constante de afinidade (Kaf) obtidos a partir das isotermas de adsorção de $\mathrm{Zn}, \mathrm{Ni}$, $\mathrm{Cu}$ e Cd, em sistema competitivo para o Nitossolo Vermelho eutroférrico (NVef)

\begin{tabular}{|c|c|c|c|c|c|c|}
\hline \multirow[t]{2}{*}{ Metais } & CI & Ceq & \multirow{2}{*}{$\begin{array}{c}\text { Quantidade } \\
\text { adsorvida } \\
\mathrm{mg} \mathrm{kg}^{-1}\end{array}$} & \multirow{2}{*}{ Equação de Langmuir } & \multirow{2}{*}{$\frac{\mathrm{b}}{\mathrm{mg} \mathrm{kg}^{-1}}$} & \multirow{2}{*}{$\frac{\mathrm{Kaf}}{\mathrm{L} \mathrm{mg}^{-1}}$} \\
\hline & 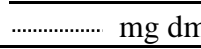 & -3. & & & & \\
\hline \multirow{7}{*}{$\mathrm{Zn}$} & 1,22 & 0,01 & 12,10 & $y=500,0 x /(1+0,5 x)$ & 476,19 & 0,437 \\
\hline & 2,10 & 0,02 & 20,80 & & & \\
\hline & 4,81 & 0,17 & 46,40 & & & \\
\hline & 12,30 & 0,72 & 115,80 & & & \\
\hline & 35,00 & 6,42 & 285,80 & & & \\
\hline & 47,20 & 14,57 & 326,30 & & & \\
\hline & 83,33 & 34,57 & 487,60 & & & \\
\hline \multirow{8}{*}{$\mathrm{Ni}$} & 1,04 & 0,13 & 9,14 & $y=101,99 x /(1+0,3 x)$ & 333,33 & 0,306 \\
\hline & 1,30 & 0,16 & 11,43 & & & \\
\hline & 4,35 & 1,17 & 31,77 & & & \\
\hline & 9,42 & 1,42 & 80,02 & & & \\
\hline & 15,52 & 1,68 & 138,42 & & & \\
\hline & 28,72 & 4,22 & 245,07 & & & \\
\hline & 43,23 & 13,64 & 295,90 & & & \\
\hline & 75,00 & 44,68 & 303,20 & & & \\
\hline \multirow{8}{*}{$\mathrm{Cu}$} & 1,00 & 0,01 & 9,90 & $y=1000,0 x /(1+1,2 x)$ & 833,33 & 1,200 \\
\hline & 2,00 & 0,02 & 19,80 & & & \\
\hline & 5,40 & 0,03 & 53,70 & & & \\
\hline & 11,00 & 0,04 & 109,60 & & & \\
\hline & 17,00 & 1,00 & 160,00 & & & \\
\hline & 35,00 & 1,10 & 339,00 & & & \\
\hline & 54,00 & 2,00 & 520,00 & & & \\
\hline & 80,00 & 5,00 & 750,00 & & & \\
\hline \multirow{8}{*}{ Cd } & 1,87 & 0,02 & 18,50 & $y=333,36 x /(1+0,37 x)$ & 909,09 & 0,367 \\
\hline & 3,70 & 0,04 & 36,60 & & & \\
\hline & 9,10 & 0,30 & 88,00 & & & \\
\hline & 18,40 & 0,40 & 180,00 & & & \\
\hline & 43,30 & 2,45 & 408,50 & & & \\
\hline & 54,10 & 5,85 & 482,50 & & & \\
\hline & 79,60 & 13,80 & 658,00 & & & \\
\hline & 136,00 & 44,80 & 912,00 & & & \\
\hline
\end{tabular}


Tabela A24. Concentração de inicial (CI), concentração de equilíbrio (Ceq.), quantidade adsorvida, equação de Langmuir, adsorção máxima (b) e constante de afinidade (Kaf) obtidos a partir das isotermas de adsorção de $\mathrm{Zn}, \mathrm{Ni}$, $\mathrm{Cu}$ e Cd, em sistema competitivo para o Gleissolo Melânico (GM)

\begin{tabular}{|c|c|c|c|c|c|c|}
\hline \multirow[t]{2}{*}{ Metais } & CI & Ceq & \multirow{2}{*}{$\begin{array}{c}\begin{array}{c}\text { Quantidade } \\
\text { adsorvida }\end{array} \\
\mathrm{mg} \mathrm{kg}^{-1}\end{array}$} & \multirow[t]{2}{*}{ Equação de Langmuir } & \multirow{2}{*}{$\frac{\mathrm{b}}{\mathrm{mg} \mathrm{kg}^{-1}}$} & \multirow{2}{*}{$\frac{\mathrm{Kaf}}{\mathrm{L} \mathrm{mg}^{-1}}$} \\
\hline & $\ldots \ldots \ldots \ldots \ldots \ldots \mathrm{mg} \mathrm{dm}^{-3}$ & $\ldots \ldots \ldots \ldots$ & & & & \\
\hline \multirow{7}{*}{$\mathrm{Zn}$} & 1,22 & 0,09 & 11,30 & $y=37,03 x /(1+0,20 x)$ & 185,18 & 0,200 \\
\hline & 2,10 & 0,29 & 18,10 & & & \\
\hline & 4,81 & 1,52 & 32,90 & & & \\
\hline & 12,30 & 5,77 & 65,30 & & & \\
\hline & 35,00 & 6,02 & 289,80 & & & \\
\hline & 47,20 & 36,47 & 107,30 & & & \\
\hline & 83,33 & 64,77 & 185,60 & & & \\
\hline \multirow{8}{*}{$\mathrm{Ni}$} & 1,04 & 0,01 & 10,34 & $y=58,82 x /(1+0,53 x)$ & 109,89 & 0,535 \\
\hline & 1,30 & 0,02 & 12,79 & & & \\
\hline & 4,35 & 1,17 & 31,77 & & & \\
\hline & 9,42 & 4,22 & 52,08 & & & \\
\hline & 15,52 & 6,25 & 92,71 & & & \\
\hline & 28,72 & 18,94 & 97,79 & & & \\
\hline & 43,23 & 32,94 & 102,91 & & & \\
\hline & 75,00 & 64,25 & 107,50 & & & \\
\hline \multirow{8}{*}{$\mathrm{Cu}$} & 1,00 & 0,01 & 9,90 & $y=200,0 x /(1+0,34 x)$ & 588,24 & 0,340 \\
\hline & 2,00 & 0,02 & 19,80 & & & \\
\hline & 5,40 & 0,03 & 53,70 & & & \\
\hline & 11,00 & 0,95 & 100,50 & & & \\
\hline & 17,00 & 2,00 & 150,00 & & & \\
\hline & 35,00 & 6,00 & 290,00 & & & \\
\hline & 54,00 & 12,00 & 420,00 & & & \\
\hline & 80,00 & 24,00 & 560,00 & & & \\
\hline \multirow{8}{*}{$\mathrm{Cd}$} & 1,87 & 0,08 & 17,90 & $y=39,07 x /(1+0,11 x)$ & 370,37 & 0,105 \\
\hline & 3,70 & 0,27 & 34,30 & & & \\
\hline & 9,10 & 1,90 & 72,00 & & & \\
\hline & 18,40 & 6,35 & 120,50 & & & \\
\hline & 43,30 & 19,55 & 237,50 & & & \\
\hline & 54,10 & 30,00 & 241,00 & & & \\
\hline & 79,60 & 55,00 & 246,00 & & & \\
\hline & 136,00 & 98,50 & 375,00 & & & \\
\hline
\end{tabular}


Tabela A25. Concentração de inicial (CI), concentração de equilíbrio (Ceq.), quantidade adsorvida, equação de Langmuir, adsorção máxima (b) e constante de afinidade (Kaf) obtidos a partir das isotermas de adsorção de $\mathrm{Zn}, \mathrm{Ni}$, Cu e Cd, em sistema competitivo para o Organossolo Háplico (OX)

\begin{tabular}{|c|c|c|c|c|c|c|}
\hline \multirow[t]{9}{*}{ Metais } & CI & Ceq & \multirow{2}{*}{$\begin{array}{c}\begin{array}{c}\text { Quantidade } \\
\text { adsorvida }\end{array} \\
\mathrm{mg} \mathrm{kg}^{-1} \\
\end{array}$} & \multirow{2}{*}{ Equação de Langmuir } & \multirow{2}{*}{$\frac{\mathrm{b}}{\mathrm{mg} \mathrm{kg}^{-1}}$} & \multirow{2}{*}{$\frac{\text { Kaf }}{\mathrm{L} \mathrm{mg}^{-1}}$} \\
\hline & \multicolumn{2}{|c|}{ 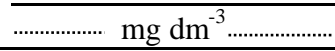 } & & & & \\
\hline & 1,22 & 0,27 & 9,50 & $y=20,75 x /(1+0,11 x)$ & 188,68 & 0,114 \\
\hline & 2,10 & 0,63 & 14,70 & & & \\
\hline & 4,81 & 2,11 & 27,00 & & & \\
\hline & 12,30 & 6,96 & 53,40 & & & \\
\hline & 35,00 & 6,91 & 280,90 & & & \\
\hline & 47,20 & 37,11 & 100,90 & & & \\
\hline & 83,33 & 65,41 & 179,20 & & & \\
\hline \multirow{8}{*}{$\mathrm{Ni}$} & 1,04 & 0,01 & 10,34 & $y=34,01 x /(1+0,33 x)$ & 103,09 & 0,330 \\
\hline & 1,30 & 0,15 & 11,46 & & & \\
\hline & 4,35 & 1,68 & 26,69 & & & \\
\hline & 9,42 & 4,72 & 47,01 & & & \\
\hline & 15,52 & 7,77 & 77,48 & & & \\
\hline & 28,72 & 19,96 & 87,63 & & & \\
\hline & 43,23 & 33,95 & 92,76 & & & \\
\hline & 75,00 & 64,99 & 100,10 & & & \\
\hline \multirow{8}{*}{$\mathrm{Cu}$} & 1,00 & 0,01 & 9,90 & $y=161,3 x /(1+0,21 x)$ & 769,23 & 0,210 \\
\hline & 2,00 & 0,10 & 19,00 & & & \\
\hline & 5,40 & 0,45 & 49,50 & & & \\
\hline & 11,00 & 1,00 & 100,00 & & & \\
\hline & 17,00 & 3,00 & 140,00 & & & \\
\hline & 35,00 & 9,50 & 255,00 & & & \\
\hline & 54,00 & 18,00 & 360,00 & & & \\
\hline & 80,00 & 36,00 & 440,00 & & & \\
\hline \multirow{8}{*}{$\mathrm{Cd}$} & 1,87 & 0,25 & 16,20 & $y=24,58 x /(1+0,07 x)$ & 344,83 & 0,071 \\
\hline & 3,70 & 0,62 & 30,80 & & & \\
\hline & 9,10 & 2,85 & 62,50 & & & \\
\hline & 18,40 & 8,05 & 103,50 & & & \\
\hline & 43,30 & 23,60 & 197,00 & & & \\
\hline & 54,10 & 33,50 & 206,00 & & & \\
\hline & 79,60 & 55,10 & 245,00 & & & \\
\hline & 136,00 & 102,80 & 332,00 & & & \\
\hline
\end{tabular}


Tabela A26. Concentração de inicial (CI), concentração de equilíbrio (Ceq.), quantidade adsorvida, equação de Langmuir, adsorção máxima (b) e constante de afinidade (Kaf) obtidos a partir das isotermas de adsorção de $\mathrm{Zn}, \mathrm{Ni}$, Cu e Cd, em sistema competitivo para o Cambissolo Háplico (CX)

\begin{tabular}{|c|c|c|c|c|c|c|}
\hline \multirow[t]{2}{*}{ Metais } & CI & Ceq & \multirow{2}{*}{$\begin{array}{c}\begin{array}{c}\text { Quantidade } \\
\text { adsorvida }\end{array} \\
\mathrm{mg} \mathrm{kg}^{-1} \\
\end{array}$} & \multirow{2}{*}{ Equação de Langmuir } & \multirow{2}{*}{$\begin{array}{c}\mathrm{b} \\
\mathrm{mg} \mathrm{kg}^{-1}\end{array}$} & \multirow{2}{*}{$\frac{\mathrm{Kaf}}{\mathrm{L} \mathrm{mg}^{-}}$} \\
\hline & \multicolumn{2}{|c|}{$\mathrm{mg} \mathrm{dm}^{-3}$} & & & & \\
\hline \multirow{7}{*}{$\mathrm{Zn}$} & 1,22 & 0,37 & 8,50 & $y=7,19 x /(1+0,05 x)$ & 140,85 & 0,051 \\
\hline & 2,10 & 0,76 & 13,40 & & & \\
\hline & 4,81 & 3,12 & 16,90 & & & \\
\hline & 12,30 & 9,47 & 28,30 & & & \\
\hline & 35,00 & 28,77 & 62,30 & & & \\
\hline & 47,20 & 41,77 & 54,30 & & & \\
\hline & 83,33 & 69,27 & 140,60 & & & \\
\hline \multirow{8}{*}{$\mathrm{Ni}$} & 1,04 & 0,05 & 9,93 & $y=13,83 x /(1+0,22 x)$ & 62,89 & 0,220 \\
\hline & 1,30 & 0,25 & 10,45 & & & \\
\hline & 4,35 & 2,69 & 16,53 & & & \\
\hline & 9,42 & 6,76 & 26,69 & & & \\
\hline & 15,52 & 10,82 & 47,01 & & & \\
\hline & 28,72 & 23,01 & 57,16 & & & \\
\hline & 43,23 & 38,02 & 52,13 & & & \\
\hline & 75,00 & 68,92 & 60,80 & & & \\
\hline \multirow{8}{*}{$\mathrm{Cu}$} & 1,00 & 0,0 & 9,90 & $y=909,1 x /(1+2,63 x)$ & 344,83 & 2,636 \\
\hline & 2,00 & 0,0 & 19,80 & & & \\
\hline & 5,40 & 0,0 & 53,70 & & & \\
\hline & 11,00 & 2,0 & 90,00 & & & \\
\hline & 17,00 & 6,0 & 110,00 & & & \\
\hline & 35,00 & 17,0 & 180,00 & & & \\
\hline & 54,00 & 33,0 & 210,00 & & & \\
\hline & 80,00 & 55,0 & 250,00 & & & \\
\hline \multirow{8}{*}{ Cd } & 1,87 & 0,52 & 13,50 & $y=5,28 x /(1+0,028 x)$ & 188,67 & 0,028 \\
\hline & 3,70 & 1,09 & 26,10 & & & \\
\hline & 9,10 & 5,45 & 36,50 & & & \\
\hline & 18,40 & 13,25 & 51,50 & & & \\
\hline & 43,30 & 37,00 & 63,00 & & & \\
\hline & 54,10 & 47,25 & 68,50 & & & \\
\hline & 79,60 & 69,70 & 99,00 & & & \\
\hline & 136,00 & 114,60 & 214,00 & & & \\
\hline
\end{tabular}


Tabela A27. Concentração de inicial (CI), concentração de equilíbrio (Ceq.), quantidade adsorvida, equação de Langmuir, adsorção máxima (b) e constante de afinidade (Kaf) obtidos a partir das isotermas de adsorção de $\mathrm{Zn}, \mathrm{Ni}$, Cu e Cd, em sistema competitivo para o Luvissolo Crômico (TC)

\begin{tabular}{|c|c|c|c|c|c|c|}
\hline \multirow[t]{2}{*}{ Metais } & CI & Ceq & \multirow{2}{*}{$\begin{array}{c}\begin{array}{c}\text { Quantidade } \\
\text { adsorvida }\end{array} \\
\mathrm{mg} \mathrm{kg}^{-1} \\
\end{array}$} & \multirow{2}{*}{ Equação de Langmuir } & \multirow{2}{*}{$\frac{\mathrm{b}}{\mathrm{mg} \mathrm{kg}^{-1}}$} & \multirow{2}{*}{$\frac{\mathrm{Kaf}}{\mathrm{L} \mathrm{mg}^{-1}}$} \\
\hline & ............... $\mathrm{mg} \mathrm{dm}^{-1}$ & $1^{-3} \ldots \ldots \ldots \ldots \ldots \ldots$ & & & & \\
\hline \multirow{7}{*}{$\mathrm{Zn}$} & 1,22 & 0,0 & 12,08 & $y=14,02 x /(1+0,12 x)$ & 116,28 & 0,121 \\
\hline & 2,10 & 0,3 & 18,20 & & & \\
\hline & 4,81 & 2,0 & 27,90 & & & \\
\hline & 12,30 & 7,5 & 47,80 & & & \\
\hline & 35,00 & 27,5 & 75,30 & & & \\
\hline & 47,20 & 40,8 & 64,30 & & & \\
\hline & 83,33 & 69,9 & 134,60 & & & \\
\hline \multirow{8}{*}{$\mathrm{Ni}$} & 1,04 & 0,13 & 9,14 & $y=25,89 x /(1+0,29 x)$ & 89,28 & 0,290 \\
\hline & 1,30 & 0,16 & 11,43 & & & \\
\hline & 4,35 & 2,18 & 21,61 & & & \\
\hline & 9,42 & 5,23 & 41,93 & & & \\
\hline & 15,52 & 8,79 & 67,32 & & & \\
\hline & 28,72 & 20,97 & 77,48 & & & \\
\hline & 43,23 & 34,97 & 82,60 & & & \\
\hline & 75,00 & 66,52 & 84,80 & & & \\
\hline \multirow{8}{*}{$\mathrm{Cu}$} & 1,00 & 0,01 & 9,90 & $y=142,86 x /(1+0,74 x)$ & 192,31 & 0,743 \\
\hline & 2,00 & 0,02 & 19,80 & & & \\
\hline & 5,40 & 0,03 & 53,70 & & & \\
\hline & 11,00 & 2,00 & 90,00 & & & \\
\hline & 17,00 & 5,50 & 115,00 & & & \\
\hline & 35,00 & 18,00 & 170,00 & & & \\
\hline & 54,00 & 35,00 & 190,00 & & & \\
\hline & 80,00 & 61,00 & 190,00 & & & \\
\hline \multirow{7}{*}{$\mathrm{Cd}$} & 1,87 & 0,11 & 17,60 & $y=16,20 x /(1+0,08 x)$ & 185,19 & 0,088 \\
\hline & 3,70 & 0,28 & 34,20 & & & \\
\hline & 9,10 & 3,00 & 61,00 & & & \\
\hline & 18,40 & 9,60 & 88,00 & & & \\
\hline & 54,10 & 44,15 & 99,50 & & & \\
\hline & 79,60 & 67,40 & 122,00 & & & \\
\hline & 136,00 & 115,10 & 209,00 & & & \\
\hline
\end{tabular}


Tabela A28. Concentração de inicial (CI), concentração de equilíbrio (Ceq.), quantidade adsorvida: equação de Langmuir, adsorção máxima (b) e constante de afinidade (Kaf) obtidos a partir das isotermas de adsorção de Zn, Ni, Cu e Cd, em sistema competitivo para o Chernossolo Argilúvico (MT)

\begin{tabular}{|c|c|c|c|c|c|c|}
\hline \multirow[t]{2}{*}{ Metais } & CI & Ceq & \multirow{2}{*}{$\begin{array}{c}\begin{array}{c}\text { Quantidade } \\
\text { adsorvida }\end{array} \\
\mathrm{mg} \mathrm{kg}^{-1}\end{array}$} & \multirow{2}{*}{ Equação de Langmuir } & \multirow{2}{*}{$\frac{\mathrm{b}}{\mathrm{mg} \mathrm{kg}^{-1}}$} & \multirow{2}{*}{$\frac{\mathrm{Kaf}}{\mathrm{L} \mathrm{mg}^{-1}}$} \\
\hline & \multicolumn{2}{|c|}{$\ldots \ldots \ldots \ldots \ldots \ldots . . . \mathrm{mg} \mathrm{dm}^{-3} \ldots \ldots \ldots \ldots \ldots \ldots$} & & & & \\
\hline \multirow{7}{*}{$\mathrm{Zn}$} & 1,22 & 0,01 & 12,10 & \multirow[t]{7}{*}{$y=250,0 x /(1+0,4 x)$} & 625,00 & \multirow[t]{7}{*}{0,400} \\
\hline & 2,10 & 0,04 & 20,60 & & & \\
\hline & 4,81 & 0,17 & 46,40 & & & \\
\hline & 12,30 & 0,57 & 117,30 & & & \\
\hline & 35,00 & 4,27 & 307,30 & & & \\
\hline & 47,20 & 9,27 & 379,30 & & & \\
\hline & 83,33 & 21,77 & 615,60 & & & \\
\hline \multirow{8}{*}{$\mathrm{Ni}$} & 1,04 & 0,01 & 10,34 & \multirow[t]{8}{*}{$y=107,27 x /(1+0,23 x)$} & 454,54 & \multirow[t]{8}{*}{0,236} \\
\hline & 1,30 & 0,02 & 12,79 & & & \\
\hline & 4,35 & 1,17 & 31,77 & & & \\
\hline & 9,42 & 1,42 & 80,02 & & & \\
\hline & 15,52 & 1,68 & 138,42 & & & \\
\hline & 28,72 & 2,18 & 265,38 & & & \\
\hline & 43,23 & 4,50 & 387,31 & & & \\
\hline & 75,00 & 34,92 & 400,80 & & & \\
\hline \multirow{8}{*}{$\mathrm{Cu}$} & 1,00 & 0,0 & 9,90 & \multirow[t]{8}{*}{$y=1108,3 x /(1+1,33 x)$} & 833,33 & \multirow[t]{8}{*}{1,333} \\
\hline & 2,00 & 0,0 & 19,80 & & & \\
\hline & 5,40 & 0,0 & 53,70 & & & \\
\hline & 11,00 & 0,0 & 109,60 & & & \\
\hline & 17,00 & 1,0 & 160,00 & & & \\
\hline & 35,00 & 1,1 & 339,00 & & & \\
\hline & 54,00 & 2,0 & 520,00 & & & \\
\hline & 80,00 & 4,0 & 760,00 & & & \\
\hline \multirow{8}{*}{$\mathrm{Cd}$} & 1,87 & 0,02 & 18,50 & \multirow[t]{8}{*}{$\mathrm{y}=384,44 \mathrm{x} /(1+0,34 \mathrm{x})$} & 1111,11 & \multirow[t]{8}{*}{0,346} \\
\hline & 3,70 & 0,06 & 36,40 & & & \\
\hline & 9,10 & 0,25 & 88,50 & & & \\
\hline & 18,40 & 0,40 & 180,00 & & & \\
\hline & 43,30 & 1,80 & 415,00 & & & \\
\hline & 54,10 & 4,10 & 500,00 & & & \\
\hline & 79,60 & 9,10 & 705,00 & & & \\
\hline & 136,00 & 27,40 & 1086,00 & & & \\
\hline
\end{tabular}

